Utah State University

DigitalCommons@USU

\title{
A Comparison of Park Access with Park Need for Children: Case Study in Cache County, Utah
}

Shuolei Chen

Utah State University

Follow this and additional works at: https://digitalcommons.usu.edu/etd

Part of the Landscape Architecture Commons

\section{Recommended Citation}

Chen, Shuolei, "A Comparison of Park Access with Park Need for Children: Case Study in Cache County, Utah" (2017). All Graduate Theses and Dissertations. 5810.

https://digitalcommons.usu.edu/etd/5810

This Thesis is brought to you for free and open access by the Graduate Studies at DigitalCommons@USU. It has been accepted for inclusion in All Graduate Theses and Dissertations by an authorized administrator of DigitalCommons@USU. For more information, please contact digitalcommons@usu.edu.

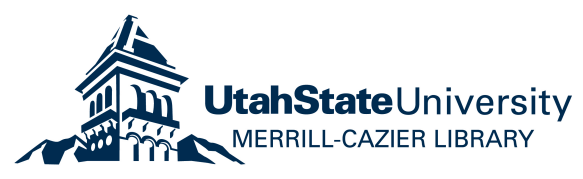




\section{Shuolei Chen}

A thesis submitted in partial fulfillment of the requirements for the degree

of

MASTER OF LANDSCAPE ARCHITECTURE

Approved:

Keith M. Christensen, Ph.D. Major Professor

Shujuan Li, Ph.D.

Committee Member
Dennis A. Nelson, Ed.D.

Committee Member

Mark R. McLellan, Ph.D.

Vice President for Research and

Dean of Graduate Studies

UTAH STATE UNIVERSITY

Logan, Utah 
Copyright (C) Shuolei Chen 2017

All Rights Reserved 


\author{
ABSTRACT \\ A Comparison of Park Access with Park Need for Children: \\ Case Study in Cache County, Utah \\ by \\ Shuolei Chen, Master of Landscape Architecture \\ Utah State University, 2017
}

Major Professor: Dr. Keith M. Christensen
Department: Landscape Architecture and Environmental Planning

Childhood obesity is one of the nation's most serious health problems. There are growing efforts to prevent childhood obesity by improving opportunities for physical activity in their communities. The outdoor settings of the built environment, such as parks and open spaces, can offer children opportunities for physical activities, experience with nature, and social interaction, which contribute to children's physical and psychological health. However, children's physical access to parks is often inequitable. Simultaneously, the quality of parks also varies. These disparities caused the inequitable distribution of health-promoting features of built environment among disadvantaged groups who may not have access to other resources. While most previous studies focused on physical park distribution inequities, the purpose of this study is to explore park access by both park physical proximity and quality related to children's (5 to 17 years old) potential need for parks. 
This study employs case study methods to explore these relationships across Cache County, Utah. Park proximity is identified by GIS network analysis methods to determine park service areas for all the 77 census block groups in Cache County. Both overall park quality and five separate park feature qualities (facilities, amenities, aesthetic feature, cleanliness and maintenance, and incivility) are measured using the PARK tool (Parks, Activity, and Recreation among Kids). The measure of children's potential park need is an index created according to the following contributing factors; the population density of children, total population density, racial minority density, population percentage whose income falls below the federal poverty line, population percentage of unemployment, population percentage of low-education, percentage of renter-occupied housing, and yard size. Comparison between the measures is both graphical (spatial) and statistical (correlational). The graphical analysis identifies spatial gaps between the measures. The statistical analysis, using multiple linear regression, assesses the extent that the park location and quality distribution is correlated with children's potential park need in the setting.

Proposed parks are added in the graphically identified spatial gaps, the effect of which is statistically analyzed to see whether children's park needs can be better met in the study area. This study can be a model for examining park access and park need among children to ultimately improve opportunities for physical activity and reduce the rate of obesity among the population. 


\title{
PUBLIC ABSTRACT
}

\author{
A Comparison of Park Access with Park Need for Children: \\ Case Study in Cache County, Utah \\ Shuolei Chen
}

Childhood obesity is one of the country's most serious health problems. There are growing efforts to prevent childhood obesity by improving opportunities for physical activity in their communities. The outdoor settings of the built environment, such as parks and open spaces, can offer children opportunities for physical activities, experience with nature, and social interaction, contributing to children's physical and psychological health. However, children's physical proximity to parks is often inequitable, while the quality of parks also varies. These disparities contribute to the inequitable distributions of park environments among disadvantaged groups. Most studies focused on physical park distribution inequities. The purpose of this study is to explore park access by both physical proximity and the quality of parks as related to children's (5 to 17 years of age) potential need for parks.

Across the 77 census block groups in Cache County, Utah, park proximity was identified by GIS network analysis methods to determine park service areas. Overall park quality was determined according to five park feature qualities (facilities, amenities, aesthetic feature, cleanliness and maintenance, and incivility) measured using the PARK tool (Parks, Activity, and Recreation among Kids). The measure of children's potential park need is an index created according to the following contributing factors within each census block group: children population density, total population density, minority 
density, percent population whose income falls below the federal poverty line, percent population unemployment, percent population with low-education, percent renteroccupied housing, and yard size. Comparison between park access and park need is both graphical (spatial) and statistical (correlational). The graphical analysis identified spatial gaps between the measures for improving park proximity and quality in the gaps. The statistical analysis, using multiple linear regression, assessed the extent that park access was correlated with park need in Cache County. After adding new parks in the identified gap areas, another multiple linear regression determined whether the correlation between park access and park need improved.

The result of the comparison showed that park need among children in Cache County was positively associated with park access, measured as a combination of park proximity and overall quality, to a significant extent $(p<.001)$ accounting for $56 \%$ of the relationship between the two. Among the two indicators of park access, park proximity was the primary association to children's potential park need, accounting for $55 \%$ of the relationship, while the relationship between overall park quality and park need was only $1 \%$.

This study proposed a new approach to identify areas of high park need for improvements in park access by empirically determining the park need and then calculating the needed improvement in park proximity to reach the average park proximity for the county. By improving the identified block groups park proximity through the addition of new park space, the correlation between children's park need and park access increased to $72 \%$, demonstrating the improvement significantly. This study suggests using a single socio-economic indicator of Park Need Index, such as poverty, 
because the Park Need Index with single indicator is as effective as using the four socio-economic indicators suggested in prior studies. Also, the overall park quality can be adequately represented by only one park feature quality, such as the number of facilities. Doing so will both save effort on the part of planners as well as avoiding subjectivity in assessing other park qualities. 


\section{ACKNOWLEDGMENTS}

I would like to thank my committee chair, Dr. Keith Christensen, for his patient direction, kind encouragement, and insightful knowledge throughout the entire process. My committee member, Dr. Shujuan Li, thanks for her incisive inspiration for my thesis

and professional technology support. Thanks, Dr. Dennis Nelson, my committee member, for his extensive connections and knowledge about the Cache County park system.

I also want to thank the Logan City Park \& Recreation Office for their help with the existing park quality and location information.

Thanks for the Department of Landscape Architecture and Environmental Planning, all of the faculty members, especially Dr. Bo Yang, Prof. David Evans, Dr. Barty Warren-Kretzschmar for all their help and encouragement during the past three years. Thanks to my colleagues, Wayne Honaker, Susie Gomez, and Logan Oates. I give my special thanks to my family, dear Dad, Mum, and my lovely Blackie for all of their support and understanding. I could not have done it without you.

Shuolei Chen 
CONTENTS

Page

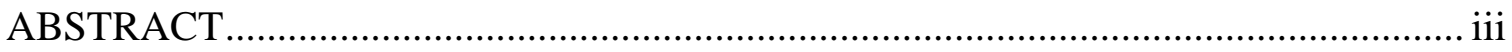

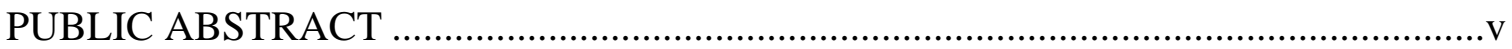

ACKNOWLEDGMENTS ……………............................................................. vii

LIST OF TABLES

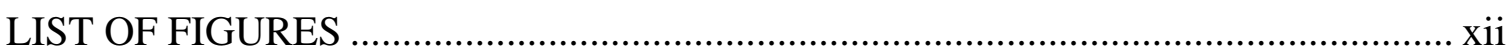

CHAPTER

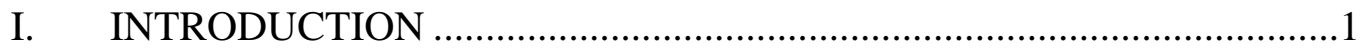

II. LITERATURE REVIEW ..........................................................

Childhood Obesity ....................................................................................

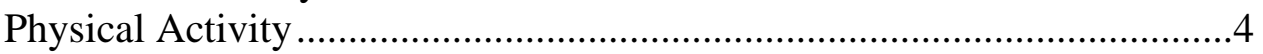

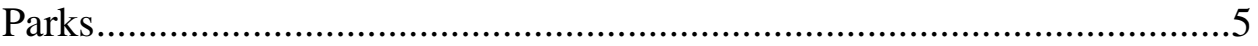

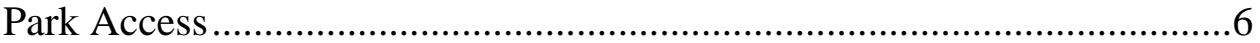

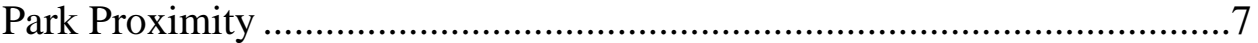

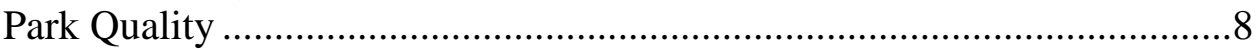

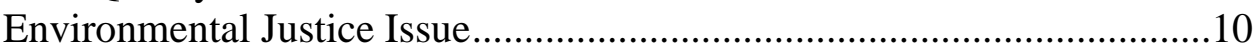

Park Need .......................................................................................

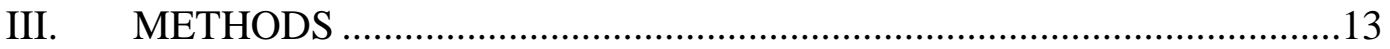

Study Setting and Sample ......................................................................14

Data Collection and Measures .................................................................17

Independent Variable I: Park Proximity ............................................18

Independent Variable II: Park Quality ...............................................20

Dependent Variable: Potential Park Need for Children......................25

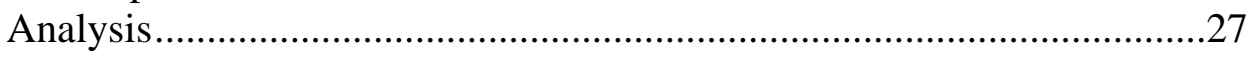

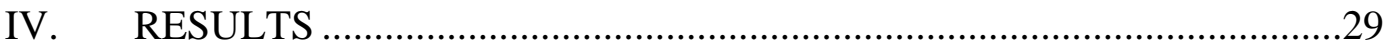

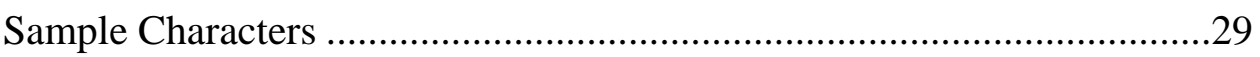

Correlation between Park Need and Park Access......................................29

Correlation between Park Need and Proposed Park Access ........................33

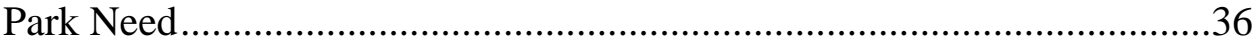




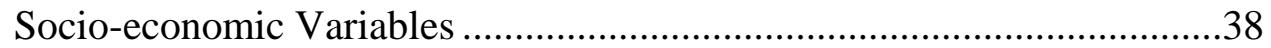

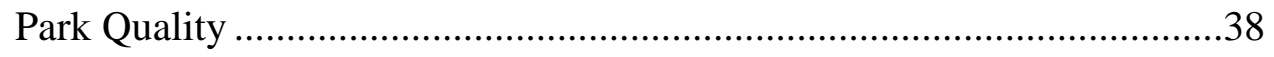

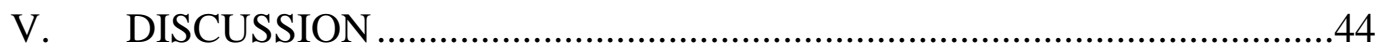

Correlation between Park Access and Park Need...................................44

Park Proximity and Park Quality ......................................................4 48

Park Quality Concerns .........................................................................48

Socio-economic Indicators of Park Need ................................................50

How to Measure Park Quality...............................................................51

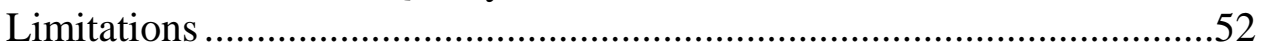

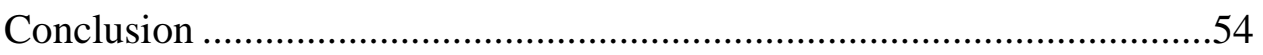

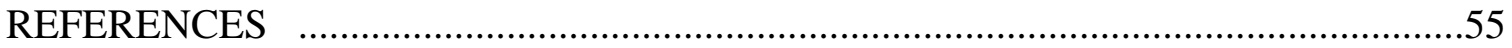

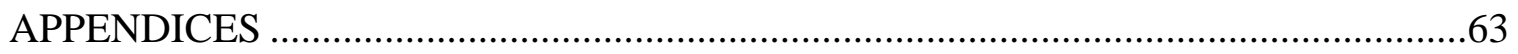

Appendix A. Population Density Data of Cache County, Utah................64

Appendix B. Socio-demographic Data of Cache County, Utah .................70

Appendix C. Standardized Socio-demographic Data of Cache County, Utah (Variables of Park Need) ..............................76

Appendix D. Park Quality Data among Block Groups of Cache County, Utah .82

Appendix E. Park Proximity, Park Quality, and Park Need among all the Block Groups in Cache County, Utah ......................88

Appendix F. Proposed Park Proximity and Park Quality among all the Block Groups in Cache County, Utah

Appendix G. Individual Park Quality of all the Parks in Cache County, Utah 100

Appendix H. Parks, Activity, and Recreation among Kids Tool (PARK Tool)

Appendix I. Simplified PARK Tool .114 


\section{LIST OF TABLES}

Table

1. Cache County Block Group Characteristics and Park Qualities across the Whole County. .30

2. The Bivariate and Partial Correlations of the Predictors with Park Need

3. The Bivariate and Partial Correlations of the Proposed Predictors with

Park Need

4. The Bivariate Correlations Assessing Different Contributing Variables of Park Need Index ${ }^{4}$ with Park Need, Park Proximity, and Overall

Park Quality.....

5. The Bivariate Correlations Assessing Different Park Need Indexes with

Different Socio-economic Variables

6. The Bivariate Correlations among Different Park Quality Scores

(Separate Park Feature Quality and Overall Park Quality)

7. The Bivariate and Partial Correlations of the Predictors with

Park Need (Facility)

8. The Bivariate Correlations between Poverty and Different Park Qualities 


\section{LIST OF FIGURES}

Figure $\quad$ Page

1. Method framework diagram.................................................................

2. An example neighborhood showing how to define Park Proximity with

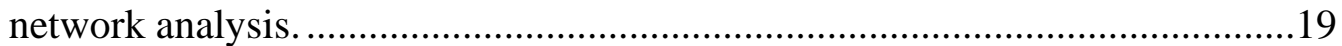

3. Bridgerland Park, Logan City, Cache County, Utah.....................................22

4. Park quality distribution in a block group............................................24

5. Bivariate scatterplot of Park Need with Park Proximity. ................................32

6. Bivariate scatterplot of Park Need with Park Quality....................................33

7. Bivariate scatterplot of Park Need with Proposed Park Proximity...................35

8. Bivariate scatterplot of Park Need with Proposed Park Overall Quality..........36

9. Bivariate scatterplot of Park Need with Park Facility...................................41

10. Overlay map: Children's potential park need and park proximity...................45

11. Gap area map: Gap block groups which need to improve park proximity........46 


\section{CHAPTER I}

\section{INTRODUCTION}

As childhood obesity becoming one of the nation's most severe health problems, one-third of children in the United States has been obese or overweight, which can cause a series of related health problems in their future lives. There have been growing efforts to prevent childhood obesity by improving opportunities for physical activity in their communities. The outdoor settings of the built environment, such as parks and open spaces, offer children opportunities for physical activities, experience with nature, and social interaction, contributing to children's physical and psychological health. However, children's physical access to parks is often inequitable. Simultaneously, the quality of parks also varies. These disparities caused the uneven distribution of health-promoting features of built environment among disadvantaged groups (e.g., low socio-economic and racial minority groups), who may not have access to other resources (Floyd \& Johnson, 2002; Taylor, Poston, Jones, \& Kraft, 2006). While most previous studies focused on physical park distribution inequities, especially for single or limited disadvantaged groups of people, the purpose of this study is to explore park access by both park physical proximity and quality related to children's potential need for parks.

Even though some recent studies stated to improve the park proximity measurement alone to the combining measurement of park proximity and quality, these studies often used park numbers as the park proximity indicator while this study, based on the GIS network analysis, represented proximity with park service area. Also, other than comparing park proximity and quality with a single population's socio-economic 
status (SES) indicator, this study broadened the scope of environmental justice issue into defining the disadvantaged groups of people who had stronger potential park need than the public.

This study employs case study methods to explore these relationships across Cache County, Utah. Park proximity is identified by GIS network analysis methods to determine park service areas for all the 77 census block groups in Cache County. Both overall park quality and five separate park feature qualities (facilities, amenities, aesthetic feature, cleanliness and maintenance, and incivility) are measured using the PARK tool (Parks, Activity, and Recreation among Kids) (Bird, Datta, Hulst, Kestens, \& Barnett, 2015). The measure of children's potential park need is an index (Loukaitou-Sideris \& Stieglitz, 2002) created according to the following contributing factors: children population density, total population density, racial minority density, percent population whose income falls below the federal poverty line, percent population of unemployment, percent population with low-education, percent of renter-occupied housing, and yard size. Comparison between the measures is both graphical (spatial) and statistical (correlational). The graphical analysis identifies spatial gaps between the measures. The statistical analysis, using multiple linear regression assessed the extent that the park location and quality distribution is correlated with children's potential park need in the setting. Proposed parks are added in the graphically identified spatial gaps, the effect of which is statistically analyzed to see whether children's park needs can be better met in the study area.

The result of the comparison showed that park need among children in Cache County was positively associated with park access, measured as a combination of park 
proximity and overall quality, to a significant extent $(p<.001)$ accounting for $56 \%$ of the relationship between the two. Among the two indicators of park access, park proximity was the primary association to children's potential park need, accounting for $55 \%$ of the relationship, while the relationship between overall park quality and park need was only $1 \%$.

This study proposed a new approach to identify areas of high park need for improvements in park access by empirically determining the park need and then calculating the needed improvement in park proximity to reach the average park proximity for the county. By improving the identified block groups park proximity through the addition of new park space, the correlation between children's park need and park access increased to $72 \%$, demonstrating the improvement significantly. This study suggests using a single socio-economic indicator of Park Need Index, such as poverty, because the Park Need Index with single indicator is as effective as using the four socioeconomic indicators suggested in prior studies. Also, the overall park quality can be adequately represented by only one park feature quality, such as the number of facilities. Doing so will both save effort on the part of planners as well as avoiding subjectivity in assessing other park qualities.

The purpose of the study is to determine to what extent park access (park proximity and park quality) and potential park need for children (age from 5 to 17) are correlated in Cache County, Utah.

This study also can be a model for examining park access and park need among children to ultimately improve opportunities for physical activity and reduce the rate of obesity among the population. 


\section{CHAPTER II}

\section{LITERATURE REVIEW}

\section{Childhood Obesity}

In recent decades, childhood obesity has received growing attention and become one of the most significant health problems in the United States. As a result, overweight childhood is regarded as the most prevalent nutritional disorders of US children and adolescents, and one of the most common problems seen by pediatricians (American Obesity Association, 2014). A series of health risks can be caused by obesity during childhood, such as high blood pressure and high cholesterol which are risk factors for cardiovascular disease (CVD), breathing problems like sleep apnea, fatty liver disease. Childhood obesity can also lead to psychological stress such as depression, behavioral problems, and issues in school (Centers for Disease Control and Prevention, 2015). It has been reported that the obesity rate for children ages 6 to 11 has more than quadrupled, and it has more than tripled among teens from 12 to 19 years old (Ogden, Carroll, Curtin, \& Lamb, 2010). In 2012, more than one-third of children and adolescents were overweight or obese in the U.S. (Ogden, Carroll, Kit, \& Flegal, 2014). Based on these facts, we should see the childhood obesity has been a major health issue prevalent among children which need to be addressed.

\section{Physical Activity}

Regarding this significant issue, growing numbers of researchers are exploring how to prevent childhood obesity. In addition to the traditional individual and 
interpersonal factors to reduce obesity, such as genetics studies and promotion of healthy diets, lots of studies suggested physical activity also exerted a strong influence on children's obesity (Budd \& Hayman, 2008; Ritchie, Ivey, Masch, Woodward-Lopez, Ikeda, \& Crawford, 2001). Physical activity can help children burn off surplus energy which contributes to healthy body weight. Additionally, physical activity can also improve many other aspects of children's lives. For example, more active children have better academic achievement, more positive self-esteem, and more positive attitudes and behaviors (American College of Sports Medicine, 2000; Canadian Paediatric Society, 2002; Ritchie et al., 2001). It has already been proven that children who have more access to physical activities often have a lower risk of obesity and other related diseases (Budd \& Hayman, 2008), higher academic performance (Basch, 2010; Taras, 2005), and being less disruptive in school (Gibson et al., 2005; Mahar, Murphy, Rowe, Golden, Shields, \& Raedeke, 2006; Sibley, Ward, Yazvac, Zullig, \& Potteiger, 2008).

\section{Parks}

Among many determinants of physical activity among young people, built environments, which can be defined as human-made space where people live, work, and create on a day-to-day basis (Roof \& Oleru, 2008) is one of the important one. Parks and open space, have been considered primary environmental elements for children to explore physical activities. Many previous studies suggested that access to the parks can influence the body weight and overall well-being of children through physical activities they provided, which can hinder the risk of obesity (Frank, Schmid, Sallis, Chapman, \& Saelens, 2005; Macintyre, Ellaway, \& Cummins, 2002; Saelens, Sallis, Black, \& Chen, 
2003). The outdoor settings of parks can give opportunities to young people to get involved in various activities, rather than stay at home, such as free play in dirt and puddles, and discovery and exploration of nature (Proshansky \& Fabian, 1987).

Parks are acknowledged as assets for children to explore physical activities. Lots of prior studies indicated the importance of parks to provide children with an experience with nature (Loukaitou-Sideris \& Stieglitz, 2002; Rigolon \& Flohr, 2014), and can give young people opportunities to discover and explore nature (Daves, 1989). Parks are also beneficial for young people to develop their motor skills, and interact with other children in environments that are usually less restrictive than those of home and school, which advances children's social and cognitive development (Hart, 1978; Saegert \& Hart, 1978). For older children and teenagers, parks can be seen as important settings for socializing with peers and getting involved in sports and physical activities (LoukaitouSideris \& Stieglitz, 2002). It has also been proposed that parks are often described as an antidote to the commercialization of leisure, contrasting with the passive and insular experiences offered to children by electronic toys, computers, and television (Burgess, Harrison, \& Lime, 1988).

\section{Park Access}

Park access is a crucial factor influencing parks' usage and people's physical activity, in particular for children (Rigolon \& Flohr, 2014). "Access" is regarded as entry into or potential use of someplace by most people (Penchansky \& Thomas, 1981). In this study, park access will be explored by both access to park proximity and park quality. 


\section{Park Proximity}

Physical proximity to a park is a primary factor that influences children's access to a park (Gaster,1991; Gordon-Larsen, Nelson, Page, \& Popkin, 2006; Hillsdon, Panter, Foster, \& Jones, 2006). It has been showed that people who live near parks are more likely to achieve recommended levels of physical activities (Aytur, Jones, Stransky, \& Evenson, 2015; Babey, Wolstein, Krumholz, Robertson, \& Diamant, 2013; Evenson, 2013; National Recreation and Park Association, 2013). What is more, physical proximity to parks for young people is sometimes a more significant issue for park access because of parents' fear of children's safety. It has been suggested that children's opportunities for outdoor play and independent mobility may be quite limited, and nearby parks can be a choice for their free active play with parents' permission (Veitch, Bagley, Ball, \& Salmon, 2006), which makes park proximity important for kids. However, children's physical access to parks is often inequitable because of the disparity in public park distribution. Disadvantaged groups of people (people who live in low-income or high Minority communities) often have less access to the environmental resources (Godbey, Caldwell, Floyd, \& Payne, 2005; Vaughan, Kaczynski, Stanis, Besenyi, Bergstrom, \& Heinrich, 2013). For example, an increasing body of research tended to examine whether various physical resources like parks were equitably distributed by the neighborhood socio-economic status (SES) or ethnic or racial composition (Vaughan et al., 2013). Even though there are some other consequences, most literature often concluded as areas with lower socio-economic status (SES) and/or higher minority population and/or lower-educated parents contain significantly fewer parks and recreational resources than their higher socio-economic status and small minority 
counterparts (Estabrooks, Lee, \& Gyurcsik, 2003; Gordon-Larsen et al., 2006; Moore, Roux, Evenson, McGinn, \& Brines, 2008; Powell, Slater, Chaloupka, \& Harper, 2006; Talen, 1997; Wolch, Wilson, \& Fehrenbach, 2005).

\section{Park Quality}

When evaluating park access, most research typically just measured the distance between the location of the park and participants' residence or generate service area around the location of the park (Barton \& Grant, 2006; Kaczynski, Potwarka, Smale, \& Havitz, 2009; Potwarka, Kaczynski, \& Flack, 2008; Roemmich, Epstein, Raja, Yin, Robinson, \& Winiewicz, 2006; Tucker, Irwin, Gilliland, He, Larsen, \& Hess, 2009; Wolch et al., 2011; Rundle, Quinn, Lovasi, Bader, Yousefzadeh, Weiss, \& Neckerman, 2013). Park access has been developed as a construct that encompassed both physical and non-physical dimensions (Aday \& Anderson, 1974; Ferreira \& Batey, 2007; Flint, Gregory, Johnston, Pratt, Watts, \& Whatmore, 2009; Lindsey, Maraj, \& Kuan, 2001; Wang, Brown, Liu, 2015). Besides the influential factor of physical proximity on distance, the quality of such resources is also positively associated with children's access to parks (Dowda et al., 2006; Cohen et al., 2006; Edward, Hooper, Knuiman, Foster, \& Giles-Corti, 2015; Roemmich et al., 2006; Jago, Baranowski, \& Harris, 2006).

Little research has evaluated whether the overall quality of parks also has the inequitable distribution problem among children who live in various neighborhoods. Although quality has been proven to be a critical component of public parks and environmental resources but actually received limited attention (Bedimo-Rung, Mowen, \& Cohen, 2005). A number of studies have identified that disparities existed in different 
park feature distribution across socioeconomically and racially diverse neighborhoods (Hughey, Walsemann, Child, Powers, Reed, \& Kaczynski, 2016; Jenkins, Yuen, Rose, Gregory, Cotton, 2015; Vaughan et al., 2013). For example, Hughey (2016) recently has found that the park incivilities, as part of the overall park quality, increased as the neighborhood minority concentration increased. High disadvantaged block groups were more likely to have more park incivilities (Hughey et al., 2016). It has been found that in Los Angeles Inner City, with more households in poverty and a high concentration of minority population than the Valley, parks' levels of maintenance and cleanliness were not as good as in the Los Angeles Valley (Loukaitou \& Stieglitz, 2002). Since the existing attention has been concentrated on some single park features, such as facility and incivility, further studies should explore if the overall quality of park including facility and incivility are equitably distributed across neighborhoods, especially for children.

There have been several ways to explain park quality while most previous studies defined it as the presence of single or limited park features or characters. Some research considered park quality to the cleanliness of the park (Kaczynski, Stanis, \& Besenyi, 2012) while some research considered it to the active aesthetic features in the parks (Vaughan et al., 2013) or the greenness (tree number and tree canopy area) (Edwards, Hooper, Knuiman, Foster, \& Giles-Corti, 2015). However, larger numbers of studies regarded park quality as a more comprehensive category, with more park features or park characters, such as facility (playground, state park, baseball field, basketball court, swimming pool, dog park) (Aytur et al., 2015; Bai, Stanis, Kaczynski, \& Besenyi, 2013; Hughey et al., 2016; Jenkins et al., 2015; Loukaitou-Sideris \& Stieglitz, 2002; LoukaitouSideris \& Sideris, 2010); amenity (parking lot, restroom, sidewalk, bike lane, bench, 
table, fountain) (Aytur et al., 2015; Hughey et al., 2016; Jenkins et al., 2015); aesthetic features (landscaping, water feature, green space, historical or educational feature) (Hughey et al., 2016; Loukaitou-Sideris \& Sideris, 2010; Macintyre et al., 2002; Vaughan et al., 2013); maintenance and cleanliness (Loukaitou-Sideris \& Sideris, 2010; Mowen, 2010; Coen \& Ross, 2006; National Recreation and Park Association, 2013).

Furthermore, Hughey et al., (2016) suggested incivilities (e.g. dangerous spots, excessive animal waste, litter, noise, graffiti, vandalism) ought to be the other aspect of evaluating Park Quality. Park safety, although often viewed as a sub-domain of park quality (Aytur et al., 2015) was often difficult to be consistent with park quality, because higher park quality came to higher use of the park (Aytur et al., 2015; Coen \& Ross, 2006; Mowen, 2010; National Recreation and Park Association, 2013), which would lead to a higher rate of crime or danger in the park.

\section{Environmental Justice Issue}

The definition of environmental justice is the fair treatment and meaningful involvement of all people in the development, implementation, and enforcement of laws, regulations, and policies about diverse environmental issues (Taylor et al., 2006). Environmental justice issue provides a conceptual foundation for studying environmental disparities in low-income and ethnically diverse communities that may impact poorer rates of physical activity and health (Floyd, Taylor, \& Whitt-Glover, 2009; Vaughan et al., 2013). Many existing research has evaluated whether the environmental resources (parks and open space) were equitably distributed by socioeconomic status (SES) and ethnic/racial composition, and whether there were inequities among disadvantaged 
groups of people. Additionally, a growing number of studies started to pay attention to the disparity in park quality by neighborhood composition in recent decades. However, does the environmental justice only exist in socioeconomic and racial diversities? Are there any other contributing factors which influence the group of people to be disadvantaged or have more desire to get access to public parks? Smith (1986) has defined the term "justice" as the fairness or equity of a situation or distribution. Referring the distribution of public parks, the researcher asked these questions: "Who gets what?" or, normatively, "Who ought to get what?" (Wicks \& Crompton, 1986, p. 342). That is to say, the environmental justice of park distribution can refer to the question of was the park or/and the proper quality of the parks located in the right places to be used by the people who need it. In addition to the socio-economic status and ethnical composition, some other elements should be added to identify the disadvantaged group of people who have higher potential park need in terms of studying both the distribution of park proximity and quality at the same time, especially for children.

\section{Park Need}

The concept of population need for parks has been raised a long time ago (Loukaitou-Sideris \& Stieglitz, 2002), but has not been furthered explored. In their study about population need for parks, a "Need Index" was created, taking consideration of several socio-demographic variables, which were not only about the socio-economic status and ethnical composition (Loukaitou-Sideris \& Stieglitz, 2002). These variables included median income, percentage below the poverty line, children density and number of people per household (Loukaitou-Sideris \& Stieglitz, 2002). Loukaitou-Sideris and 
Stieglitz (2002) also found a covariate, house yard, with the four socio-demographic factors, which can impact children's need for the park. It has been claimed that children lived in more crowded conditions at home and had less available private space to play and were less likely to live in a house with a yard often had a higher need to get access to public parks (Loukaitou-Sideris \& Stieglitz, 2002). Based on the prior works of park need, more research ought to be devoted to exploring more comprehensive aspects of children's potential need for parks. However, no further research has evaluated whether there are disparities in park proximity and quality simultaneously among children's potential need for parks.

The purpose of the study is to determine to what extent park access (park proximity and park quality) and potential park need for children (age from 5 to 17) are correlated in Cache County, Utah.

This study will be a model for examining park access, and park need among children to ultimately improve opportunities for physical activity and reduce the rate of obesity among the population. 


\section{CHAPTER III}

\section{METHODS}

To answer the research question: To what extent are Park Access and Park Need correlated in Cache County, Utah? This study employed case study method to study these relationships between Park Access and Park Need across the setting (Figure 1.).

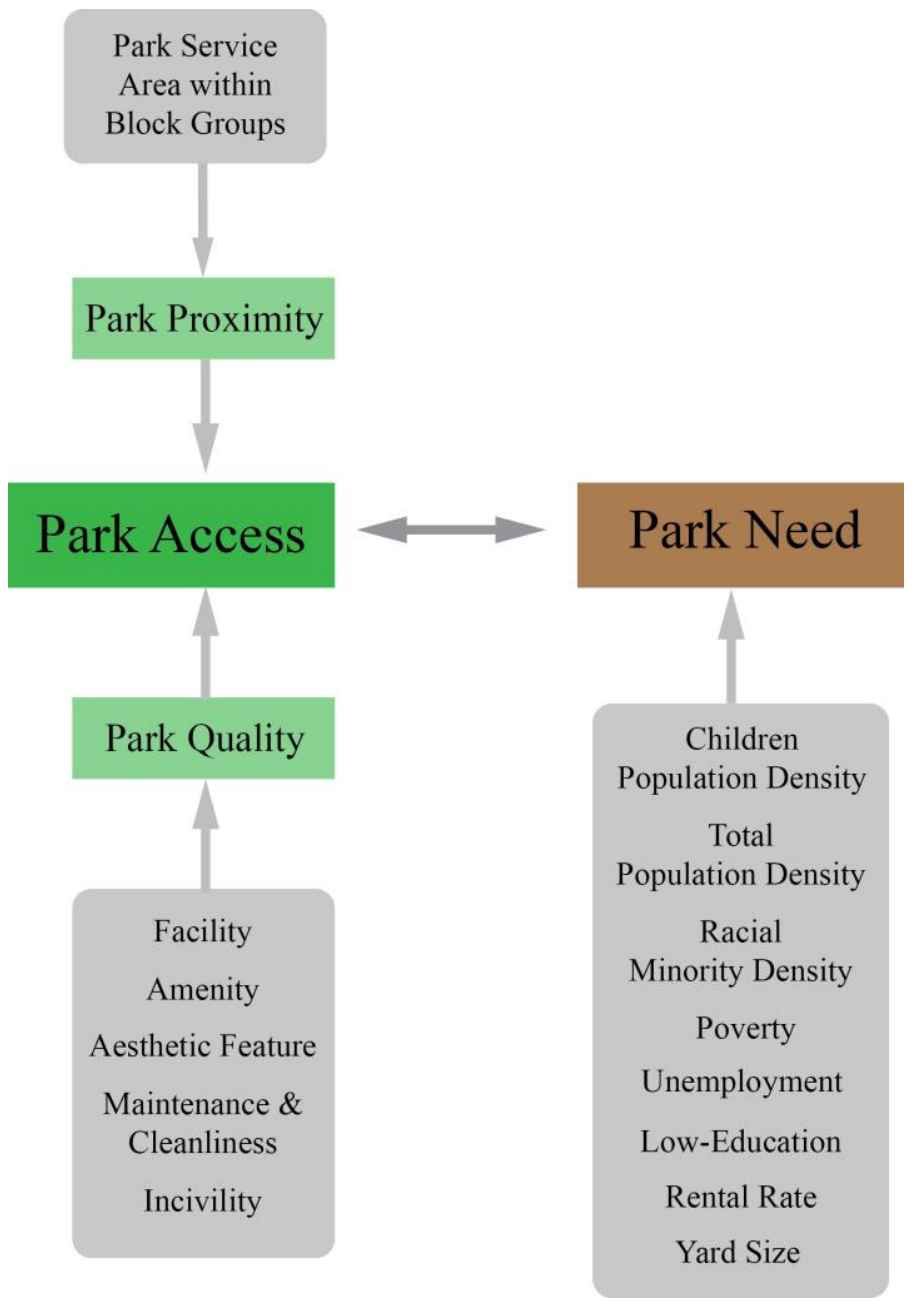

Figure 1. Method framework diagram. 
Park Access was explored by both Park Proximity and Park Quality. Park Proximity was identified by GIS network analysis methods to determine park service areas for each of the 77 census block groups in Cache County. Park Quality was also the Overall Park Quality, defined by averaging the separate park feature qualities (facilities, amenities, aesthetic feature, cleanliness and maintenance, and incivility). The measure of children's Potential Park Need is an index (Loukaitou-Sideris \& Stieglitz, 2002) created according to the following contributing factors: the population density of children, total population density, minority density, population percentage whose income falls below $125 \%$ of federal poverty line, population percentage of unemployed, population percentage of low-education, percentage of population of renter-occupied housing and yard size. Comparison between Park Access and Park Need was both graphical (spatial) and statistical (correlational). The graphical analysis identifies spatial gaps between the measures. The statistical analysis, using multiple linear regression assessed the extent that the park location and quality distribution were correlated with children's potential Park Need in the setting.

\section{Study Setting and Sample}

The investigation was conducted in Cache County, a semi-urban area of northern Utah, located in the intermountain west of the United States, with Logan metropolitan area as the county seat and largest city (Geographic Names Information System, 2016). The total area of the county is 1,173 square miles. According to 2010 Census, the total population in this county was 112,656 , of which $89.12 \%$ was white, $9.96 \%$ was Hispanic or Latino (United States Census Bureau, 2012). The median household income was 
$\$ 48,441$ with about $10.4 \%$ of the residents living below the U.S. federal poverty level. The state of Utah has the highest total birth rate among the United States (The Atlantic, 2013), and accordingly, Utah also has the highest percentage of young people than any other U.S. states (The Salt Lake Tribune, 2012). 41.34\% out of the total of 34,722 households in Cache County has children who are younger than 18 years old in the year of 2012 (United States Census Bureau, 2012). From this, we can see the youth is a significant age group in Cache County, Utah and it is important to study further about this population.

Children whose age ranged from 5 to 17 in Cache County were the population of this study. The health weight status of children between the ages of 2 to 17 was related to proximity to public parks and park features, such as playgrounds (Potwarka et al., 2008). However, not all of the children between the ages 2-17 were able to have access to parks and park features by themselves. Younger children tended to be accompanied by adults and were under their direct supervision (Loukaitou-Sideris \& Stieglitz, 2002). If the children were older than ten years old, they were still dependent on their parents but had some freedom to enter the park without direct adult supervision (Loukaitou-Sideris \& Sideris, 2010). The 14 and older group were less dependent than the younger ones and were more capable of traveling a long distance for a better park quality (LoukaitouSideris \& Stieglitz, 2002).

As one of the safest states in the United States, Utah has had the top Home and Community safety ranking in recent years (WalletHub, 2016). Most subsidiaries of Cache County, such as Smithfield, Providence, Richmond, and Mendon are all quiet and safe communities. The county seat, Logan, the only big city in Cache County, can also be 
recognized as a safe and harmonious area by the general public. The population data, in five-year increment groups, was available in American Fact Finder. Due to the higher safety of the study setting than most parts of United States, and the data availability, the population for the study needed to include children who were 5 to 10 years old. For those reasons, the population of this study has been determined to be 5-year-old to 17-year-old children in Cache County.

The sampling unit for this study was the census block group in Cache County, Utah $(\mathrm{n}=86)$. There were nine block groups having no humanity information, which were not able to include in this study, resulting in 77 block groups studied $(n=86-9=77)$. According to United States Census Bureau, the block group is the small geographical unit which was only larger than a block, which was also generally a permanent subdivision of a county and completely within the county line. They usually contained from 600 to 3000 people for each one, and their sizes often varied depending on the population density of the area (United States Census Bureau, 2012). Overall, a census block group is a good way to understand the community regarding population characters, economic status, and living conditions. For Cache County, most block groups were concentrated in the Logan metropolitan area, with most population and public resources, and the size of these was much smaller than the surrounding block groups.

The other data of the project included the parks which have already been identified by both the local county office and geographic information systems (GIS) department. The total number of the parks in Cache County was 91 with the area of each park ranging from 0.04 to 52.49 acres. There were various types of parks in the county with multiple functions and sizes, such as a mini park, pocket park, natural resource area, 
greenway, community park, and neighborhood park. All of the parks were edited by an in-person observation tool: The Parks, Activity, and Recreation among Kids tool (PARK), to evaluate their particular qualities for children. These qualities are facility (e.g., playground, state park, baseball field, basketball court, swimming pool, dog park), amenity (e.g., parking lot, restroom, sidewalk, bike lane, bench, table, fountain), aesthetic features (e.g., landscaping, water feature, green space, historical or educational feature), maintenance and cleanliness, and incivilities (e.g., dangerous spots, excessive animal waste, litter, noise, graffiti, vandalism).

\section{Data Collection and Measures}

This study employed case study methods to explore these relationships across Cache County, Utah. Park proximity, one of the independent variable, was identified by GIS network analysis methods to determine park service areas for each of the 77 census block groups in Cache County. The other independent variable, Park Quality, and five separate park feature qualities (facilities, amenities, aesthetic feature, cleanliness and maintenance, and incivility) were measured using the PARK tool (Parks, Activity, and Recreation among Kids) (Bird et al., 2015). The measure of children's potential Park Need was an index (Loukaitou-Sideris \& Stieglitz, 2002) created according to the following contributing factors; the population density of children, total population density, population percentage whose income fell below the federal poverty line, population percentage of unemployed, minority density, and yard size. Comparison between the measures was both graphical (spatial) and statistical (correlational). The graphical analysis identified spatial gaps between the measures. The statistical analysis, 
using multiple linear regression assessed the extent that the park location and quality distribution was correlated with children's Potential Park Need in the setting. Proposed parks were added in the graphically identified spatial gaps, the effect of which was statistically analyzed to see whether children's park needs can be better met in the study area.

\section{Independent Variable I: Park Proximity}

As one of the independent variables to explore park access, the physical proximity of parks was defined as the proportion of park service area within the block group. Park Proximity was identified by the Network analysis method of GIS (Comber, Brunsdon, \& Green, 2008; Cutts, Darby, Boone, \& Brewis, 2009; Gilliland, Holmes, Irwin, \& Tucker, 2006; Jones, Brainard, Bateman, \& Lovett, 2009; Talen, 2003; Rigolon \& Flohr, 2014) to map the service area of parks for children in Cache County. The park shape file, provided by Utah Automated Geographic Reference Center, contained polygons representing the boundaries and total areas of all the parks in Cache County. Via network analysis of GIS (Figure. 2), each park was established as the location center. The service distance from the location centers was set as 0.5 miles (800 meters), which was within an acceptable walking distance for children (Chillón, Panter, Corder, Jones, \& Van Sluijs, 2015). For a more accurate representation of network buffer, a 50-meter buffer depth was selected to ensure that land use along the selected automobile/pedestrian network would be included (Oliver, Schuurman, \& Hall, 2007). The proportion of park service area for all block groups $(n=77)$ in Cache County were evaluated and illustrated both by graphics and statistics. The graphic illustration was by the park allocation map which visually mapped 


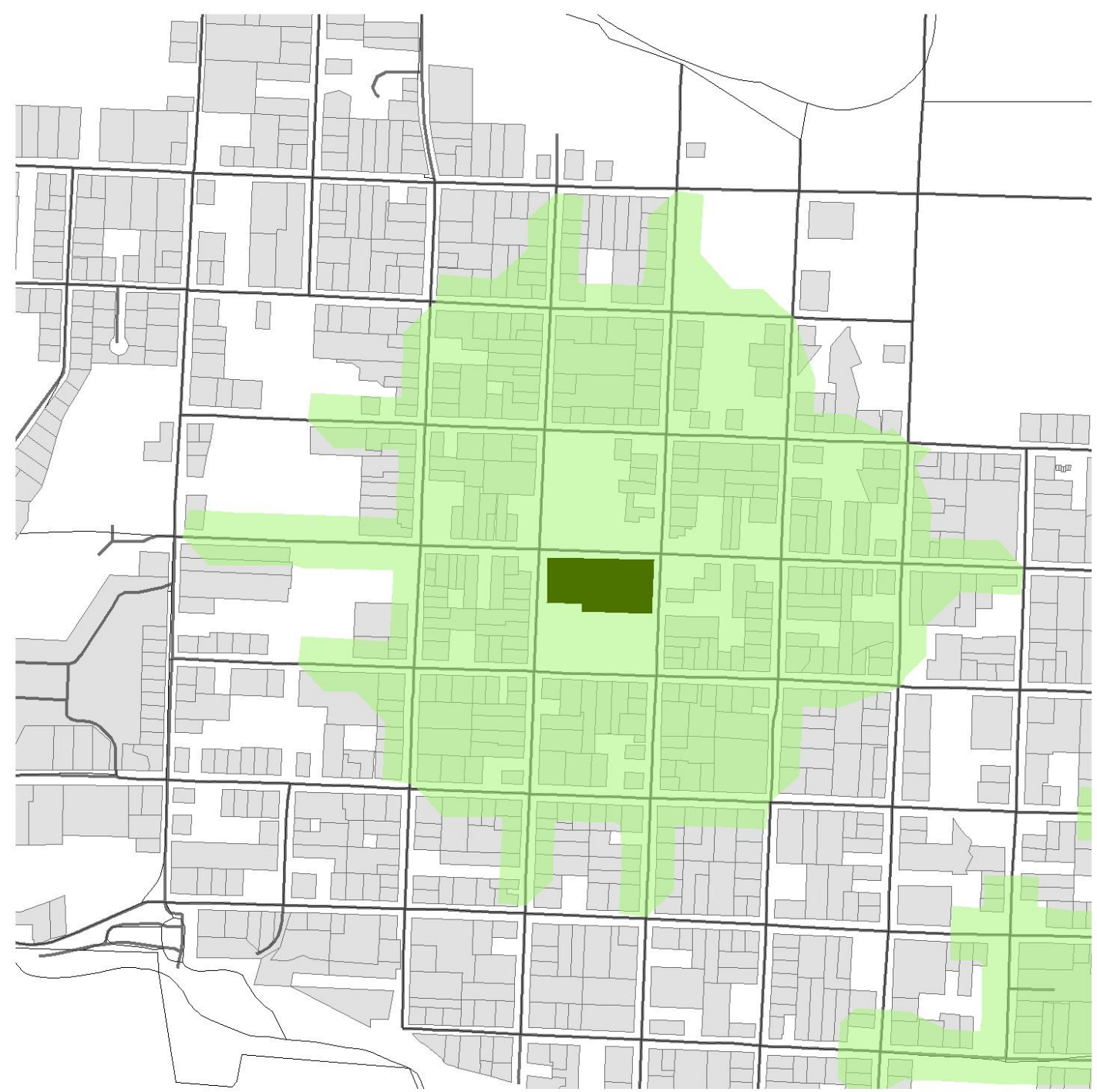

Legend

Parks

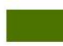

Park Service Area

Road

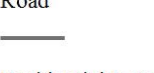

Residential Lots

Cache County Block

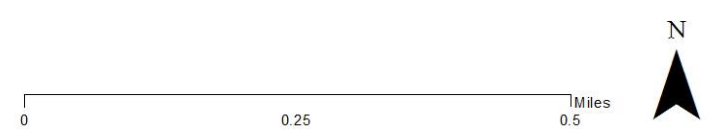

$\square$

Figure 2. An example neighborhood showing how to define Park Proximity with network analysis. 
the park service areas within all block groups while the statistical one indicated the standardized percentage of the service area of each block group in the county.

\section{Independent Variable II: Park Quality}

Park Quality distribution was the other factor to study children's access to the parks in the setting area. In this study, both overall park quality and separate park character qualities were explored to evaluate children's access to Park Quality in Cache County. Several park characters, such as park facility and amenity were assessed for all parks in the setting area using the Parks, Activity, and Recreation among Kids (PARK) tool (Bird et al., 2015). PARK (See Appendix H) was a newly developed tool for evaluating park quality from different aspects including facility, amenity, aesthetic feature, cleanliness and maintenance, and incivility, geared towards children (Bird et al., 2015). There were 46 questions on the tool both exploring the individual items presence and the overall characteristics of the park (See Appendix H). It has been illustrated that the PARK tool was a reliable direct observation park evaluation tool which could be used to test park qualities and youth physical activity successfully (Bird et al., 2015). Even though this tool was conceptually designed to be attractive for youth, the limitation for PARK was that this had not been validated (Bird et al., 2015). Two auditing observers including the author were trained in using the PARK tool to assess all the parks in the county during September 2016 to October 2016 (Appendix G).

Different park features--Park Facility, Amenity, Aesthetic Feature, Cleanliness and Maintenance, and Incivility--were audited separately and would have their scores to represent their individual qualities (Appendix I). Park Facilities were defined as playing 
areas which can provide people with opportunities to get access to both active and passive activities (Hughey et al., 2016), such as a playground, basketball court, soccer field, and pool.

According to the PARK tool, there were 18 points in total to assess the quality of the park facility which includes both facilities number score (12 points) and overall facility condition scores (6 points). The presence of each park facility in the park if also shown in PARK could gain one point for this park's facility number score. The overall facility condition score was evaluated by two questions: is this park appealing for active play, and is this park appealing for walking? Each question accounted for 3 points. Park auditors were intended to capture the presence and a total number of the facilities in this park and evaluated the facility condition to see whether it met the requirement of active playing. Based on the two aspects, the park facility score (less than or equal to 18) can be calculated according to the two auditors' agreement. The same auditing method also applied to examine the performance of Park Amenity, Aesthetic Feature, Cleanliness and Maintenance, and Incivility. The park amenity has been regarded as the park features enhanced park use and visitation (e.g., footpath, sitting bench, parking lot, and No Dog sign). The PARK contained a comprehensive list of 19 park amenity items (19 points) and one general question ( 3 points) which contribute to 22 points in total for assessing amenities for each park in Cache County. The sum of 22 points based on the parks' performance would represent the park's amenity condition. The other three separate park feature qualities are: sum of 9 points for aesthetic feature ( 6 items points and 3 overall performance points) such as cultural elements, decorative elements, and water feature; sum of 10 points for cleanliness and maintenance ( 7 items points and 3 general 


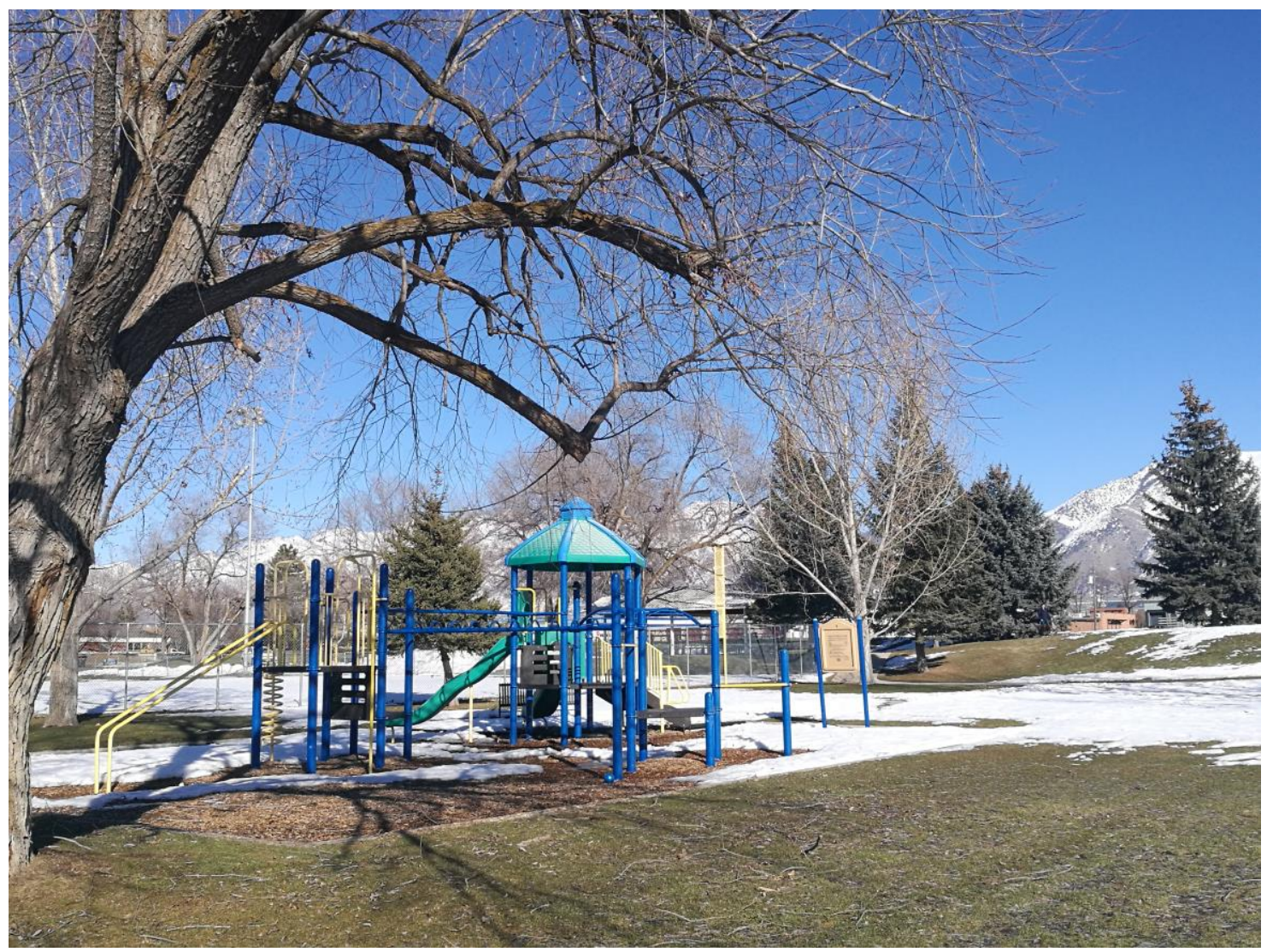

Figure 3. Bridgerland Park, Logan City, Cache County, Utah.

performance points) such as safe measures, pool condition, and toilet condition; sum of 7 for incivilities (4 items points and 3 general performance points) such as graffiti, broken items, and garbage, which is the only reverse-coded individual (Appendix I).

For assessing the overall quality of each park in Cache County, a standardized sub-score $(0$ - 100) was created, and then all the above-calculated separate qualities were intended to average to obtain the overall park quality for each park (0 - 100) (Hughey et al., 2016). For example, Bridgerland Park (Figure. 3) in Logan City had 11 points of facility ( 5 item score and 6 general performance score), 17 points of amenity (14 item 
score and 3 general performance score), 5 points of aesthetic feature ( 2 item score and 3 general performance score), 3 points of cleanliness and maintenance (3 item score and 0 general performance score), and 3 incivility score (4 item score and 0 general performance score), because it is reverse-coded, the incivility score is 3 . The standardized sub-score $(0-100)$ for each variable are 61 for facility $(11 / 18=.61), 77$ for amenity $(17$ / $22=.77), 56$ for aesthetic feature $(5 / 9=.56), 30$ for cleanliness and maintenance $(3 /$ $10=.3), 43$ for incivility $(3 / 7=.43)$. Based on the five variables, the overall quality of the park can be averaged to be $53((61+77+56+30+43) / 5=53)$.

When comparing Park Need, Park Proximity, and Park Quality, both Park Need and Park Proximity were under the block group units. To keep the comparison units consistent, a further calculation was required for classifying all individual park qualities of the county into block group unit. That is to say; we need to have park quality scores (separate feature scores and overall scores) for each block group (Appendix D). Based on the Park Proximity analysis, service area for each park within block groups already existed in GIS mapping (Figure 4). Different parks with different sizes of service areas had different contributions to the block group they belonged to. The parks having larger service areas could serve more people in these block groups than the smaller ones, which means these park qualities are more beneficial to people than the smaller ones. For the Park Quality in each block group, we averaged the qualities of all the parks according to their service area proportion within the whole park service area in this block group. For example, there are two parks in one block group (Park A: service area 10.3 acres, overall quality 53.8; Park B: service area: 1.4 acres, overall quality 62.4), with the total service area of $11.7(10.3+1.4=11.7)$. 


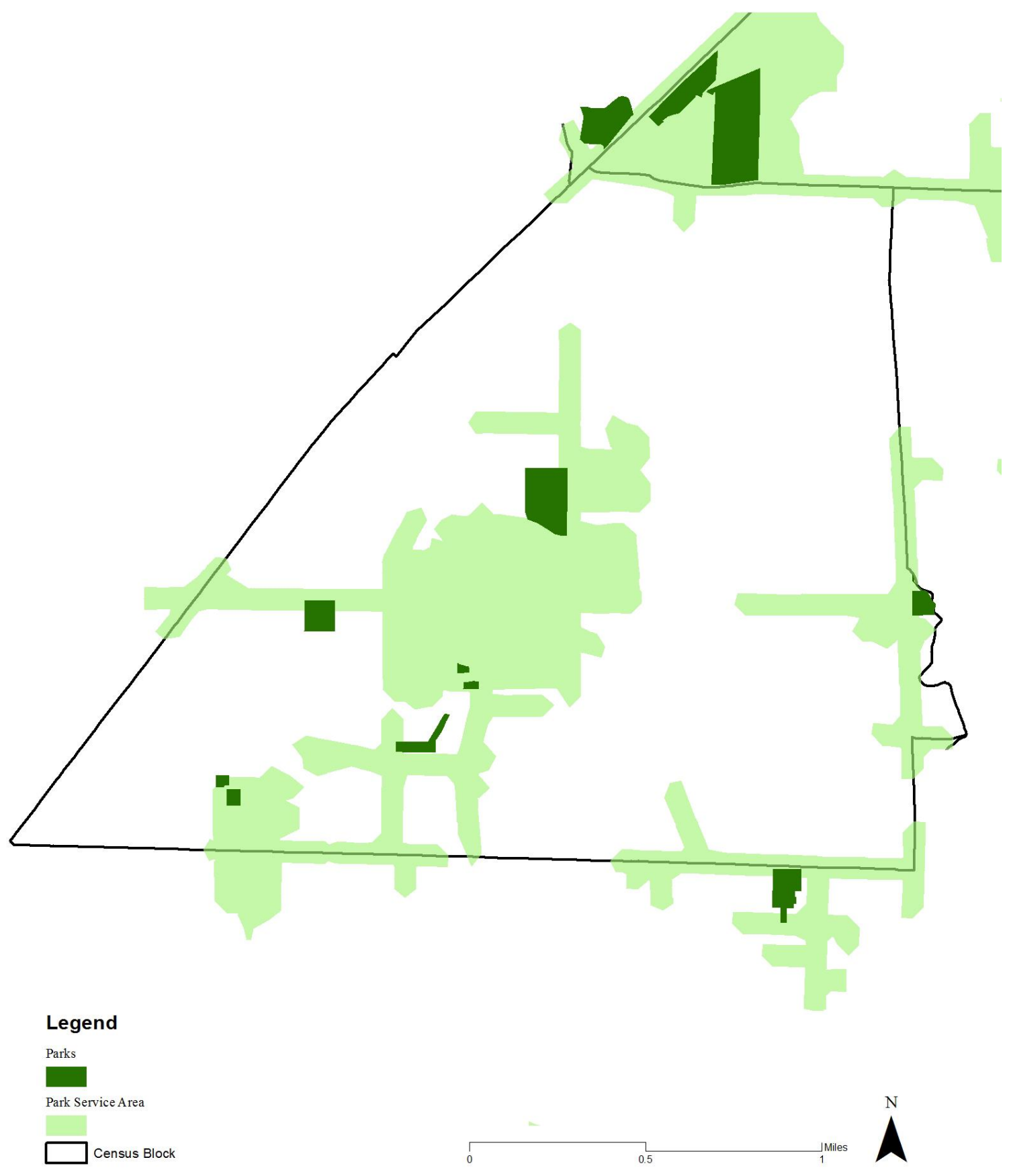

Figure 4. Park quality distribution in a block group. 
The overall Park Quality score for this block group is $54.8(10.3 / 11.7 * 53.8+$ $1.4 / 11.7 * 62.4=54.8)$. The procedures for calculation of each separate park feature qualities into the block group unit were the same.

Both of the separate feature qualities and overall quality for each block group in Cache County were evaluated and illustrated among children's need both by graphics and statistics. The graphic illustration is via the park quality distribution maps which visually mapped all park's quality scores in the whole county, the darker color for the block group represents higher park quality. The statistic illustration was indicating both of the separate feature scores and the standardized average scores for all the parks in Cache County.

\section{Dependent Variable: Potential Park Need for Children}

The dependent variable in this study was potential Park Need among children in Cache County, which was studied among different block groups according to their varying socio-demographic contributing factors and co-variables. To determining the several factors, the original data was from the demographic information of the United Census Bureau. All the socio-demographic information of Cache County (2010 to 2014 USA census data) required for the project was available at the block group level and downloaded from the American Fact Finder. Based on the previous research of population need for park, we also created a Park Needs Index (Loukaitou-Sideris \& Stieglitz, 2002) in the unit of block group, specifically for children, which determined by more comprehensive socio-demographic factors: children population density (age from 5 to 17 ), total population density, racial minority density, population percentage below 
$125 \%$ federal poverty line, population percentage of unemployed, population percentage of low-education, population percentage of people in renter-occupied housing, which were all achieved in American Fact Finder, and yard size (See Appendix A and Appendix B). Yard size was the only factor that negatively related to park need: the larger size yard provided children more open space for physical activity at home, which meant less potential need for public parks. The total yard size for each block group was calculated and analyzed within Cache County Block Parcel data through GIS (yard size $=$ parcel building size). Which means, building size was actually positively associated with park need. The proportion of total building size within the block group was the important covariable with the other socio-demographic factors. The socio-demographic variables (Children Population Density, Total Population Density, and Racial Minority Density), socio-economic variables (Poverty, Unemployment, Low-Education, and Renter Rate), and a co-variable (Yard Size) contributed to the Park Need Index to determine children's potential park need in Cache County. All eight variables for each block group were standardized into percentile scale (Appendix C). Averaging the eight percentile variables can have the park need to indicate children's need for a park for this block group (Appendix E). By this park need index, all block groups in Cache County were evaluated and illustrated their potential park need among children graphically and statistically.

\section{Analysis}

To answer the research question, to what extent is park access (park proximity and park quality) among children (age from 8 to 17) relate to children's potential need for parks in Cache County. This study analyzed the data through both graphics and statistics. 
The graphic analysis was conducted by overlaying different maps: The Park Need Map with the Park Allocation Map. By looking for the gap areas which were not served by parks and high-quality parks, some proposals for the future city planning, especially for park planning, could be made.

During the statistical analysis period, the data was studied by the multiple linear regression, using the IBM Statistical Product and Service Solution (IBM SPSS) statistic version 22. Descriptive information was achieved for all block groups and all parks in the Setting to explore the characteristics of all block groups, Potential Park Need among children, Park Proximity, and Park Qualities. Multiple Linear Regression was conducted to examine the association between Potential Park Need among Children and Park Proximity and Overall Park Quality in the studying area (See Appendix E). The linear regression assessed the extent that the Potential Park Need changed with the Proximity and Overall Quality in the setting. Some further analysis studied which contributing variables of Park Need (Children Population Density, Total Population Density, Racial Minority Density, Poverty, Unemployment, Low-Education, Renter Rate, and Building Size) were more related to Park Proximity and Overall Quality. Unemployment, LowEducation, and Renter Rate had been included to contribute to a neighborhood socioeconomic disadvantaged index (Hughey et al., 2016). In this study, we examined whether these variables were significantly correlated with Park Proximity and Quality by Pearson product-moment correlation coefficient. We also conducted another Pearson analysis to evaluate the correlations between different Park Need Indexes including different socioeconomic variables of Park Need (Poverty, Unemployment, Low-Education, Rental Rate). By comparing different Indexes, it can be seen that whether there was any 
difference with or without Unemployment, Low-Education, and Renter Rate as one of the contributing variables to Park Need. To explore more information from Park Quality, all separate park qualities (facility, amenity, aesthetic feature, maintenance and cleanliness, and incivility) were tested by another Pearson analysis with Overall Park Quality, to study the relation between the variables and the sample. If more information found, more statistical analyses can be conducted.

From the analysis made by the graphical analysis, the block groups with gap areas were detected from the overlays of different maps. With the gap block groups assigned to specific park proximity and park qualities (Appendix F), the new running of Multiple Linear Regression was implemented and statistically evaluated again. Regarding the different levels of park need, from high to low, we classified the numbers of park need into five groups according to quantile. Based on the same park need quantile, the park proximity from $0-100 \%$, was also categorized into five groups, which are $90 \%, 70 \%$, $50 \%, 30 \%$, and $10 \%$. These gap block groups were also assigned to the mean park quality, including the overall park quality and separate park feature quality. With these proposed parks proximity and park qualities promoted, the performance of Cache County parks and whether they can better serve children's park needs, promote children's physical activity, and reduce childhood obesity can be determined. 


\section{CHAPTER IV}

RESULTS

\section{Sample Characteristics}

The Cache County block group characteristics and park qualities across the county are shown in Table 1 . The average total population density, children population density, and racial minority density in Cache County are 3132, 676, and 557 per acre respectively. The highest density of total population, children population, and minority are 33065,4199 , and 7475 per acre respectively. There are about $28.18 \%$ of people, on average, living under the $125 \%$ federal poverty line and $35.29 \%$ of people are unemployed. On average, only about $7 \%$ of residents in the setting area received less than high school education. The averaging percent of building size within each block group for the whole county is 29.32 . Based on those contributing variables, the final averaged Park Need score for Cache County is 40.79 , changing from 15.42 to 87.82 .

For the park characteristics in the setting area, the average percentage of park service area within the block group (Park Proximity) is 31.51; some block groups are entirely served by parks (100\%) while some have no service area (0\%). Most average park quality scores, both separate park feature scores and overall quality score, are quite similar, around 55. Only average facility score (45.11) is less than others. On average, the overall park quality score is 53.30 , ranging from 0 to 78 .

\section{Correlation between Park Need and Park Access}

To answer the research question: to what extent Park Access (Park Proximity 
Table 1

Cache County Block Group Characteristics and Park Qualities across the Whole County

Mean SD Range

\begin{tabular}{|c|c|c|c|}
\hline \multicolumn{4}{|l|}{ Block Group Characteristics } \\
\hline $\begin{array}{l}\text { Total population density } \\
\text { (standardized } *)\end{array}$ & $\begin{array}{l}3151.9 \\
(50.65)\end{array}$ & $\begin{array}{l}5178.07 \\
(29.05)\end{array}$ & $\begin{array}{l}(0,33065) \\
(1.3,100)\end{array}$ \\
\hline $\begin{array}{l}\text { Children population density } \\
\qquad(\text { standardized } *)\end{array}$ & $\begin{array}{l}675.884 \\
(50.65)\end{array}$ & $\begin{array}{l}771.73 \\
(29.05)\end{array}$ & $\begin{array}{l}(0,4199.34) \\
(1.3,100)\end{array}$ \\
\hline $\begin{array}{l}\text { Racial minority density } \\
\qquad \text { (standardized } * \text { ) }\end{array}$ & $\begin{array}{l}556.69 \\
(50.65)\end{array}$ & $\begin{array}{l}1021.11 \\
(29.05)\end{array}$ & $\begin{array}{l}(0,7474.82) \\
(1.3,100)\end{array}$ \\
\hline $\begin{array}{l}\text { Population below } 125 \% \text { poverty }(\%) \\
\qquad(\text { standardized } *)\end{array}$ & $\begin{array}{l}28.18 \\
(50.65)\end{array}$ & $\begin{array}{l}19.26 \\
(29.05)\end{array}$ & $\begin{array}{l}(0,83.41) \\
(1.3,100)\end{array}$ \\
\hline $\begin{array}{l}\text { Unemployment }(\%) \\
\qquad(\text { standardized } *)\end{array}$ & $\begin{array}{l}35.29 \\
(50.65)\end{array}$ & $\begin{array}{l}8.37 \\
(29.05)\end{array}$ & $\begin{array}{l}(17.6,61.07) \\
(1.3,100)\end{array}$ \\
\hline $\begin{array}{l}\text { Low-Education }(\%) \\
\quad(\text { standardized } *)\end{array}$ & $\begin{array}{l}0.07 \\
(50.9)\end{array}$ & $\begin{array}{l}0.07 \\
(28.65)\end{array}$ & $\begin{array}{l}(0,0.27) \\
(7.8,100)\end{array}$ \\
\hline $\begin{array}{l}\text { Renter Rate }(\%) \\
\text { (standardized } *)\end{array}$ & $\begin{array}{l}34.78 \\
(51.21)\end{array}$ & $\begin{array}{l}30.65 \\
(28.91)\end{array}$ & $\begin{array}{l}(0,100) \\
(2.6,100)\end{array}$ \\
\hline $\begin{array}{l}\text { Building size }(\%) \\
\qquad(\text { standardized } *)\end{array}$ & $\begin{array}{l}29.32 \\
(50.75)\end{array}$ & $\begin{array}{l}19.25 \\
(28.94)\end{array}$ & $\begin{array}{l}(0,68.5) \\
(3.9,100)\end{array}$ \\
\hline Park Need $(\%)$ & 50.76 & 19.41 & $(15.42,87.82)$ \\
\hline \multicolumn{4}{|c|}{ Park characteristics of all block groups } \\
\hline Park Proximity $(\%)$ & 31.51 & 34.82 & $(0,100)$ \\
\hline Facility score* & 45.11 & 17.15 & $(0,73.1)$ \\
\hline Amenity score* & 54.46 & 19.66 & $(0,86)$ \\
\hline Aesthetic feature score* & 57.16 & 21.34 & $(0,88.9)$ \\
\hline Maintenance \& cleanliness score* & 55.03 & 18.89 & $(0,100)$ \\
\hline Incivility score* & 55.18 & 19.17 & $(0,86)$ \\
\hline Overall park quality score* & 53.3 & 17.15 & $(0,78)$ \\
\hline
\end{tabular}

*Standardized to 100 point scale.

and Park Quality) and Potential Park Need for children (age from 5 to 17) are correlated in Cache County, Utah, a multiple linear regression analysis was conducted to evaluate how well Park Proximity and Overall Park Quality measure children's Potential Park Need. The predictors were Cache County Park Proximity and Cache County Overall Park 
Quality, while the criterion variable was the Potential Park Need for children in Cache County. The linear combination with both predictors was significantly related to the Park Need Index, F $(2,74)=48.12, p<.001$. The sample multiple correlation coefficient $\mathrm{R}$ was .75 , indicating that approximately $56 \%$ of the variance of the Park Need Index in the sample can be accounted for by the linear relationship of Park Access, which is also the combination of Park Proximity and Park Quality.

By the correlational analysis, among the two predictors of Park Access (Park Proximity and Park Quality), we conclude that the only useful predictor of Park Access is only the Park Proximity. As it is shown in Table 2, Park Proximity alone accounted for $55 \%\left(.74^{2}=.55\right)$ of the variance of Park Need Index, to a significant extent. While the Park Quality predictor only accounted for the rest $1 \%(.56-.55=.01)$, the partial correlation between Park Need Index and Overall Park Quality is not significant, as shown in Table 2.

Table 2

The Bivariate and Partial Correlations of the Predictors with Park Need

\begin{tabular}{lll}
\hline Predictor & $\begin{array}{l}\text { Correlation with Park } \\
\text { Need Index }\end{array}$ & $\begin{array}{l}\text { Correlation with Park } \\
\text { Need Index }{ }^{4} \text { controlling } \\
\text { for all other predictors }\end{array}$ \\
\hline Park Proximity & $.74^{*}$ & $.73^{*}$ \\
Overall park quality & -.22 & -.15 \\
\hline
\end{tabular}

$*_{p}<.001$ 


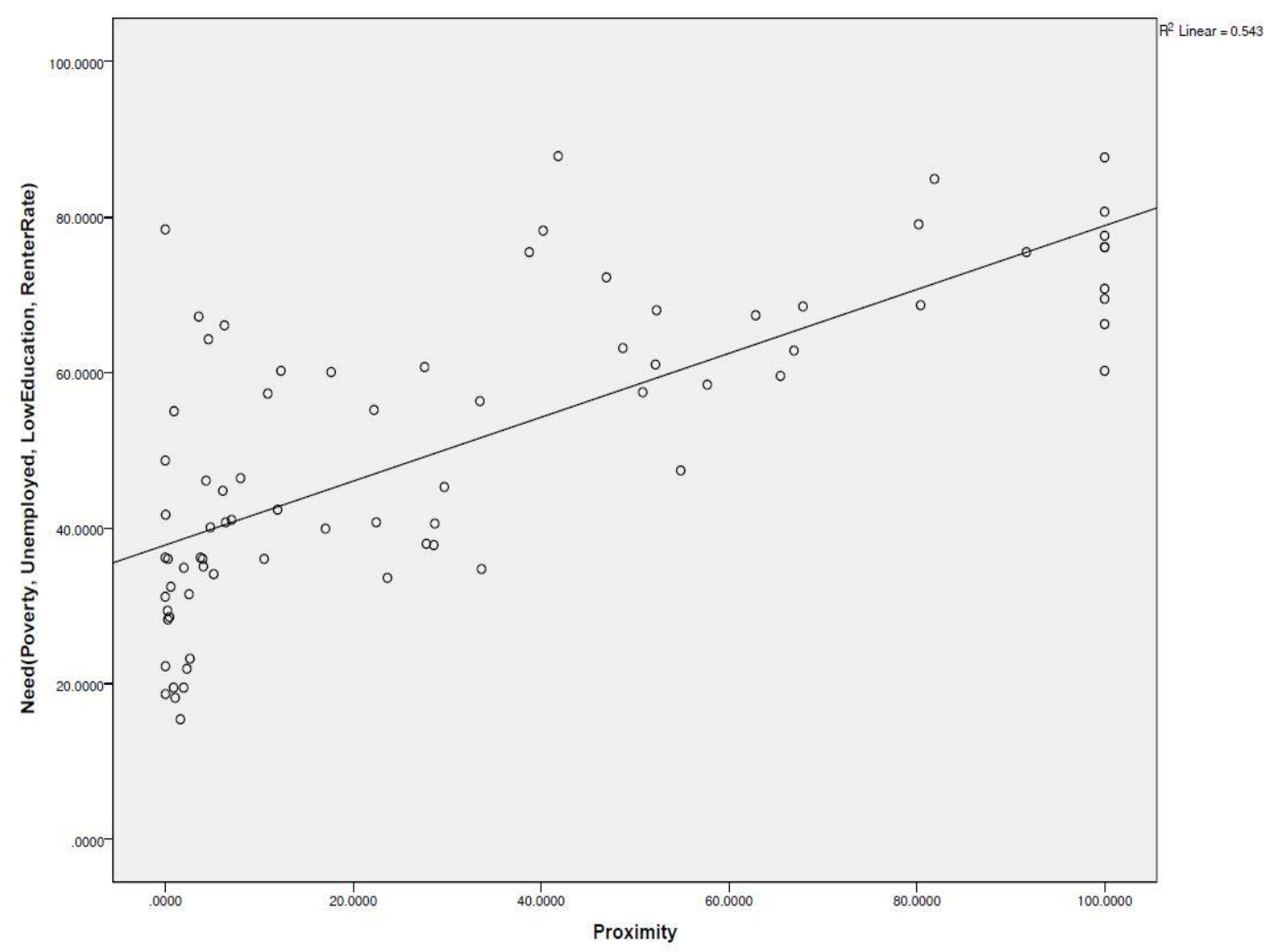

Figure 5. Bivariate scatterplot of Park Need with Park Proximity.

As it shown in Figure 5, children's Potential Park Need was positively related to Park Proximity. The measure of Park Proximity increases as Park Need increases. The results of the correlational analysis conducted using Pearson's R indicates that the correlation is significant, $r(75)=.74, p<.001, \mathrm{R}^{2}=.54$.

As it shown in Figure 6, children's Potential Park Need in Cache County was slightly negatively related to Overall Park Quality. Overall park quality went down with the Park Need went up. The statistics illustrated that approximately $3.6 \%$ of the variance of the Park Need Index in the sample area could be accounted for by its linear 


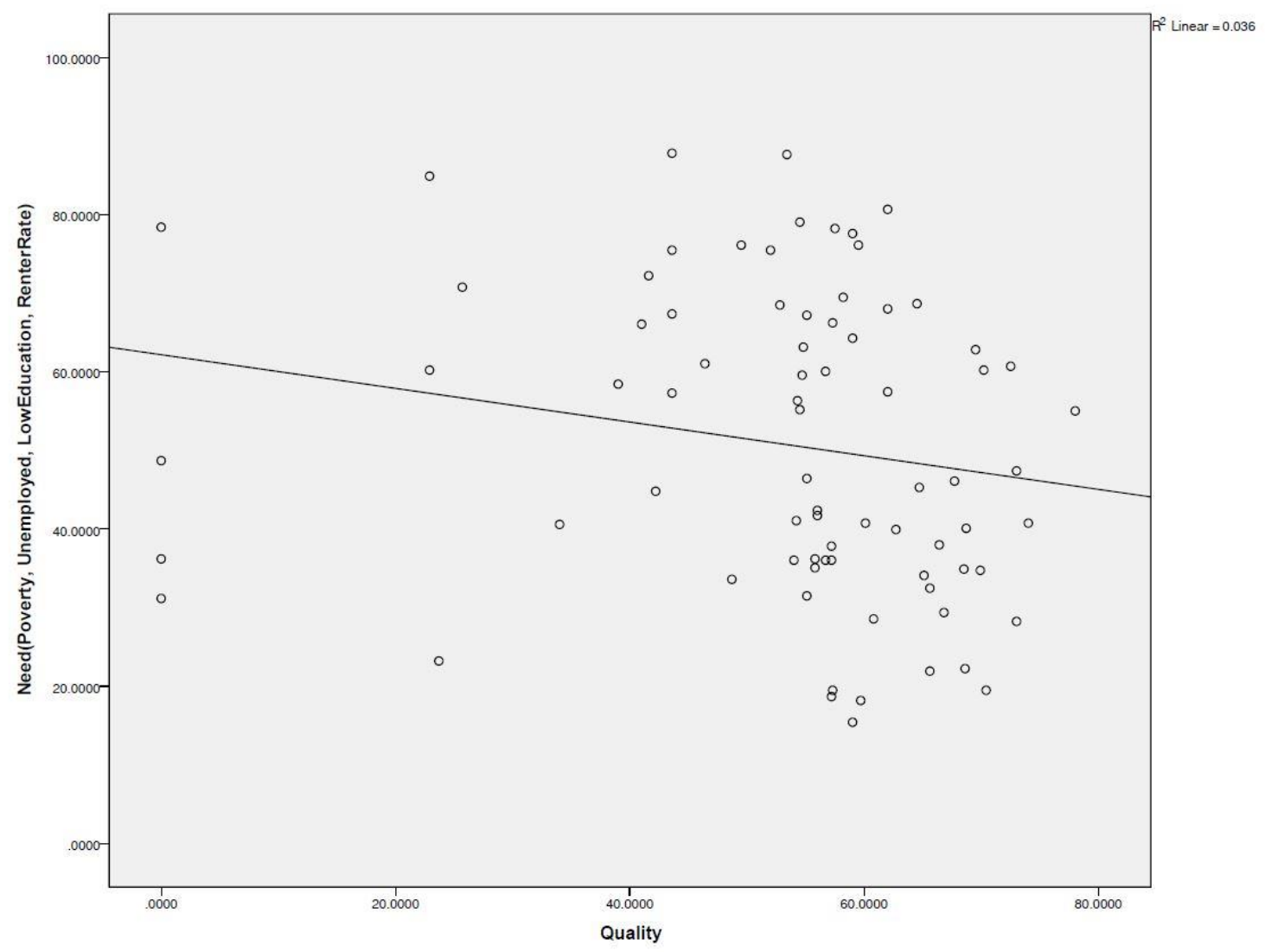

Figure 6. Bivariate scatterplot of Park Need with Park Quality.

relationship with Overall Park Quality.

\section{Correlation between Park Need and Proposed Park Access}

In the second running of multiple linear regression model, with the proposed parks added in, the correlation between Park Need and Park Access has been modified. The predictors were Proposed Park Proximity and Cache County Overall Park Quality, while the criterion variable was still the Potential Park Need for children in Cache County. The linear combination with both predictors was significantly related to the Park 
Need Index, F $(2,74)=95.56, p<.001$. The sample multiple correlation coefficient $\mathrm{R}$ was .85 , indicating that approximately $72 \%$ of the variance of the Park Need Index in the sample can be accounted for by the linear combination of Proposed Park Proximity and Overall Park Quality.

Based on the correlational analysis, we conclude that the only useful predictor is the Park Proximity, shown in Table 3. It alone accounted for $69 \%\left(.83^{2}=.69\right)$ of the variance of Park Need Index, while the Park Quality predictor only accounted for 3\% $(.72-.69=.03)$ although the partial correlation is not significant.

As it shown in Figure 7, children's Potential Park Need was more positively related to Proposed Park Proximity. The measure of Proposed Park Proximity increases as Park Need increases. The results of the correlational analysis conducted using Pearson's $\mathrm{R}$ and indicates that the correlation is significant, $r(75)=.70, p<.001$. The proposed Park Proximity still accounted for most of the relationship between Park Access and Park Need. This result aligned with the existing relationship between Park Proximity and Park Quality in the setting area.

Table 3

The Bivariate and Partial Correlations of the Proposed Predictors with Park Need Predictor Correlation with Park Need Index ${ }^{4}$ Correlation with Park

\begin{tabular}{lcc} 
& Need Index ${ }^{4}$ & $\begin{array}{c}\text { Need Index }{ }^{4} \text { controlling } \\
\text { for all other predictors }\end{array}$ \\
\hline Park Proximity & $.83^{*}$ & $.80^{*}$ \\
Overall Park Quality & -.24 & -.13 \\
\hline
\end{tabular}

$* p<.001$ 


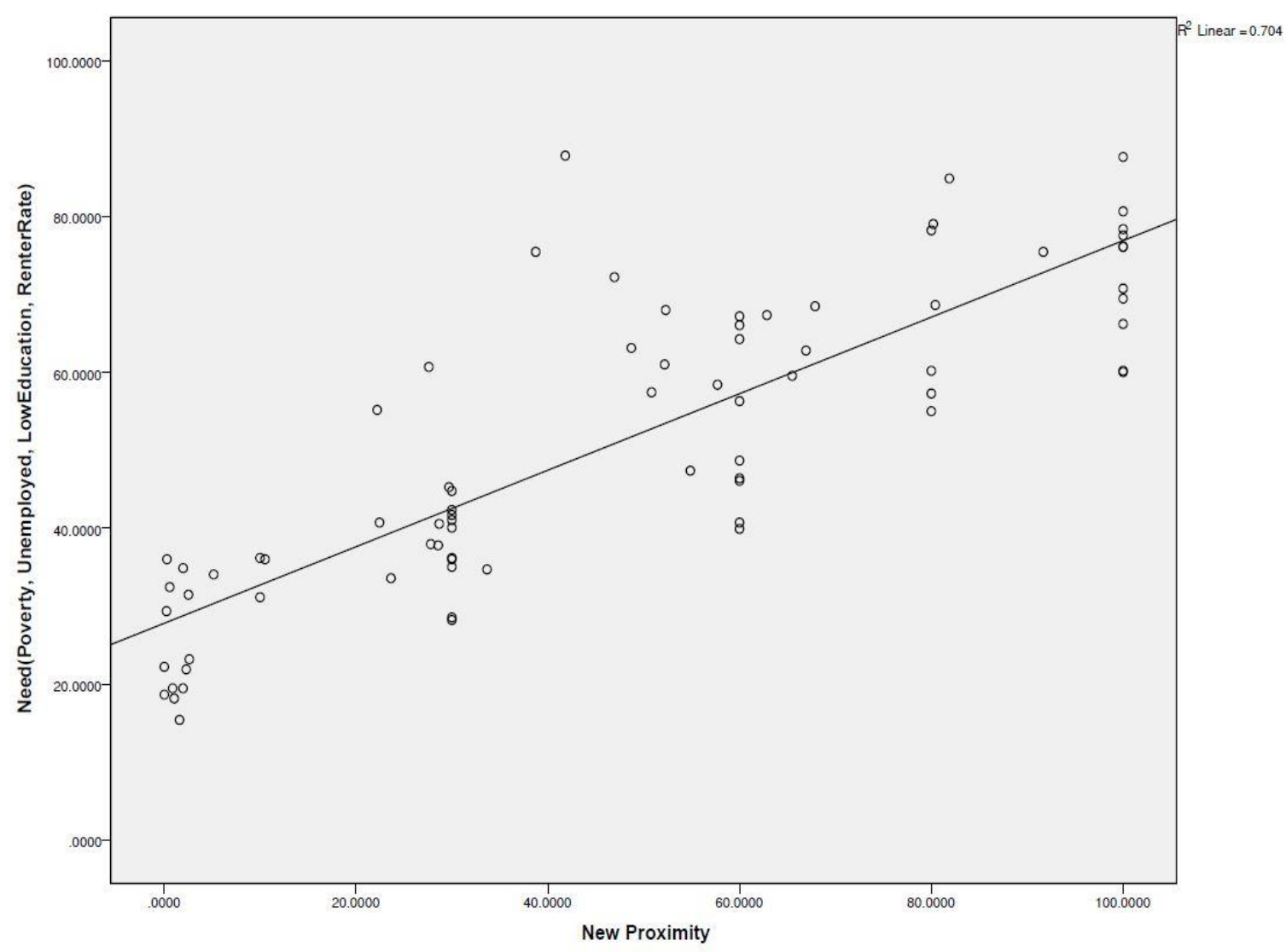

Figure 7. Bivariate scatterplot of Park Need with Proposed Park Proximity.

As it shown in Figure 8, even though with the proposed parks added into the gap areas, the children's Potential Park Need in Cache County was still negatively related to Overall Park Quality. The Proposed Overall Park Quality still went down as the Park Need went up. It illustrated that approximately $8.8 \%$ of the variance of the Park Need Index in the sample could be accounted for by its linear relationship with Proposed Overall Park Quality. This negative correlation increased but still to a not significant extent. 


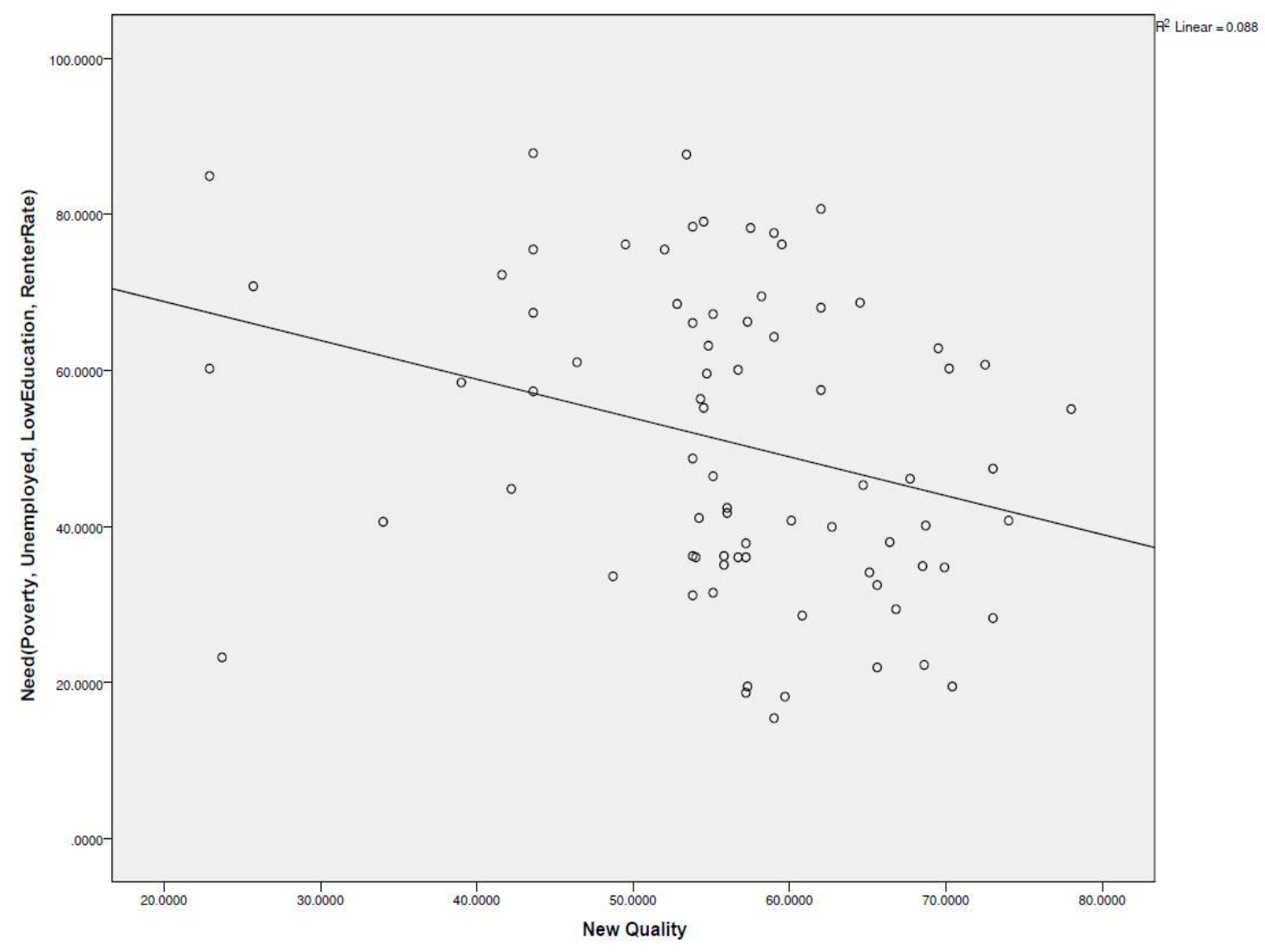

Figure 8. Bivariate scatterplot of Park Need with Proposed Park Overall Quality.

\section{Park Need}

To explore which contributing variables for Park Need were also correlated with Park Proximity and Overall Park Quality, a bivariate analysis was conducted in this study to explore these relationships (Table 4.). From the tabular form, Park Need and Park Proximity were correlated with most contributing variables. At the same time, there were also some other contributing variables which are not significantly related to Park Need or Park Proximity. 
Park Need was significantly related to Children Population Density, $r$ (75) $=.831, p .001$, Total Population Density, $r(75)=.928, p .001$, Racial Minority Density, $r$ $(75)=.952, p .001$, Poverty, $r(75)=.763, p .001$, and Low-Education, $r(75)=.273$, $p .005$, Renter Rate, $r(75)=.84, p .0001$, Building Size, $r(75)=.618, p .001$. Park Need was not significantly related to Unemployment. Park Proximity was significantly related to Children Population Density, $r(75)=.618, p .001$, Total Population Density, $r(75)$ $=.731, p .001$, Racial Minority Density, $r(75)=.726, p .001$, Poverty, $r(75)=.541$, $p .001$, Renter Rate, $r(75)=.545, p .001$, and Building Size, $r(75)=.692, p .001$. Park Proximity was not related to Unemployment and Low-Education. For the correlations between Overall Park Quality and those contributing variables, only Poverty, $r(75)=$ $-.306, p .001$, and Renter Rate $r(75)=-.261, p .005$ were related to Park Quality.

Table 4

The Bivariate Correlations Assessing Different Contributing Variables of Park Need Index ${ }^{4}$ with Park Need, Park Proximity, and Overall Park Quality

\begin{tabular}{|c|c|c|c|c|c|c|c|c|}
\hline & \multicolumn{8}{|c|}{ Park Need Index ${ }^{4}$ contributing variables } \\
\hline & $\begin{array}{l}\text { Children } \\
\text { populatio } \\
\text { n }\end{array}$ & $\begin{array}{l}\text { Total } \\
\text { populatio } \\
\text { n }\end{array}$ & $\begin{array}{l}\text { Minorit } \\
y\end{array}$ & $\begin{array}{l}\text { Povert } \\
\mathrm{y}\end{array}$ & $\begin{array}{l}\text { Unempl } \\
\text { oyment }\end{array}$ & $\begin{array}{l}\text { Low- } \\
\text { Educati } \\
\text { on }\end{array}$ & $\begin{array}{l}\text { Renter } \\
\text { Rate }\end{array}$ & $\begin{array}{l}\text { Build } \\
\text { ing } \\
\text { Size }\end{array}$ \\
\hline $\begin{array}{l}\text { Park } \\
\text { Need }\end{array}$ & $.831 * *$ & $.928 * *$ & $.952 * *$ & $.76^{* *}$ & .15 & $.273^{*}$ & $.84 * *$ & $.618 * *$ \\
\hline $\begin{array}{l}\text { Park } \\
\text { Proximit }\end{array}$ & $.618 * *$ & $.731 * *$ & $.726 * *$ & $.54 * *$ & -.069 & .162 & $.545^{* *}$ & $.692 * *$ \\
\hline $\begin{array}{l}\text { y } \\
\text { Overall } \\
\text { Park } \\
\text { Quality }\end{array}$ & -.044 & -.092 & -.154 & $\begin{array}{c}-.31 * \\
*\end{array}$ & -.171 & -.138 & $-.261 *$ & .151 \\
\hline
\end{tabular}




\section{Socio-economic Variables}

To further explore whether Park Need Index ${ }^{4}$ with all the different socioeconomic variables (Poverty, Unemployment, Low-Education, and Renter Rate) is different from other Park Need Indexes without some other socio-economic variables. This study analyzed the relationships between Park Need Index ${ }^{1}$ (Poverty) Park Need Index ${ }^{2}$ (Poverty and Unemployment), Park Need Index ${ }^{3}$ (Poverty, Unemployment, and Low-Education), and Park Need Index ${ }^{4}$ (Poverty, Unemployment, Low-Education, and Renter Rate) shown in Table 5. The correlations between all the different Park Need Indexes were close to $100 \%$, to a very significant degree. This suggests that LowEducation, Unemployment, Renter Rate variables are highly correlated with Poverty, and the inclusion of Unemployment, Low-Education, and Renter Rate measures do not impact the Park Need Index. The Park Need Index is not necessary to including a series of socio-economic factors.

\section{Park Quality}

To assess the correlations between Overall Park Quality and the five separate park feature qualities which were used to calculate Overall Park Quality, we tested for the partial correlations using Pearson's R Analysis, the results of which are shown in Table 6.

The test indicated that Overall Park Quality score was strongly related to all separate park feature scores, including Facility $(r(75)=.884, p .001)$, Amenity $(r(75)=.862, p .001)$, Aesthetic Feature $(r(75)=.900, p .001)$, Maintenance \& Cleanliness $(r(75)=.889$, $p .001)$, and Incivility $(r(75)=.839, p .001)$. The correlations between Overall Park Quality and the separate feature qualities are almost perfect. 
Table 5

The Bivariate Correlations Assessing Different Park Need Indexes with Different Socio-economic Variables

\begin{tabular}{|c|c|c|c|c|}
\hline & $\begin{array}{c}\text { Park Need } \\
\text { Index }\end{array}$ & $\begin{array}{c}\text { Park Need } \\
\text { Index }^{3}\end{array}$ & $\begin{array}{l}\text { Park Need } \\
\text { Index }^{2}\end{array}$ & $\begin{array}{c}\text { Park Need } \\
\text { Index }^{1}\end{array}$ \\
\hline $\begin{array}{c}\text { Park Need } \\
\text { Index }\end{array}$ & 1 & $.993^{*}$ & $.964 *$ & $.947^{*}$ \\
\hline $\begin{array}{c}\text { Park Need } \\
\text { Index }^{3}\end{array}$ & $.993^{*}$ & 1 & $.976^{*}$ & $.956^{*}$ \\
\hline $\begin{array}{c}\text { Park Need } \\
\text { Index }^{2}\end{array}$ & $.964 *$ & $.976^{*}$ & 1 & $.974 *$ \\
\hline $\begin{array}{c}\text { Park Need } \\
\text { Index }^{1}\end{array}$ & $.947 *$ & $.956^{*}$ & $.974^{*}$ & 1 \\
\hline $\begin{array}{l}{ }^{*} P<0.001 \\
1 \text { Park Need } \\
{ }^{2} \text { Park Need } \\
{ }^{3} \text { Park Need }\end{array}$ & $\begin{array}{l}\text { dex with or } \\
\text { dex with bo } \\
\text { dex with Pc }\end{array}$ & $\begin{array}{l}\text { Poverty } \\
\text { Poverty ar } \\
\text { rty, Unem }\end{array}$ & $\begin{array}{l}\text { Unemploy } \\
\text { yment, an }\end{array}$ & $\begin{array}{l}\text { nt } \\
\text { ow-Educa }\end{array}$ \\
\hline
\end{tabular}

As we found that Overall Park Quality was very positively correlated with individual Park Facility Quality measures, $r(75)=.884, p<.001$, it is possible that one separate feature quality, such as Facility can represent the overall park quality. When auditing park qualities using the PARK tool, the park facility score was the easiest to determine as it is based on the presence of the facility items and their conditions.

To determining whether the single park facility score can represent the Overall Park Quality, a multiple linear regression analysis was conducted to evaluate how well the correlation between Park Proximity and Park Facility with children's Potential Park Need. The predictors were Cache County Park Proximity and Park Facility Quality, 
Table 6

The Bivariate Correlations among Different Park Quality Scores (Separate Park Feature Quality and Overall Quality)

\begin{tabular}{lcccccc}
\hline & \multicolumn{5}{c}{ Park Quality } \\
\cline { 2 - 7 } Park Quality & Overall & Facility & Amenity & Aesthetic & Maintenance & Incivility \\
\hline Overall & 1 & $.884^{*}$ & $.862^{*}$ & $.900^{*}$ & $.889^{*}$ & $.839^{*}$ \\
Facility & $.884^{*}$ & 1 & $.808^{*}$ & $.792^{*}$ & $.709 *$ & $.612^{*}$ \\
Amenity & $.862^{*}$ & $.808^{*}$ & 1 & $.725^{*}$ & $.735^{*} *$ & $.554^{*}$ \\
Aesthetic & $.900^{*}$ & $.792^{*}$ & $.725^{*}$ & 1 & $.690^{*}$ & $.734^{*}$ \\
Maintenance & $.889 *$ & $.709 *$ & $.735^{*}$ & $.690^{*}$ & 1 & $.793^{*}$ \\
Incivility & $.839 *$ & $.612^{*}$ & $.554^{*}$ & $.734^{*}$ & $.793^{*}$ & 1 \\
\hline
\end{tabular}

*. $P<0.001$

while the dependent variable was still the Potential Park Need for children in Cache County.

The linear combination with both predictors was significantly related to the Park Need Index, F $(2,74)=44.23, p<.001$. As shown in Table 7 , the sample multiple correlation coefficient $\mathrm{R}$ was .74, indicating that approximately $54 \%$ of the variance of the Park Need Index ${ }^{4}$ in the sample can be accounted for by the linear combination of Park Proximity and Facility Quality.

Figure 9 shows children's Potential Park Need in Cache County was still slightly negatively related to Park Facility Quality, as the relationship between Park Need and Overall Park Quality. The Park Facility Quality went down with the Park Need went up. It illustrated that approximately $0.17 \%$ of the variance of the Park Need Index ${ }^{4}$ in the sample could be accounted for by its linear relationship with Park Facility. 


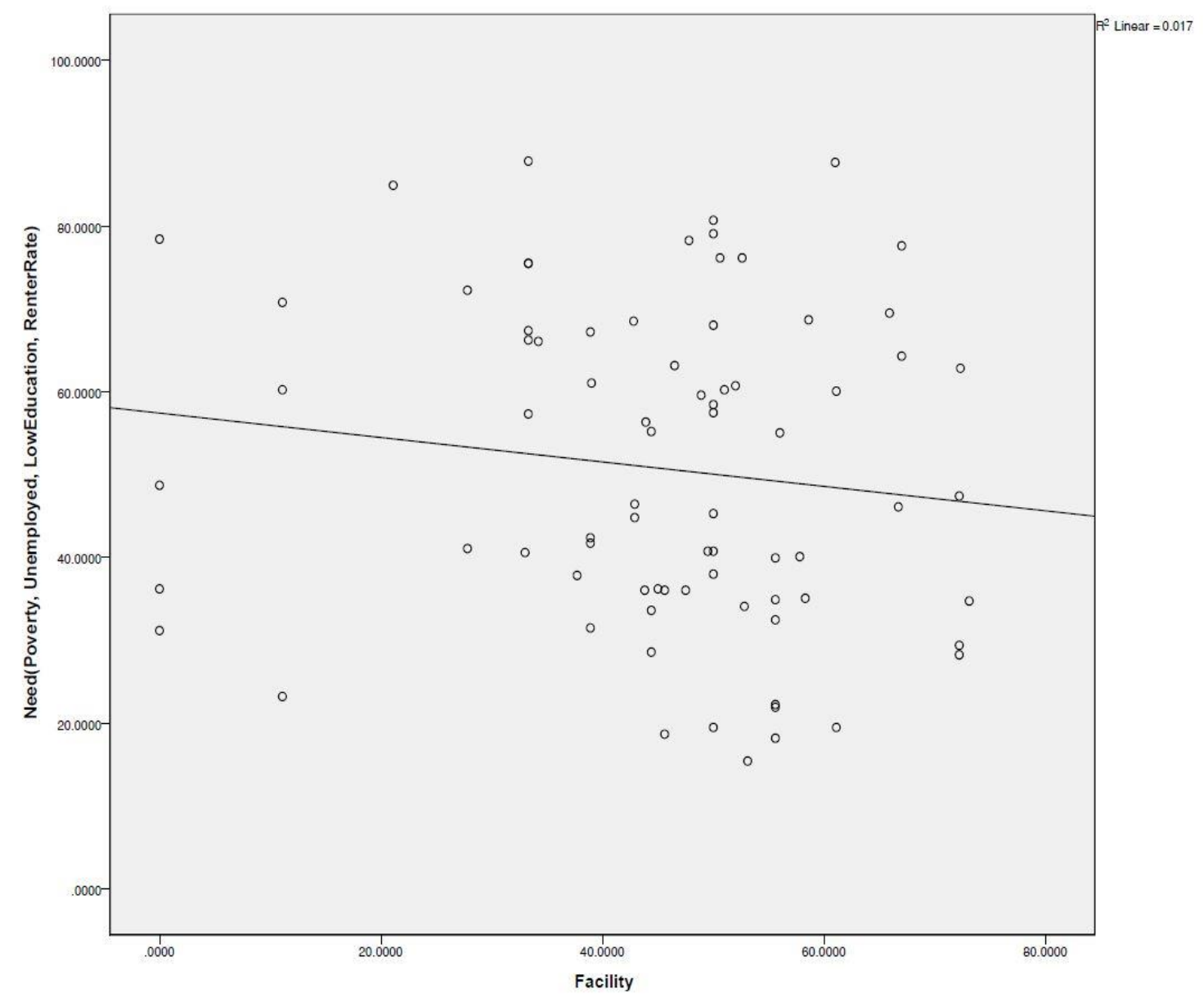

Figure 9. Bivariate scatterplot of Park Need with Park Facility.

The correlational analysis concluded that the only useful predictor is Park Proximity. It alone accounted for $55 \%\left(.74^{2}=.55\right)$ of the variance of Park Need Index with Park Access, while Park Facility contributed only an additional $1 \%\left(-.13^{2}=.01\right)$. All of these results were very similar to the correlations between Park Need, Park Proximity, and Overall Park Quality. This indicated that Park Facility can be a good alternative of Overall Park Quality to do the comparison with Park Proximity and Potential Park Need. 
Table 7

The Bivariate and Partial Correlations of the Predictors with Park Need (Facility)

Predictor Correlation with Park Correlation with Park Need Index ${ }^{4}$ Need Index ${ }^{4}$ controlling for all other predictors

\begin{tabular}{lcc}
\hline Park Proximity & $.74^{*}$ & $.74^{*}$ \\
Overall Park Quality & -.13 & -.09
\end{tabular}

$* p<.001$

Table 8 The Bivariate Correlations between Poverty and Different Park Qualities

\begin{tabular}{lcccccc}
\hline & \multicolumn{5}{c}{ Park Quality } \\
\cline { 2 - 6 } & Facility & Amenity & Aesthetic & Maintenance & Incivility & Overall \\
\hline Poverty & -.189 & $-.299^{*} *$ & $-.275^{*}$ & $-.256^{*}$ & $-.273^{*}$ & $-.306^{* *}$ \\
Renter & -.183 & $-.235^{*}$ & $-.24^{*}$ & -.204 & $-.244^{*}$ & $-.261^{*}$ \\
Rate & & & & & & \\
\hline$* * P<0.001$ & & & & \\
$* . P<0.05$
\end{tabular}

In Table 8, Poverty and Renter Rate were the contributing factors of Park Need that related to Overall Park Quality, $r(75)=-.306, p .001, r(75)=-.261, p .005$. This Pearson analysis (Table 8.) illustrated that the correlation between Poverty and Renter Rate with those different park qualities, especially with the separate park feature qualities. There was a significant correlation between Poverty and Amenity, $r(75)=$ -.299, $p$.001. There were also correlations between Aesthetic Feature with Poverty, $r$ (75) $=-.275, p .005$, Maintenance \& Cleanliness with Poverty, $r(75)=-.290, p .005$, Incivility with Poverty, $r(75)=-.273, p .005$. Renter Rate was also correlated with some of the separate feature qualities: Amenity, $r(75)=-.235, p .005$, Aesthetic Feature, $r$ 
$(75)=-.24, p .005$, and Incivility, $r(75)=-.244, p .005$. However, Park Facility was not correlated with Poverty or Renter Rate. The feature of Maintenance and Cleanliness was not related to Renter Rate but related to Poverty. 


\section{CHAPTER V}

\section{DISCUSSION}

\section{Correlations between Park Access and Park Need}

Recent studies have improved the measure of park proximity by adding a measure of overall park quality. However, these studies often used the number of parks as the park proximity indicator, while this study, based on the GIS network analysis, represented proximity with park service area. Also, while prior studies have compared park proximity and quality with a single socio-economic status (SES) indicator for the population, this study broadened the scope of environmental justice issues by defining disadvantaged groups of people using multiple socio-economic status indicators.

Regarding the research question, to what extent park access (park proximity and park quality) and potential park need for children are correlated in Cache County, Utah, it has been found that potential park need among children in Cache County, Utah was significantly associated with park access measured as the combination of park proximity and overall park quality. Park access increased when children's potential park need increased in most block groups in Cache County, which means that the existing parks in most areas of Cache County do meet children's needs for parks. As shown in Figure. 10, most block groups with higher potential park need among children have already been covered by the existing parks service area. This indicated that most children who desire to go to parks are able to access a park within a walkable distance in Cache County, Utah. At the same time, there were also some gap areas which had a high park need but are outside of the park service areas (Figure. 10). 


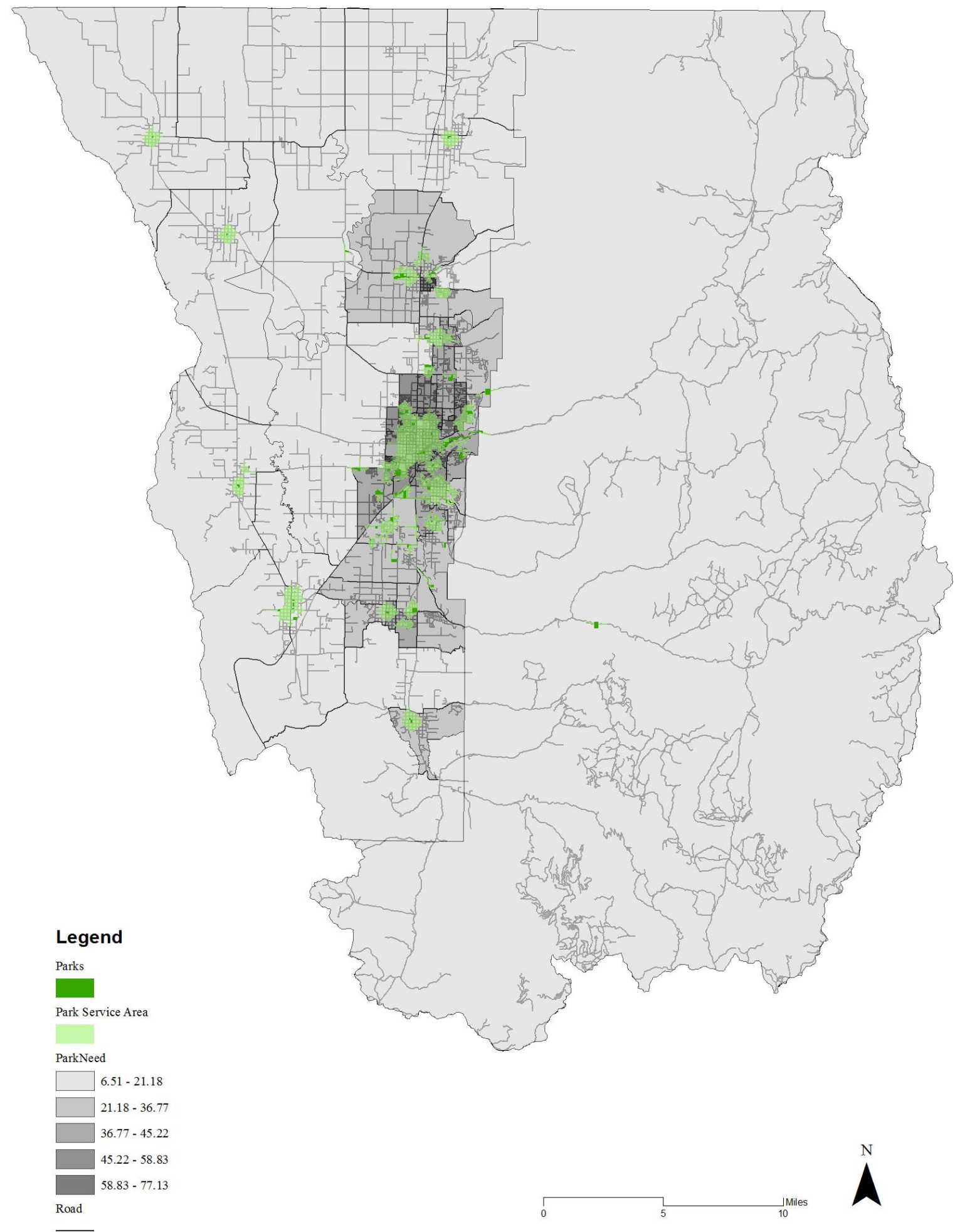

Figure 10. Overlay map: Children's potential park need and park proximity. 


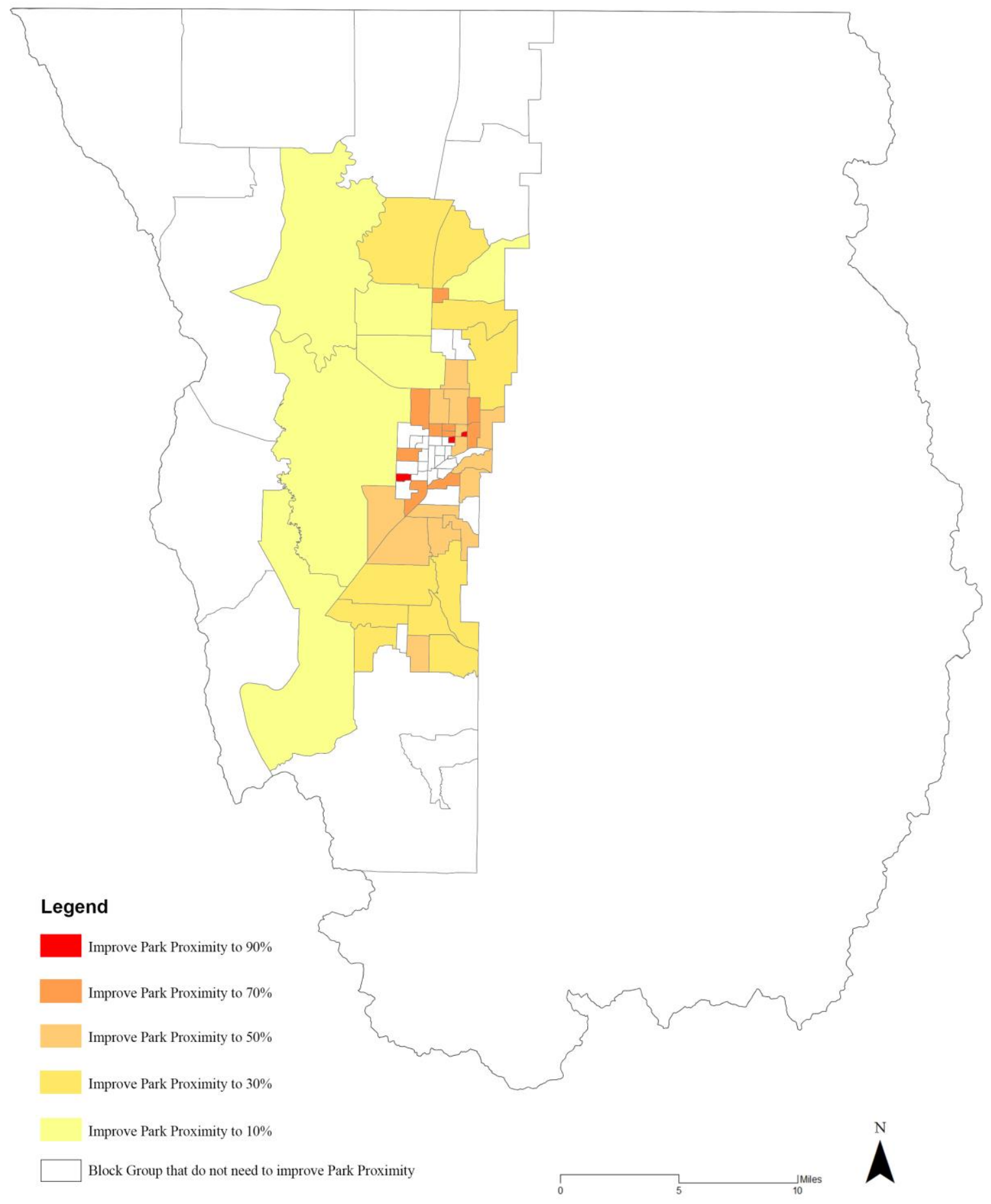

Figure 11. Gap area map: Gap block groups which need to improve park proximity. 
This showed that even though most high-park-need block groups have been served by existing parks, there were still some block groups with a strong park need who do not have adequate access to parks, at least within walking distance. The children living in these gap block groups did not have equal opportunities as those who live in other block groups. For the block groups with gap areas, city planners should seek to develop parks to meet the need for the children who live there.

This research also indicated that some block groups should receive more attention than others. In Figure. 11. the different colors represent the different levels of need for future parks. The red block groups had the highest park need among the other block groups but did not have as much park proximity as others. The findings suggested that the red block groups should increase their park proximity (park service area within the block group) to at least $90 \%$ to better serve the population's potential park need. For the other highlighted block groups, the findings also suggested strengthening their park proximity to the target numbers shown in Figure. 11. This study statistically indicated that if these highlighted block groups improve their park access (both park proximity and park quality) to those targets, the calculated correlation would grow from $55 \%$ to $74 \%$, which is a significant improvement. That is to say, children's park needs can be better met with the addition of parks in these areas, resulting in greater opportunities for physical activity and possibly less childhood obesity as a result.

\section{Park Proximity and Park Quality}

Among the two indicators of Park Access, Park Proximity was most related to children's Potential Park Need, accounting for over half of the relationship with Park 
Access, while Park Quality is only accounting for $2 \%$. The association between park need among children, and park quality was not as meaningful as the association between park proximity and park need. Not only did park quality decline slightly while park need increased, but park quality accounted for little of the relationship. In other words, while the physical locations of parks in Cache County served the local children's need for parks well, the quality of parks does not. Indeed, according to this study, the quality of parks would possibly disappoint the children who have the greatest park need. This might discourage children's visitation and use of parks, which can also influence their physical activity and the issue of childhood obesity.

\section{Park Quality Concerns}

Some previous research demonstrated that low-income areas often suffered from lacking total recreational resources which indicated that public funding often lay behind in these areas of less economic capital (Floyd et al., 2009; Gordon-Larsen et al., 2006; Wolch et al., 2005). Results in this study supported this demonstration. This study explored Park Need Index with seven different variables, children population density, total population density, racial minority density, the percentage of poverty, the percentage of unemployment, the percentage of low education, the percentage of renter rate, and yard size. Among all the contributing variables, the findings suggested that the only two useful predictor of park quality is the percentage of the population who lived under the $125 \%$ federal poverty line, which was the Poverty measure in this study, and the percentage of renter rate. When the percent of poverty or the percentage of renter rate climbed in Cache County, the overall Park Quality measure accordingly declined. This 
aligned with the previous studies that low-income community often received less park quality service (Wolch, Wilson, \& Fehrenbach, 2005).

As for the separate park feature qualities, amenity, aesthetic feature, maintenance, and cleanliness, as well as incivility, there were all significant negative associations existing between these park features with poverty respectively. This research found that as the percent of poverty and renter rate in a block group increased, the above-mentioned park feature scores reduced simultaneously. For those low-income block groups in Cache County, the parks there were often lacking amenity and aesthetic features, having poor maintenance and cleanliness, and more incivility. Such conclusions had been drawn before that low-income neighborhoods often had more issues with park quality concerns, including higher incivility and poor maintenance (Hughey et al., 2016; Vaughan et al., 2013). However, the relationship was correlational and may be the result of less investment and maintenance being put into parks in higher poverty areas, rather than the result of increased incivilities in these area. Some research suggested that it was the former more than the later. These park quality issues were important for the planners to consider, because these park features, including facility, amenity, aesthetic features, maintenance and cleanliness, and incivility, all directly influenced park visitation and use, which ultimately impacts people's health promoting behaviors (Giles-Corti et al., 2005; McCormack et al., 2010).

Some research suggested that park quality may have equal or even more significant importance than park proximity regarding physical activity (Sugiyama et al., 2007). This study indicated that the future environmental justice issue for park planning may lie more with equal park quality distribution, especially for lower socio-economic 
areas with higher potential park need. Doing so may promote the equal allocation of recreational and environmental resources to ensure disadvantaged groups of people have equivalent opportunities for physical activity, thus contributing to equitable healthpromoting environmental planning.

\section{Socio-economic Indicators of Park Need}

Prior study concluded that neighborhood socio-economic status, represented by percent unemployed, the percent of the population under $125 \%$ of the federal poverty threshold, and the percent of the population with less than a high school education, percent of renter-occupied housing were the crucial indicators to assess whether park proximity was equally distributed (Hughey et al., 2016). This study evaluated whether all three socio-economic status indices were associated with park proximity but found only poverty and renter rate were significantly related to park proximity. The relationships between unemployment and/or low-education and park proximity were not significant, or were accounted for by their correlation with poverty. Given that poverty and renter rate were strongly correlated with low-education and unemployment, the inclusion of all three as a measure of socio-economic status is confounded, and the relationship with park proximity may be adequately assessed using a single measure only, such as poverty, or less measurement, like poverty and renter rate, rather than all the four different variables together.

For the socio-economic status indices (Poverty, Unemployment, Low- education, and renter rate) included in the Park Need Index, there was no variance whether we included the single indices, Poverty, or both Poverty and Unemployment, or Poverty, 
Unemployment, and Low-Education, or all four indicts. The four individual Park Need Indexes (Park Need Index with only Poverty, Park Need Index with both Poverty and Unemployment, Park Need Index with Poverty, Unemployment, and Low-Education, and Park Need Index with Poverty, Unemployment, and Low-Education, and Renter Rate) were perfectly correlated, suggesting that the Park Need Index which included only the Poverty indices would show the same results. Future studies may need to only include the Poverty indices or use a fewer number of variables to represent the socio-economic aspect of Park Need.

\section{How to Measure Park Quality}

Whether to include Park Quality as an environmental justice issue has not reached a consistent agreement. Some studies determine Park Quality with a single park feature while others use a measure combining multiple indices. This study used the later method to indicate the Overall Park Quality by averaging the individual park feature qualities (Facility, Amenity, Aesthetic Features, Maintenance and Cleanliness, and Incivilities). However, it was a difficult and time-consuming process to audit the different park feature qualities even with an established auditing tool because some park feature measurements relied mostly on the auditors' perception, which is more subjective than simply detecting the existence of facilities in the park. For example, when we measured park aesthetic feature quality, there was a question requiring the auditor to subjectively decide whether the park was attractive for youth. Such kinds of questions usually took a greater length of time and were more subjective according to the perceptions of the auditor. In this case, measuring only Facility is easier, as it can be determined by just 
counting the presence of specific items.

The further statistical analysis found that the overall Park Quality was positively correlated with all those separate feature qualities, including facility, amenity, aesthetic feature, maintenance and cleanliness, and incivility, very strongly. Additionally, park facility was not only significantly related to overall Park Quality but also related to other feature qualities in a significant degree. The parks with more facilities and amenities often have better maintenance, cleanliness and fewer incivilities so the parks would show more aesthetics, which also meant that more facilities can represent better overall Park Quality. The results show that the correlation between Facility, Park Proximity, and Park Need was almost the same as the correlation between overall Park Quality, Proximity, and Park Need. That is to say, only using the park facility feature can represent the overall park quality. Future researchers can just use the single facility measurement to determine park quality, which would be more efficient and accurate.

\section{Limitations}

There were several limitations existing in this study. Firstly, the setting area of this study was Cache County, Utah, a semi-urban area. Although most block groups we studied were concentrated in Logan metropolitan area, with smaller sizes and more crowded population than the surrounding ones. The vast variation of population and block group sizes are not typical for the most areas in the United States. With the particular demographic and geographical features in Cache County, the community planning proposals this study made to add new parks in the gap areas might not be the same applicable to the other cities of The United States. These characters of the study 
area might bring some difference in the results we obtained above. The future scholars can conduct similar research in some other areas to verify whether the results we gained are reliable.

Secondly, our study was designed to capture park quality for children. Although we used a particular park quality editing tool (PARK tool) that aimed to measure park quality for children, this tool had not been validated particularly for children yet (Bird et al., 2015). The park quality we assessed in this study cannot be verified to appeal to children, so the park quality we detected according to the PARK tool still needs to validate whether it can attract more children to do physical activity and reduce childhood obesity.

Lastly, the contributing variables of Park Need Index still need more exploration. In this study, socio-demographic data (Children Population Density, Total Population Density, and Racial Minority Density), socio-economic data (Poverty, Unemployment, Low-Education, and Renter Rate), and a co-variables factor (Yard Size) were included to determine park need. Some more factors might have an influence on Park Need Index, which needs the future studies to determine. According to our study, different contributing variables to Park Need Index were significantly correlated, such as Poverty, Unemployment, Low-Education, and Renter Rate. The Park Need Index showed the same status no matter what was contained only Poverty, both Poverty and Unemployment, or Poverty, Unemployment, and Low-Education, or all Poverty, Unemployment, and LowEducation, and Renter Rate into the Index. From this, it can be assumed that some other socio-economic information also strongly associated with these variables already 
included in this study. There might be no difference to park need whether the future study includes this information into Park Need Index or not.

\section{Conclusions}

This study broadened the scope of environmental justice issue defining the disadvantaged groups of people who had stronger potential park need, to compare their park need with their actual park access (park proximity and park quality). We found the variance of the potential park need among children in Cache County was positively associated with park access, the combination of park proximity and overall quality, to a significant extent. Among the two indicators of park access, park proximity was strongly related to children's potential park need and contributed to most of the positive correlation between park need and park access, while the relationship between Park Quality and Park Need is not apparent. Park Quality slightly decreased when the Park increased.

We also proposed a new approach to enhance the correlation between park need among children and their park access, with improving the targeted block groups' park proximity and quality. For the future research, we suggest using a single socioeconomic indicator, such as poverty, for Park Need Index, other than the combining indicators, to save some time and energy. Also, the overall park quality can be represented by only one park feature quality, such as park facility. Future scholars can consider only measuring park facility to indicate park quality, not only to save time but to avoid people's perceptional assessment. 


\section{REFERENCES}

Aday, L. A., \& Andersen, R. (1974). A framework for the study of access to medical care. Health Services Research, 9(3), 208-220.

American College of Sports Medicine (2000). ACSM's guidelines for exercise testing and prescription (6th ed). Philadelphia PA: Lippincott.

American Obesity Association. Childhood Overweight Research. (2014). Retrieved from http://www.obesity.org/resources/facts-about-obesity/childhood-overweight

Aytur, S. A., Jones, S. A., Stransky, M., \& Evenson, K. R. (2015). Measuring physical activity in outdoor community recreational environments: Implications for research, policy, and practice. Current Cardiovascular Risk Reports, 9(1), 1-13.

Babey, S. H., Wolstein, J., Krumholz, S., Robertson, B., \& Diamant, A. L. (2013). Physical activity, park access and park use among California adolescents. UCLA Center for Health Policy Research.

Bai, H., Stanis, S. A. W., Kaczynski, A. T., \& Besenyi, G. M. (2013). Perceptions of neighborhood park quality: associations with physical activity and body mass index. Annals of Behavioral Medicine, 45(1), 39-48.

Barton, H., \& Grant, M. (2006). A health map for the local human habitat. The Journal for the Royal Society for the Promotion of Health, 126(6), 252-253.

Basch, C. E. (2011). Healthier students are better learners: A missing link in school reforms to close the achievement gap. Journal of School Health, 81(10), 593-598.

Bedimo-Rung, A. L., Mowen, A. J., \& Cohen, D. A. (2005). The significance of parks to physical activity and public health: a conceptual model. American Journal of Preventive Medicine, 28(2), 159-168.

Bird, M. E., Datta, G. D., Van Hulst, A., Kestens, Y., \& Barnett, T. A. (2015). A reliability assessment of a direct-observation park evaluation tool: The Parks, activity and recreation among kids (PARK) tool. BMC Public Health, 15(1), 906.

Budd, G. M., \& Hayman, L. L. (2008). Addressing the childhood obesity crisis: A call to action. MCN: The American Journal of Maternal/Child Nursing, 33(2), 111-118.

Burgess, J., Harrison, C. M., \& Limb, M. (1988). People, parks and the urban green: a study of popular meanings and values for open spaces in the city. Urban Studies, 25(6), 455-473. 
Canadian Paediatric Society (CPS) (2002). Healthy active living for children and youth. Pediatrics and Child Health, 7, 339-345.

Center for Disease Control and Prevention. Childhood Obesity Fact. (2015). Retrieved from http://www.cdc.gov/healthyschools/obesity/facts.htm

Chillón, P., Panter, J., Corder, K., Jones, A. P., \& Van Sluijs, E. M. (2015). A longitudinal study of the distance that young people walk to school. Health \& Place, 31, 133-137.

Coen, S. E., \& Ross, N. A. (2006). Exploring the material basis for health: characteristics of parks in Montreal neighborhoods with contrasting health outcomes. Health \& Place, 12(4), 361-371.

Cohen, D. A., Ashwood, J. S., Scott, M. M., Overton, A., Evenson, K. R., Staten, L. K., Porter, D., McKenzie, T.L., \& Catellier, D. (2006). Public parks and physical activity among adolescent girls. Pediatrics, 118(5), e138-1e1389.

Comber, A., Brunsdon, C., \& Green, E. (2008). Using a GIS-based network analysis to determine urban greenspace accessibility for different ethnic and religious groups. Landscape and Urban Planning, 86(1), 103-114.

Cutts, B. B., Darby, K. J., Boone, C. G., \& Brewis, A. (2009). City structure, obesity, and environmental justice: an integrated analysis of physical and social barriers to walkable streets and park access. Social Science \& Medicine, 69(9), 13141-322.

Daves, M. M. (1989). Profile of park issues in Santa Monica, California (Doctoral dissertation, University of California, Los Angeles--Urban planning.).

Dowda, M., McKenzie, T. L., Cohen, D. A., Scott, M. M., Evenson, K. R., BedimoRung, A. L., Voorhees, C.C., \& Almeida, M. J. (2007). Commercial venues as supports for physical activity in adolescent girls. Preventive Medicine, 45(2), 163-168.

Edwards, N., Hooper, P., Knuiman, M., Foster, S., \& Giles-Corti, B. (2015). Associations between park features and adolescent park use for physical activity. International Journal of Behavioral Nutrition and Physical Activity, 12(1), 21.

Estabrooks, P. A., Lee, R. E., \& Gyurcsik, N. C. (2003). Resources for physical activity participation: does availability and accessibility differ by neighborhood socioeconomic status? Annals of Behavioral Medicine, 25(2), 100-104.

Evenson, K. R., Wen, F., Hillier, A., \& Cohen, D. A. (2013). Assessing the contribution of parks to physical activity using GPS and accelerometry. Medicine and Science in Sports and Exercise, 45(10), 1981. 
Ferreira, A., \& Batey, P. (2007). Re-thinking accessibility planning: A multi-layer conceptual framework and its policy implications. Town Planning Review, $78(4), 429-458$.

Flint, C., Gregory, D., Johnston, R., Pratt, G., Watts, M., \& Whatmore, S. (2009). Hegemony. The Dictionary of Human Geography, 327.

Floyd, M. F., \& Johnson, C. Y. (2002). Coming to terms with environmental justice in outdoor recreation: A conceptual discussion with research implications. Leisure Sciences, 24(1), 59-77.

Floyd, M. F., Taylor, W. C., \& Whitt-Glover, M. (2009). Measurement of park and recreation environments that support physical activity in low-income communities of color: Highlights of challenges and recommendations. American Journal of Preventive Medicine, 36(4), S156-S160.

Frank, L.D., Schmid, T.L., Sallis, J.F., Chapman, J., \& Saelens, B.E. (2005). Linking objectively measured physical activity with the objectively measured urban form: findings from SMARTRAQ. American Journal of Preventive Medicine, 28, 117125.

Gibson, C. A., Smith, B. K., DuBose, K. D., Greene, J. L., Bailey, B. W., Williams, S. L., Ryan, J.J., Schmelzle, K.H., Washburn, R.A., Sullivan, D.K., \& Mayo, M. S. (2008). Physical activity across the curriculum: year one process evaluation results. International Journal of Behavioral Nutrition and Physical Activity, 5(1), 36.

Giles-Corti, B., Broomhall, M. H., Knuiman, M., Collins, C., Douglas, K., Ng, K., et al. (2005). Increasing walking: How important is the distance to, attractiveness, and size of public open space? American Journal of Preventive Medicine, 28(2), 169176.

Gilliland, J., Holmes, M., Irwin, J. D., \& Tucker, P. (2006). Environmental equity is child's play: Mapping public provision of recreation opportunities in urban neighbourhoods. Vulnerable Children and Youth Studies, 1(3), 256-268.

Godbey, G. C., Caldwell, L. L., Floyd, M., \& Payne, L. L. (2005). Contributions of leisure studies and recreation and park management research to the active living agenda. American journal of preventive medicine, 28(2), 150-158.

Gordon-Larsen, P., Nelson, M. C., Page, P., \& Popkin, B. M. (2006). Inequality in the built environment underlies key health disparities in physical activity and obesity. Pediatrics, 117(2), 417-424. 
Hart, R. (1978), Children's Experience of Place, New York, Irvington Press.

Hillsdon, M., Panter, J., Foster, C., \& Jones, A. (2006). The relationship between access and quality of urban green space with population physical activity. Public Health, 120(12), 1127-1132.

Hughey, S. M., Walsemann, K. M., Child, S., Powers, A., Reed, J. A., \& Kaczynski, A. T. (2016). Using an environmental justice approach to examine the relationships between park availability and quality indicators, neighborhood disadvantage, and racial/ethnic composition. Landscape and Urban Planning, 148, 159-169.

Jago, R., Baranowski, T., \& Harris, M. (2006). Relationships between GIS environmental features and adolescent male physical activity: GIS coding differences. Journal of Physical Activity and Health, 3(2), 230-242.

Jenkins, G.R., Yuen, H.K., Rose, E.J., Gregory, K.C., Cotton, M.E. (2015). Disparities in quality of park play spaces between two cities with diverse income and race composition: A pilot study. International Journal of Environmental Research and Public Health. 12(2015), 8009-8022.

Jones, A. P., Brainard, J., Bateman, I. J., \& Lovett, A. A. (2009). Equity of access to public parks in Birmingham, England. Environmental Research Journal, 3(2), 237-256.

Kaczynski, A. T., Potwarka, L. R., Smale, B. J., \& Havitz, M. E. (2009). Association of parkland proximity with neighborhood and park-based physical activity: variations by gender and age. Leisure Sciences, 31(2), 174-191.

Kaczynski, A. T., Stanis, S. A. W., \& Besenyi, G. M. (2012). Development and testing of a community stakeholder park audit tool. American Journal of Preventive Medicine, 42(3), 242-249.

Lindsey, G., Maraj, M., \& Kuan, S. (2001). Access, equity, and urban greenways: An exploratory investigation. The Professional Geographer, 53(3), 332-346.

Loukaitou-Sideris, A., \& Sideris, A. (2010). What brings children to the park? Analysis and measurement of the variables affecting children's use of parks. Journal of the American Planning Association, 76(1), 89-107.

Loukaitou-Sideris, A., \& Stieglitz, O. (2002). Children in Los Angeles parks: A study of equity, quality, and children's satisfaction with neighborhood parks. Town Planning Review, 73 (4), 467-488. 
Macintyre, S., Ellaway, A., \& Cummins, S. (2002). Place effects on health: how can we conceptualize, operationalise, and measure them? Social Science and Medicine, 55, 125-139.

Mahar, M. T., Murphy, S. K., Rowe, D. A., Golden, J., Shields, A. T., \& Raedeke, T. D. (2006). Effects of a classroom-based program on physical activity and on-task behavior. Medicine and Science in Sports and Exercise, 38(12), 2086.

McCormack, G. R., Rock, M., Toohey, A. M., \& Hignell, D. (2010). Characteristics of urban parks associated with park use and physical activity: a review of qualitative research. Health \& Place, 16(4), 712-726.

Moore, L. V., Roux, A. V. D., Evenson, K. R., McGinn, A. P., \& Brines, S. J. (2008). Availability of recreational resources in minority and low socioeconomic status areas. American Journal of Preventive Medicine, 34(1), 16-22.

Mowen, A. J. (2010). Parks, playgrounds and active living. San Diego, CA: Robert Wood Johnson Foundation.

National Recreation and Park Association. Parks and recreation in underserved areas: $a$ public health perspective. (2013). Retrieved from http://www.nrpa.org/uploadedFiles/nrpa.org/Publications_and_Research/Research /Papers/Parks-Rec-Underserved-Areas.pdf.

Ogden, C. L., Carroll, M. D., Curtin, L. R., Lamb, M. M., \& Flegal, K. M. (2010). Prevalence of high body mass index in US children and adolescents, 20072008. Jama, 303(3), 242-249.

Ogden, C. L., Carroll, M. D., Kit, B. K., \& Flegal, K. M. (2014). Prevalence of childhood and adult obesity in the United States, 2011-2012. Jama, 311(8), 806-814.

Oh, K., \& Jeong, S. (2007). Assessing the spatial distribution of urban parks using GIS. Landscape and Urban Planning, 82(1), 25-32.

Oliver, L. N., Schuurman, N., \& Hall, A. W. (2007). Comparing circular and network buffers to examine the influence of land use on walking for leisure and errands. International Journal of Health Geographics 6(1), 41.

Penchansky, R., \& Thomas, J. W. (1981). The concept of access: definition and relationship to consumer satisfaction. Medical Care, 19(2), 127-140.

Potwarka, L. R., Kaczynski, A. T., \& Flack, A. L. (2008). Places to play: association of park space and facilities with healthy weight status among children. Journal of Community Health, 33(5), 344-350. 
Powell, L. M., Slater, S., Chaloupka, F. J., \& Harper, D. (2006). Availability of physical activity-related facilities and neighborhood demographic and socioeconomic characteristics: a national study. American Journal of Public Health, 96(9), 16761680 .

Proshansky, H. M., \& Fabian, A. K. (1987). The development of place identity in the child. Springer US: In Spaces for children.

Rigolon, A., \& Flohr, T. L. (2014). Access to parks for youth as an environmental justice issue: access inequalities and possible solutions. Buildings, 4(2), 69-94.

Ritchie, L., Ivey, S., Masch, M., Woodward-Lopez, G., Ikeda, J., \& Crawford, P. (2001). Pediatric overweight: A review of the literature. University of California. Berkley, CA: The Centre for Weight and Health.

Roemmich, J. N., Epstein, L. H., Raja, S., Yin, L., Robinson, J., \& Winiewicz, D. (2006). Association of access to parks and recreational facilities with the physical activity of young children. Preventive Medicine, 43(6), 437-441.

Roof, K. (2008). Public health: Seattle and King County's push for the built environment. Journal of Environmental Health, 71(1), 24.

Rundle, A., Quinn, J., Lovasi, G., Bader, M. D., Yousefzadeh, P., Weiss, C., \& Neckerman, K. (2013). Associations between body mass index and park proximity, size, cleanliness, and recreational facilities. American Journal of Health Promotion, 27(4), 262-269.

Saegert, S, and Hart, R. (1978), The development of sex differences in the environmental competence of girls and boys' in P. Stevens, Jr. (ed.), Studies in the Anthropology of Play. Cornwall, NY: Leisure Press.

Saelens, B., Sallis, J.F., Black, J.B., \& Chen, D. (2003). Neighbourhood-based differences in physical activity: An environment scale evaluation. American Journal of Public Health, 93, 1552-1563.

Sibley, B. A., Ward, R. M., Yazvac, T. S., Zullig, K., \& Potteiger, J. A. (2008). Making the Grade with Diet and Exercise. AASA Journal of Scholarship \& Practice, 5(2), $38-45$.

Smith, D.M. (1986). The Dictionary of Human Geography. In R.J. Johnston, D. Gregory, and D.R. Stoddart (Eds.), Equity, (pp. 139). Oxford, England: Blackwell.

Sugiyama, T., Francis, J., Middleton, N. J., Owen, N., \& Giles-Corti, B. (2010). Associations between recreational walking and attractiveness, size, and proximity 
of neighborhood open spaces. American Journal of Public Health, 100(9), $1752-1757$.

Stanis, S. A. W., Schneider, I. E., Shinew, K. J., Chavez, D. J., \& Vogel, M. C. (2009). Physical activity and the recreation opportunity spectrum: Differences in important site attributes and perceived constraints. Journal of Park and Recreation Administration, 27(4), 73-91.

Talen, E. (1997). The social equity of urban service distribution: An exploration of park access in Pueblo, Colorado, and Macon, Georgia. Urban Geography, 18(6), 521541.

Talen, E. (2003). Neighborhoods as service providers: a methodology for evaluating pedestrian access. Environment and Planning B: Planning and Design, 30(2), $181-200$.

Taras, H. (2005). Physical activity and student performance at school. Journal of School Health, 75(6), 214-218.

Taylor, W. C., Poston, W. S. C., Jones, L., \& Kraft, M. K. (2006). Environmental justice: obesity, physical activity, and healthy eating. Journal of Physical Activity and Health, 3(s1), S30-S54.

The Salt Lake Tribune. (2012). Census: Utah is growing, and fast. [Press release]. Retrieved from http://archive.sltrib.com/story.php?ref=/sltrib/politics/5550499690/birth-census-grew-growing.html.csp

Tucker, P., Irwin, J. D., Gilliland, J., He, M., Larsen, K., \& Hess, P. (2009). Environmental influences on physical activity levels in youth. Health \& Place, 15(1), 357-363.

Vaughan, K. B., Kaczynski, A. T., Stanis, S. A. W., Besenyi, G. M., Bergstrom, R., \& Heinrich, K. M. (2013). Exploring the distribution of park availability, features, and quality across Kansas City, Missouri by income and race/ethnicity: an environmental justice investigation. Annals of behavioral medicine, 45(1), 28-38.

Veitch, J., Bagley, S., Ball, K., \& Salmon, J. (2006). Where do children usually play? A qualitative study of parents' perceptions of influences on children's active freeplay. Health \& Place, 12(4), 383-393.

WalletHub. (2016). 2016 safest Sates in America [Press release]. Retrieved from https://wallethub.com/edu/safest-states-to-live-in/4566/ 
Wang, D. Brown, G. Liu, Y. (2015). The physical and non-physical factors that influence perceived access to urban parks. Landscape and Urban Planning, 133(2015)5366.

Wicks, B.E., and Crompton, J.L. (1986) Citizen and administrator perspectives of equity in the delivery of park services. Leisure Sciences, 8, 341-365.

Wolch, J., Wilson, J. P., \& Fehrenbach, J. (2005). Parks and park funding in Los Angeles: An equity-mapping analysis. Urban Geography, 26(1), 4-35.

Wolch, J., Jerrett, M., Reynolds, K., McConnell, R., Chang, R., Dahmann, N., Brady, K., Gilliland, F., Su, J.G., \& Berhane, K. (2011). Childhood obesity and proximity to urban parks and recreational resources: a longitudinal cohort study. Health \& Place, 17(1), 207-214. 
APPENDICES 
Appendix A. Population Density Data of Cache County, Utah (Variables of Park Need) 


\begin{tabular}{|c|c|c|c|c|c|c|}
\hline GEOdisplaylabel & ChildrenD & Children & TotalD & Total & MinorityD & Minority \\
\hline $\begin{array}{l}\text { Census Tract } \\
11.02 \\
\text { Block Group 2, } \\
\text { Census Tract }\end{array}$ & 892.04 & 77.92 & 2816.00 & 64.94 & 165.74 & 51.95 \\
\hline $\begin{array}{l}12.01 \\
\text { Block Group 3, } \\
\text { Census Tract }\end{array}$ & 557.15 & 58.44 & 1427.00 & 45.45 & 42.05 & 28.57 \\
\hline $\begin{array}{l}5.01 \\
\text { Block Group 2, } \\
\text { Census Tract }\end{array}$ & 665.94 & 61.04 & 3272.00 & 71.43 & 840.41 & 79.22 \\
\hline 5.01 & 2141.18 & 96.10 & 7966.00 & 93.51 & 2056.38 & 96.10 \\
\hline $\begin{array}{l}\text { Block Group 3, } \\
\text { Census Tract } 6\end{array}$ & 124.58 & 28.57 & 2118.00 & 58.44 & 338.87 & 62.34 \\
\hline $\begin{array}{l}\text { Block Group 2, } \\
\text { Census Tract } 6\end{array}$ & 1592.40 & 88.31 & 5592.00 & 85.71 & 1077.65 & 85.71 \\
\hline $\begin{array}{l}\text { Block Group 1, } \\
\text { Census Tract } 6\end{array}$ & 845.09 & 75.32 & 2991.00 & 67.53 & 640.42 & 71.43 \\
\hline $\begin{array}{l}\text { Block Group 4, } \\
\text { Census Tract } 8 \\
\text { Block Group 3, } \\
\text { Census Tract } \\
7.01\end{array}$ & 985.98 & 81.82 & 6966.00 & 92.21 & 1707.61 & 93.51 \\
\hline $\begin{array}{l}\text { Block Group 3, } \\
\text { Census Tract } 8\end{array}$ & 541.14 & 57.14 & 3654.00 & 74.03 & 656.27 & 72.73 \\
\hline $\begin{array}{l}\text { Block Group 2, } \\
\text { Census Tract } 8\end{array}$ & 1855.55 & 92.21 & 6675.00 & 90.91 & 1019.60 & 83.12 \\
\hline $\begin{array}{l}\text { Block Group 1, } \\
\text { Census Tract } 8\end{array}$ & 468.97 & 48.05 & 16260.00 & 97.40 & 1503.94 & 90.91 \\
\hline $\begin{array}{l}\text { Block Group } 3 \text {, } \\
\text { Census Tract } 9\end{array}$ & 1587.79 & 87.01 & 4744.00 & 81.82 & 612.16 & 70.13 \\
\hline $\begin{array}{l}\text { Block Group } 1 \text {, } \\
\text { Census Tract } 9\end{array}$ & 1103.95 & 83.12 & 5430.00 & 84.42 & 1070.27 & 84.42 \\
\hline $\begin{array}{l}\text { Block Group 2, } \\
\text { Census Tract } 9 \\
\text { Block Group 2, } \\
\text { Census Tract }\end{array}$ & 799.73 & 72.73 & 4185.00 & 76.62 & 765.94 & 77.92 \\
\hline $\begin{array}{l}10.02 \\
\text { Block Group 1, } \\
\text { Census Tract }\end{array}$ & 1426.71 & 85.71 & 3729.00 & 75.32 & 1271.73 & 88.31 \\
\hline $\begin{array}{l}10.02 \\
\text { Block Group 1, } \\
\text { Census Tract }\end{array}$ & 760.07 & 68.83 & 4271.00 & 77.92 & 689.22 & 74.03 \\
\hline 2.02 & 2165.36 & 97.40 & 4837.00 & 83.12 & 383.63 & 63.64 \\
\hline $\begin{array}{l}\text { Block Group 1, } \\
\text { Census Tract } 3\end{array}$ & 15.66 & 9.09 & 41.00 & 7.79 & 5.18 & 11.69 \\
\hline $\begin{array}{l}\text { Block Group 2, } \\
\text { Census Tract } 3\end{array}$ & 11.13 & 7.79 & 31.00 & 6.49 & 2.08 & 5.19 \\
\hline
\end{tabular}




\begin{tabular}{|c|c|c|c|c|c|c|}
\hline $\begin{array}{l}\text { Block Group 1, } \\
\text { Census Tract } 13\end{array}$ & 28.42 & 12.99 & 71.00 & 11.69 & 3.76 & 7.79 \\
\hline $\begin{array}{l}\text { Block Group 2, } \\
\text { Census Tract } 13 \\
\text { Block Group 2, } \\
\text { Census Tract }\end{array}$ & 26.82 & 11.69 & 82.00 & 12.99 & 4.28 & 10.39 \\
\hline $\begin{array}{l}1.01 \\
\text { Block Group 1, } \\
\text { Census Tract }\end{array}$ & 17.30 & 10.39 & 53.00 & 10.39 & 6.64 & 14.29 \\
\hline $\begin{array}{l}4.01 \\
\text { Block Group 2, } \\
\text { Census Tract }\end{array}$ & 485.36 & 50.65 & 2183.00 & 61.04 & 397.65 & 64.94 \\
\hline $\begin{array}{l}4.01 \\
\text { Block Group 1, } \\
\text { Census Tract }\end{array}$ & 424.06 & 45.45 & 1224.00 & 41.56 & 91.92 & 38.96 \\
\hline $\begin{array}{l}4.03 \\
\text { Block Group 2, } \\
\text { Census Tract }\end{array}$ & 860.65 & 76.62 & 1851.00 & 54.55 & 146.25 & 48.05 \\
\hline $\begin{array}{l}7.02 \\
\text { Block Group 1, } \\
\text { Census Tract }\end{array}$ & 36.19 & 16.88 & 4681.00 & 80.52 & 744.42 & 75.32 \\
\hline $\begin{array}{l}1.01 \\
\text { Block Group 1, } \\
\text { Census Tract }\end{array}$ & 44.05 & 18.18 & 126.00 & 16.88 & 5.66 & 12.99 \\
\hline $\begin{array}{l}9801 \\
\text { Block Group 3, } \\
\text { Census Tract }\end{array}$ & 0.01 & 1.30 & 0.00 & 1.30 & 0.00 & 1.30 \\
\hline $\begin{array}{l}1.01 \\
\text { Block Group 4, } \\
\text { Census Tract }\end{array}$ & 30.60 & 14.29 & 89.00 & 14.29 & 6.87 & 15.58 \\
\hline $\begin{array}{l}2.02 \\
\text { Block Group 2, } \\
\text { Census Tract }\end{array}$ & 108.67 & 25.97 & 346.00 & 24.68 & 18.89 & 22.08 \\
\hline $\begin{array}{l}2.02 \\
\text { Block Group 2, } \\
\text { Census Tract }\end{array}$ & 265.85 & 37.66 & 634.00 & 33.77 & 47.06 & 32.47 \\
\hline 4.03 & 91.08 & 24.68 & 242.00 & 22.08 & 43.10 & 29.87 \\
\hline $\begin{array}{l}\text { Block Group 3, } \\
\text { Census Tract } 3 \\
\text { Block Group 2, } \\
\text { Census Tract }\end{array}$ & 6.91 & 3.90 & 42.00 & 9.09 & 9.67 & 16.88 \\
\hline $\begin{array}{l}5.02 \\
\text { Block Group 3, } \\
\text { Census Tract }\end{array}$ & 771.13 & 70.13 & 2752.00 & 63.64 & 753.68 & 76.62 \\
\hline $\begin{array}{l}4.03 \\
\text { Block Group 1, } \\
\text { Census Tract }\end{array}$ & 404.00 & 42.86 & 1307.00 & 44.16 & 80.80 & 36.36 \\
\hline $\begin{array}{l}4.02 \\
\text { Block Group 4, } \\
\text { Census Tract }\end{array}$ & 113.55 & 27.27 & 325.00 & 23.38 & 14.84 & 19.48 \\
\hline 4.03 & 694.14 & 64.94 & 1847.00 & 53.25 & 81.58 & 37.66 \\
\hline
\end{tabular}


Block Group 4,

Census Tract

5.01

Block Group 1,

Census Tract

5.01

Block Group 1,

Census Tract

7.02

$\begin{array}{llllll}2048.79 & 94.81 & 5918.00 & 87.01 & 1537.83 & 92.21\end{array}$

Block Group 4,

Census Tract 6

Block Group 6,

Census Tract 6

Block Group 1,

Census Tract

14.02

Block Group 2,

Census Tract

14.02

Block Group 4,

Census Tract

10.02

Block Group 1,

Census Tract

10.01

Block Group 5,

Census Tract 6

Block Group 1,

Census Tract

11.02

2048.79

$\begin{array}{llllll}1822.10 & 90.91 & 6135.00 & 88.31 & 1732.57 & 94.81\end{array}$

$\begin{array}{llllll}231.21 & 36.36 & 832.00 & 36.36 & 303.14 & 58.44\end{array}$

$\begin{array}{llllll}1688.23 & 89.61 & 6409.00 & 89.61 & 876.90 & 80.52\end{array}$

$\begin{array}{llllll}2000.00 & 93.51 & 33065.00 & 100.00 & 2403.35 & 97.40\end{array}$

$\begin{array}{llllll}155.20 & 33.77 & 412.00 & 29.87 & 45.65 & 31.17\end{array}$

$\begin{array}{llllll}373.40 & 40.26 & 777.00 & 35.06 & 248.78 & 54.55\end{array}$

$\begin{array}{llllll}667.04 & 62.34 & 1833.00 & 51.95 & 422.89 & 66.23\end{array}$

$\begin{array}{llllll}920.26 & 79.22 & 2830.00 & 66.23 & 922.36 & 81.82\end{array}$

$\begin{array}{llllll}739.84 & 67.53 & 8786.00 & 96.10 & 1464.27 & 89.61\end{array}$

Block Group 4,

Census Tract 3

Block Group 3,

Census Tract

12.01

Block Group 1,

Census Tract

12.02

Block Group 1,

Census Tract

11.01

Block Group 3,

Census Tract

11.02

Block Group 3,

Census Tract

14.02

Block Group 3,

Census Tract

14.01

$\begin{array}{llllll}518.41 & 54.55 & 1525.00 & 48.05 & 127.29 & 44.16 \\ 513.22 & 51.95 & 1135.00 & 38.96 & 322.01 & 61.04 \\ & & & & & \\ 83.57 & 22.08 & 368.00 & 25.97 & 19.07 & 23.38 \\ 153.68 & 32.47 & 375.00 & 27.27 & 35.91 & 25.97 \\ & & & & & \\ 732.31 & 66.23 & 2366.00 & 62.34 & 214.61 & 53.25 \\ & & & & & \\ 430.97 & 46.75 & 1560.00 & 49.35 & 156.53 & 49.35 \\ & & & & & \\ 358.20 & 38.96 & 1190.00 & 40.26 & 320.49 & 59.74 \\ & & & & & \\ 143.47 & 29.87 & 425.00 & 32.47 & 54.54 & 33.77\end{array}$


Block Group 2, Census Tract

14.01

776.2

71.43

1870.00

55.84

$276.06 \quad 57.14$

Block Group 1

Census Tract

14.01

197.8

Block Group 3, Census Tract

2.02

146.84

Block Group 1, Census Tract

5.02

Block Group 2, Census Tract

12.02

Block Group 3,

Census Tract

11.02

Block Group 3,

Census Tract

7.02

Block Group 2,

Census Tract

4.02

Block Group 1,

Census Tract

12.01

Block Group 2,

Census Tract

2.01

Block Group 2,

Census Tract

10.01

Block Group 1,

Census Tract 15

Block Group 2,

Census Tract 15

Block Group 1,

Census Tract

2.01

Block Group 2,

Census Tract

1.02

Block Group 1,

Census Tract

1.02

Block Group 1, Census Tract

7.01

Block Group 2, Census Tract

7.01

\begin{tabular}{|c|c|c|c|c|c|}
\hline 945.68 & 80.52 & 3220.00 & 70.13 & 554.51 & 68.83 \\
\hline 534.11 & 55.84 & 1115.00 & 37.66 & 142.79 & 46.75 \\
\hline 687.19 & 63.64 & 2137.00 & 59.74 & 257.70 & 55.84 \\
\hline 4199.34 & 100.00 & 26015.00 & 98.70 & 7474.82 & 100.00 \\
\hline 803.05 & 74.03 & 3004.00 & 68.83 & 142.51 & 45.45 \\
\hline 585.70 & 59.74 & 1438.00 & 46.75 & 118.45 & 42.86 \\
\hline 62.17 & 19.48 & 212.00 & 18.18 & 17.16 & 20.78 \\
\hline 3255.96 & 98.70 & 8622.00 & 94.81 & 3261.66 & 98.70 \\
\hline 7.05 & 5.19 & 22.00 & 3.90 & 1.13 & 3.90 \\
\hline 69.35 & 20.78 & 232.00 & 20.78 & 10.97 & 18.18 \\
\hline 89.81 & 23.38 & 231.00 & 19.48 & 21.30 & 24.68 \\
\hline 6.42 & 2.60 & 18.00 & 2.60 & 0.47 & 2.60 \\
\hline 7.53 & 6.49 & 25.00 & 5.19 & 3.11 & 6.49 \\
\hline 482.76 & 49.35 & 1694.00 & 50.65 & 98.71 & 41.56 \\
\hline 515.47 & 53.25 & 4475.00 & 79.22 & 452.66 & 67.53 \\
\hline
\end{tabular}


Block Group 3,

Census Tract

10.02

Block Group 2,

$\begin{array}{llllll}1296.51 & 84.42 & 3389.00 & 72.73 & 1148.96 & 87.01\end{array}$

Census Tract

11.01

415.55

44.16

1267.00

42.86

71.08

35.06

Block Group 3,

Census Tract 13

35.73

15.58

$90.00 \quad 15.58$

4.17

9.09

ChildrenD: children density

Children: standardized children density

TotolD: total population density

Total: standardized total population density

MinorityD: racial minority density

Minority: standardized racial minority density 
Appendix B. Socio-demographic Data of Cache County, Utah 


\begin{tabular}{|c|c|c|c|c|c|}
\hline $\begin{array}{l}\text { GEOdisplaylabel } \\
\text { Block Group 2, } \\
\text { Census Tract }\end{array}$ & Poverty & Unemployed & LowEducation & RenterRate & BuildingSize \\
\hline $\begin{array}{l}11.02 \\
\text { Block Group 2, } \\
\text { Census Tract }\end{array}$ & 20.95 & 48.49 & 0.03 & 31.00 & 49.30 \\
\hline $\begin{array}{l}12.01 \\
\text { Block Group 3, } \\
\text { Census Tract }\end{array}$ & 9.60 & 30.66 & 0.04 & 13.00 & 40.80 \\
\hline $\begin{array}{l}5.01 \\
\text { Block Group 2, } \\
\text { Census Tract }\end{array}$ & 48.29 & 29.39 & 0.20 & 47.00 & 34.90 \\
\hline 5.01 & 45.68 & 33.88 & 0.07 & 83.00 & 48.50 \\
\hline $\begin{array}{l}\text { Block Group 3, } \\
\text { Census Tract } 6\end{array}$ & 32.53 & 42.11 & 0.05 & 39.00 & 39.10 \\
\hline $\begin{array}{l}\text { Block Group 2, } \\
\text { Census Tract } 6\end{array}$ & 49.92 & 30.46 & 0.17 & 89.00 & 27.90 \\
\hline $\begin{array}{l}\text { Block Group } 1 \text {, } \\
\text { Census Tract } 6\end{array}$ & 76.79 & 17.61 & 0.00 & 83.00 & 24.20 \\
\hline $\begin{array}{l}\text { Block Group 4, } \\
\text { Census Tract } 8 \\
\text { Block Group 3, } \\
\text { Census Tract } \\
7.01\end{array}$ & 55.41 & 32.31 & 0.06 & 68.00 & 49.30 \\
\hline $\begin{array}{l}\text { Block Group 3, } \\
\text { Census Tract } 8\end{array}$ & 54.21 & 44.75 & 0.17 & 83.00 & 25.30 \\
\hline $\begin{array}{l}\text { Block Group 2, } \\
\text { Census Tract } 8\end{array}$ & 59.90 & 24.27 & 0.00 & 78.00 & 58.30 \\
\hline $\begin{array}{l}\text { Block Group 1, } \\
\text { Census Tract } 8\end{array}$ & 72.74 & 36.40 & 0.04 & 94.00 & 61.00 \\
\hline $\begin{array}{l}\text { Block Group 3, } \\
\text { Census Tract } 9\end{array}$ & 53.40 & 18.96 & 0.07 & 54.00 & 45.70 \\
\hline $\begin{array}{l}\text { Block Group 1, } \\
\text { Census Tract } 9\end{array}$ & 40.98 & 37.40 & 0.04 & 61.00 & 64.70 \\
\hline $\begin{array}{l}\text { Block Group 2, } \\
\text { Census Tract } 9 \\
\text { Block Group 2, } \\
\text { Census Tract }\end{array}$ & 38.22 & 29.39 & 0.02 & 33.00 & 65.60 \\
\hline $\begin{array}{l}10.02 \\
\text { Block Group 1, } \\
\text { Census Tract }\end{array}$ & 31.14 & 25.87 & 0.24 & 80.00 & 29.50 \\
\hline $\begin{array}{l}10.02 \\
\text { Block Group 1, } \\
\text { Census Tract }\end{array}$ & 33.04 & 28.48 & 0.11 & 55.00 & 38.30 \\
\hline 2.02 & 20.48 & 34.36 & 0.01 & 17.00 & 54.00 \\
\hline $\begin{array}{l}\text { Block Group 1, } \\
\text { Census Tract } 3\end{array}$ & 26.45 & 31.24 & 0.08 & 12.00 & 12.30 \\
\hline $\begin{array}{l}\text { Block Group 2, } \\
\text { Census Tract } 3\end{array}$ & 9.85 & 35.45 & 0.04 & 3.00 & 6.90 \\
\hline
\end{tabular}


Block Group 1, Census Tract

13

22.22

0.02

8.00

10.30

Census Tract

13

$13.75 \quad 39.05$

0.08

18.00

10.80

Block Group 2, Census Tract

1.01

26.8

32.77

0.09

12.00

9.70

Block Group 1, Census Tract

4.01

$42.73 \quad 41.44$

0.15

74.00

15.30

Block Group 2,

Census Tract

4.01

$16.34 \quad 50.97$

0.00

20.00

30.90

Block Group 1,

Census Tract

4.03

$5.96 \quad 38.97$

0.01

10.00

44.90

Block Group 2,

Census Tract

7.02

$37.04 \quad 55.56$

0.07

100.00

1.40

Block Group 1,

Census Tract

1.01

$16.95 \quad 17.60$

0.04

13.00

11.30

Block Group 1,

Census Tract

9801

0.00

35.16

0.08

18.00

0.00

Block Group 3 ,

Census Tract

1.01

$33.12 \quad 35.02$

0.04

21.00

9.10

Block Group 4,

Census Tract

2.02

14.91

29.52

0.01

0.00

9.60

Block Group 2,

Census Tract

2.02

Block Group 2,

23.79

41.64

0.03

13.00

13.90

Census Tract

4.03

$9.02 \quad 33.36$

0.13

14.00

5.20

Block Group 3,

Census Tract 3

Block Group 2,

$22.06 \quad 36.09$

0.11

22.00

9.70

Census Tract

5.02

32.4

21.66

0.24

73.00

14.20

Block Group 3,

Census Tract

4.03

20.00

24.98

0.02

6.00

36.50

Block Group 1,

Census Tract

4.02

6.58

44.17

0.01

5.00

19.50

Block Group 4,

Census Tract

4.03

$5.41 \quad 37.28$

0.03

10.00

56.70 
Block Group 4,

Census Tract

5.01

$46.38 \quad 32.39$

0.13

44.00

56.40

Block Group 1,

Census Tract

5.01

50.5

41.71

0.19

85.00

40.90

Block Group 1,

Census Tract

7.02

$57.14 \quad 35.65$

0.00

100.00

0.00

Block Group 4, Census Tract 6

22.96

0.06

48.00

57.30

Block Group 6, Census Tract 6 Block Group 1,

$69.11 \quad 35.94$

0.06

100.00

66.80

Census Tract

14.02

12.7

30.29

0.04

7.00

13.10

Block Group 2, Census Tract

14.02

$8.87 \quad 29.31$

0.27

27.00

22.80

Block Group 4, Census Tract

10.02

$34.67 \quad 23.33$

0.12

40.00

28.00

Block Group 1, Census Tract

10.01

$20.19 \quad 38.33$

0.07

24.00

47.50

Block Group 5,

Census Tract 6

$70.50 \quad 46.66$

0.06

78.00

66.60

Block Group 1 , Census Tract

11.02

$19.67 \quad 30.42$

0.05

0.00

36.40

Block Group 4, Census Tract 3 Block Group 3,

$42.17 \quad 49.61$

0.20

45.00

20.40

Census Tract

12.01

11.99

39.96

0.05

7.00

25.60

Block Group 1,

Census Tract

12.02

$12.13 \quad 35.00$

0.05

24.00

14.30

Block Group 1, Census Tract

11.01

Block Group 3,

Census Tract

11.02

Block Group 3,

Census Tract

14.02

Block Group 3,

Census Tract

14.01

27.53

37.15

0.06

30.00

32.60

9.42

31.87

0.03

17.00

37.00

26.53

31.96

0.03

16.00

52.70

$16.74 \quad 38.01$

0.06

16.00

18.50 
Block Group 2, Census Tract

14.01

$10.52 \quad 33.86$

0.19

19.00

31.10

Block Group 1, Census Tract

14.01

29.6

Block Group 3, Census Tract

2.02

10.8

Block Group 1, Census Tract

5.02

Block Group 2,

Census Tract

12.02

Block Group 3,

Census Tract

11.02

Block Group 3,

Census Tract

7.02

Block Group 2, Census Tract

4.02

Block Group 1,

Census Tract

12.01

Block Group 2,

Census Tract

2.01

Block Group 2,

Census Tract

10.01

Block Group 1,

Census Tract

15

Block Group 2,

Census Tract

15

Block Group 1,

Census Tract

2.01

Block Group 2,

Census Tract

1.02

Block Group 1,

Census Tract

1.02

$42.85 \quad 31.44$

0.03

10.75

35.83

0.06

4.00

28.40

23.39

36.69

0.07

29.00

32.00

83.4

61.07

0.03

99.00

0.00

16.67

37.57

0.01

15.00

68.50

8.69

33.72

0.01

6.00

41.00

18.75

34.92

0.06

15.00

15.00

27.56

23.75

0.08

25.00

57.20

$11.46 \quad 26.20$

0.10

5.00

5.70

$11.88 \quad 48.08$

0.04

8.00

31.70

$16.51 \quad 35.58$

0.06

16.00

14.70

8.52

37.43

0.05

7.00

1.40

Block Group 1, Census Tract

7.01

Block Group 2,

$29.07 \quad 36.92$

0.14

18.00

9.20

Census Tract

7.01

11.38

39.95

0.00

3.00

27.70

16.92

47.10

0.01

25.00

38.20 
Block Group 3,

Census Tract

10.02

45.51

43.37

0.27

66.00

19.20

Block Group 2,

Census Tract

11.01

7.02

37.13

0.00

2.00

36.10

Block Group 3,

Census Tract

13

$13.08 \quad 33.04$

0.05

9.00

4.70

Poverty: population percentage whose income falls below $125 \%$ of federal poverty line

Unemployed: population percentage of unemployment

Low-education: population percentage of people who achieved less than high school education

Building Size: parcel size minus yard size

Renter Rate: Percentage of renter occupied housing 
Appendix C. Standardized Socio-demographic Data of Cache County, Utah (Variables of Park Need) 


\begin{tabular}{|c|c|c|c|c|c|}
\hline GEOdisplaylabel & Poverty & Unemployment & $\begin{array}{l}\text { Low- } \\
\text { education }\end{array}$ & RenterRate & BuildingSize \\
\hline $\begin{array}{l}\text { Block Group 2, } \\
\text { Census Tract }\end{array}$ & & & & & \\
\hline $\begin{array}{l}11.02 \\
\text { Block Group 2, } \\
\text { Census Tract }\end{array}$ & 48.0519 & 93.5065 & 23.3766 & 62.3377 & 83.1169 \\
\hline $\begin{array}{l}12.01 \\
\text { Block Group 3, } \\
\text { Census Tract }\end{array}$ & 14.2857 & 27.2727 & 41.5584 & 31.1688 & 72.7273 \\
\hline $\begin{array}{l}5.01 \\
\text { Block Group 2, } \\
\text { Census Tract }\end{array}$ & 84.4156 & 19.4805 & 94.8052 & 71.4286 & 62.3377 \\
\hline $\begin{array}{l}5.01 \\
\text { Block Group 3, }\end{array}$ & 81.8182 & 44.1558 & 62.3377 & 90.9091 & 80.5195 \\
\hline $\begin{array}{l}\text { Census Tract } 6 \\
\text { Block Group 2, }\end{array}$ & 66.2338 & 84.4156 & 44.1558 & 66.2338 & 71.4286 \\
\hline $\begin{array}{l}\text { Census Tract } 6 \\
\text { Block Group 1, }\end{array}$ & 85.7143 & 25.974 & 88.3117 & 93.5065 & 50.6494 \\
\hline $\begin{array}{l}\text { Census Tract } 6 \\
\text { Block Group 4, }\end{array}$ & 98.7013 & 2.5974 & 7.7922 & 90.9091 & 44.1558 \\
\hline $\begin{array}{l}\text { Census Tract } 8 \\
\text { Block Group 3, } \\
\text { Census Tract }\end{array}$ & 90.9091 & 33.7662 & 54.5455 & 79.2208 & 83.1169 \\
\hline $\begin{array}{l}7.01 \\
\text { Block Group 3, }\end{array}$ & 71.4286 & 97.4026 & 22.0779 & 64.9351 & 45.4545 \\
\hline $\begin{array}{l}\text { Census Tract } 8 \\
\text { Block Group 2, }\end{array}$ & 89.6104 & 88.3117 & 89.6104 & 90.9091 & 46.7532 \\
\hline $\begin{array}{l}\text { Census Tract } 8 \\
\text { Block Group 1, }\end{array}$ & 93.5065 & 10.3896 & 7.7922 & 85.7143 & 92.2078 \\
\hline $\begin{array}{l}\text { Census Tract } 8 \\
\text { Block Group 3, }\end{array}$ & 97.4026 & 59.7403 & 38.961 & 94.8052 & 93.5065 \\
\hline $\begin{array}{l}\text { Census Tract } 9 \\
\text { Block Group 1, }\end{array}$ & 88.3117 & 3.8961 & 66.2338 & 74.026 & 77.9221 \\
\hline $\begin{array}{l}\text { Census Tract } 9 \\
\text { Block Group 2, }\end{array}$ & 75.3247 & 68.8312 & 36.3636 & 76.6234 & 94.8052 \\
\hline $\begin{array}{l}\text { Census Tract } 9 \\
\text { Block Group 2, } \\
\text { Census Tract }\end{array}$ & 74.026 & 20.7792 & 20.7792 & 63.6364 & 96.1039 \\
\hline $\begin{array}{l}10.02 \\
\text { Block Group 1, } \\
\text { Census Tract }\end{array}$ & 63.6364 & 14.2857 & 97.4026 & 87.013 & 54.5455 \\
\hline $\begin{array}{l}10.02 \\
\text { Block Group 1, } \\
\text { Census Tract }\end{array}$ & 67.5325 & 16.8831 & 79.2208 & 75.3247 & 70.1299 \\
\hline 2.02 & 46.7532 & 45.4545 & 15.5844 & 42.8571 & 85.7143 \\
\hline
\end{tabular}


Block Group 1,

Census Tract 3

Block Group 2,

$\begin{array}{lllll}54.5455 & 28.5714 & 72.7273 & 27.2727 & 23.3766\end{array}$

Census Tract 3

$15.5844 \quad 51.9481$

40.2597

6.4935

11.6883

Block Group 1,

Census Tract 13

$27.2727 \quad 6.4935$

18.1818

19.4805

19.4805

Block Group 2,

Census Tract 13

31.1688

76.6234

68.8312

46.7532

20.7792

Block Group 2,

1.01

57.1429

36.3636

75.3247

27.2727

18.1818

Block Group 1,

Census Tract

4.01

77.9221

80.5195

87.013

81.8182

33.7662

Block Group 2,

Census Tract

4.01

33.7662

96.1039

7.7922

49.3506

55.8442

Block Group 1,

Census Tract

4.03

$3.8961 \quad 75.3247$

12.987

23.3766

76.6234

Block Group 2,

Census Tract

7.02

72.7273

98.7013

63.6364

100

6.4935

Block Group 1,

Census Tract

1.01

40.2597

1.2987

32.4675

31.1688

22.0779

Block Group 1,

Census Tract

9801

1.2987

50.6494

71.4286

46.7532

3.8961

Block Group 3,

Census Tract

1.01

68.8312

49.3506

33.7662

50.6494

12.987

Block Group 4,

Census Tract

2.02

32.4675

22.0779

10.3896

2.5974

15.5844

Block Group 2,

Census Tract

2.02

53.2468

81.8182

31.1688

31.1688

27.2727

Block Group 2,

Census Tract

4.03

$11.6883 \quad 38.961$

83.1169

32.4675

9.0909

Block Group 3, Census Tract 3 Block Group 2, $49.3506 \quad 58.4416$

$80.5195 \quad 51.9481$

18.1818

Census Tract

5.02

$64.9351 \quad 5.1948$

96.1039

80.5195

28.5714 
Block Group 3,

Census Tract

4.03

44.1558

11.6883

19.4805

12.987

66.2338

Block Group 1,

Census Tract

4.02

5.1948

87.013

16.8831

10.3896

38.961

Block Group 4,

Census Tract

4.03

$2.5974 \quad 67.5325$

24.6753

23.3766

88.3117

Block Group 4,

Census Tract

5.01

83.1169

35.0649

84.4156

68.8312

87.013

Block Group 1,

Census Tract

5.01

87.013

83.1169

90.9091

92.2078

74.026

Block Group 1,

Census Tract

7.02

92.2078

54.5455

7.7922

100

3.8961

Block Group 4,

Census Tract 6

$50.6494 \quad 12.987$

51.9481

72.7273

90.9091

Block Group 6,

94.805

57.1429

61.039

100

98.7013

Block Group 1,

Census Tract

14.02

$28.5714 \quad 23.3766$

37.6623

16.8831

24.6753

Block Group 2,

Census Tract

14.02

Block Group 4,

10.3896

18.1818

98.7013

58.4416

42.8571

Census Tract

10.02

$70.1299 \quad 7.7922$

81.8182

67.5325

51.9481

Block Group 1,

Census Tract

10.01

$45.4545 \quad 74.026$

67.5325

54.5455

79.2208

Block Group 5,

Census Tract 6

Block Group 1,

$96.1039 \quad 89.6104$

57.1429

85.7143

97.4026

Census Tract

11.02

$42.8571 \quad 24.6753$

42.857

2.5974

64.9351

Block Group 4,

Census Tract 3

Block Group 3,

Census Tract

12.01

24.6753

79.2208

48.0519

16.8831

48.0519 
Block Group 1, Census Tract

12.02

$25.974 \quad 48.0519$

$45.4545 \quad 54.5455$

29.8701

Block Group 1,

Census Tract

11.01

$58.4416 \quad 66.2338$

59.7403

61.039

61.039

Block Group 3,

Census Tract

11.02

$12.987 \quad 31.1688$

25.974

42.8571

67.5325

Block Group 3,

Census Tract

14.02

$55.8442 \quad 32.4675$

$27.2727 \quad 40.2597$

84.4156

Block Group 3,

Census Tract

14.01

37.6623

72.7273

55.8442

40.2597

36.3636

Block Group 2,

Census Tract

14.01

16.8831

42.8571

92.2078

48.0519

57.1429

Block Group 1,

Census Tract

14.01

Block Group 3,

$62.3377 \quad 40.2597$

74.026

24.6753

25.974

Census Tract

2.02

19.4805

62.3377

76.6234

40.2597

35.0649

Block Group 1,

Census Tract

5.02

Block Group 2,

$79.2208 \quad 29.8701$

29.8701

83.1169

40.2597

Census Tract

12.02

$18.1818 \quad 55.8442$

50.6494

7.7922

53.2468

Block Group 3,

Census Tract

11.02

Block Group 3,

$51.9481 \quad 61.039$

64.9351

59.7403

59.7403

Census Tract

7.02

100

100

28.5714

96.1039

3.8961

Block Group 2,

Census Tract

4.02

36.3636

71.4286

9.0909

35.0649

100

Block Group 1,

Census Tract

12.01

9.0909

41.5584

14.2857

12.987

75.3247

Block Group 2,

Census Tract

2.01

$41.5584 \quad 46.7532$

58.4416

35.0649

32.4675 
Block Group 2,

Census Tract

9.0909

70.1299

57.1429

89.6104

Block Group 1,

Census Tract 15

22.0779

15.5844

77.9221

10.3896

10.3896

Block Group 2,

Census Tract 15

23.3766

92.2078

35.0649

19.4805

58.4416

Block Group 1,

Census Tract

$35.0649 \quad 53.2468$

53.2468

40.2597

31.1688

Block Group 2,

Census Tract

1.02

$7.7922 \quad 70.1299$

46.7532

16.8831

6.4935

Block Group 1,

Census Tract

1.02

$61.039 \quad 63.6364$

85.7143

46.7532

14.2857

Block Group 1,

Census Tract

7.01

$20.7792 \quad 77.9221$

7.7922

6.4935

49.3506

Block Group 2,

Census Tract

7.01

$38.961 \quad 90.9091$

11.6883

57.1429

68.8312

Block Group 3,

Census Tract

10.02

80.5195

85.7143

100

77.9221

37.6623

Block Group 2,

Census Tract

11.01

6.4935

64.9351

7.7922

3.8961

63.6364

Block Group 3,

37.6623

49.3506

20.7792

7.7922

Poverty: Standardized population percentage whose income falls below $125 \%$ of federal poverty line

Unemployed: Standardized population percentage of unemployment

Low-education: Standardized population percentage of people who achieved less than high school education

Building Size: Standardized parcel size minus yard size

Renter Rate: Standardized percentage of renter occupied housing 
Appendix D. Park Quality Data among Block Groups of Cache County, Utah 
GEOdisplaylabel Facility Amenity Aesthetic Maintain Incivility Overall

Block Group 2,

Census Tract

11.02

$\begin{array}{llllll}46.5 & 57.10 & 57.70 & 55.60 & 56.80 & 54.80\end{array}$

Block Group 2,

Census Tract

12.01

$\begin{array}{llllll}55.6 & 50.00 & 66.70 & 70.00 & 71.40 & 62.70\end{array}$

Block Group 3,

Census Tract

5.01

$\begin{array}{llllll}50 & 36.40 & 77.80 & 60.00 & 85.70 & 62.00\end{array}$

Block Group 2,

Census Tract

5.01

$\begin{array}{llllll}50 & 36.40 & 77.80 & 60.00 & 85.70 & 62.00\end{array}$

Block Group 3,

Census Tract 6

Block Group 2,

$\begin{array}{llllll}11.1 & 18.20 & 22.20 & 20.00 & 43.00 & 22.90\end{array}$

Census Tract 6

Block Group 1,

Census Tract 6

Block Group 4,

Census Tract 8

Block Group 3,

Census Tract

7.01

Block Group 3,

Census Tract 8

Block Group 2,

Census Tract 8

Block Group 1,

Census Tract 8

Block Group 3,

Census Tract 9

Block Group 1,

Census Tract 9

Block Group 2,

Census Tract 9

Block Group 2,

Census Tract

10.02

Block Group 1,

Census Tract

10.02

$\begin{array}{llllll}33.3 & 36.40 & 55.60 & 50.00 & 43.00 & 43.60\end{array}$

$\begin{array}{llllll}33.3 & 36.40 & 55.60 & 50.00 & 43.00 & 43.60\end{array}$

$\begin{array}{llllll}52.6 & 65.10 & 62.00 & 58.00 & 50.90 & 59.50\end{array}$

$\begin{array}{llllll}43.9 & 55.50 & 59.20 & 54.70 & 57.60 & 54.30\end{array}$

$\begin{array}{llllll}50.6 & 66.10 & 70.00 & 56.70 & 56.90 & 49.50\end{array}$

$\begin{array}{llllll}65.9 & 66.80 & 55.30 & 59.00 & 42.70 & 58.20\end{array}$

$\begin{array}{llllll}67 & 68.00 & 56.00 & 60.00 & 43.00 & 59.00\end{array}$

$\begin{array}{llllll}58.6 & 70.10 & 73.00 & 63.70 & 56.90 & 64.50\end{array}$

$\begin{array}{llllll}33.3 & 55.00 & 22.00 & 80.00 & 71.00 & 52.00\end{array}$

$\begin{array}{llllll}72.3 & 73.00 & 80.00 & 67.00 & 51.00 & 69.50\end{array}$

Block Group 1,

Census Tract

2.02

$\begin{array}{llllll}11.1 & 36.40 & 22.20 & 30.00 & 28.60 & 25.70\end{array}$

$\begin{array}{llllll}33.3 & 56.00 & 56.00 & 70.00 & 71.40 & 57.30\end{array}$

$\begin{array}{llllll}61.1 & 72.70 & 66.70 & 40.00 & 42.90 & 56.70\end{array}$ 
Block Group 1,

Census Tract 3

Block Group 2,

$\begin{array}{llllll}72.2 & 81.80 & 55.60 & 60.00 & 64.30 & 66.80\end{array}$

Census Tract 3

Block Group 1,

Census Tract 13

Block Group 2,

Census Tract 13

Block Group 2,

Census Tract

1.01

Block Group 1,

Census Tract

4.01

$\begin{array}{llllll}55.6 & 59.10 & 66.70 & 60.00 & 57.10 & 59.70\end{array}$

$\begin{array}{llllll}53.1 & 55.80 & 71.30 & 57.10 & 58.00 & 59.00\end{array}$

$\begin{array}{llllll}55.6 & 75.00 & 80.00 & 64.00 & 67.90 & 68.50\end{array}$

Block Group 2,

Census Tract

4.01

Block Group 1,

Census Tract

Block Group 2,

Census Tract

7.02

$\begin{array}{llllll}43.8 & 55.00 & 58.00 & 55.00 & 56.70 & 53.80\end{array}$

Block Group 1,

Census Tract

1.01

Block Group 1,

Census Tract

9801

$\begin{array}{llllll}38.9 & 68.20 & 55.60 & 70.00 & 42.90 & 55.10\end{array}$

$\begin{array}{llllll}66.7 & 68.20 & 66.70 & 80.00 & 57.10 & 67.70\end{array}$

Block Group 3,

Census Tract

1.01

Block Group 4,

$\begin{array}{llllll}42.9 & 68.20 & 55.60 & 70.00 & 42.90 & 55.10\end{array}$

Census Tract

2.02

Block Group 2,

Census Tract

2.02

Block Group 2,

Census Tract

4.03

Census Tract 3

$\begin{array}{llllll}55.6 & 77.30 & 77.80 & 60.00 & 57.10 & 65.60\end{array}$

$\begin{array}{llllll}67 & 68.00 & 56.00 & 60.00 & 43.00 & 59.00\end{array}$

Block Group 2,

Census Tract

5.02

$\begin{array}{llllll}55.6 & 77.30 & 88.90 & 50.00 & 71.40 & 68.60\end{array}$

$\begin{array}{llllll}55.6 & 77.30 & 77.80 & 60.00 & 57.10 & 65.60\end{array}$

$\begin{array}{llllll}61.1 & 63.60 & 88.90 & 60.00 & 78.60 & 70.40\end{array}$

$\begin{array}{llllll}27.8 & 31.80 & 55.60 & 70.00 & 85.70 & 54.20\end{array}$

$\begin{array}{llllll}38.9 & 68.20 & 55.60 & 70.00 & 42.90 & 55.10\end{array}$

$\begin{array}{llllll}43.8 & 55.00 & 58.00 & 55.00 & 56.70 & 54.00\end{array}$

$\begin{array}{llllll}52 & 65.00 & 77.80 & 70.00 & 80.00 & 72.50\end{array}$ 
Block Group 3,

Census Tract

4.03

$73.1 \quad 68.20$

68.60

68.30

71.40

69.90

Block Group 1,

Census Tract

4.02

$\begin{array}{llllll}44.4 & 63.60 & 88.90 & 50.00 & 57.10 & 60.80\end{array}$

Block Group 4,

Census Tract

4.03

Block Group 4,

Census Tract

5.01

$50 \quad 50.00$

55.60

60.00

57.10

54.50

Block Group 1,

Census Tract

5.01

$61 \quad 77.00$

$55.60 \quad 30.00$

$43.00 \quad 53.40$

Block Group 1,

Census Tract

7.02

$\begin{array}{llllll}43.8 & 55.00 & 58.00 & 55.00 & 56.70 & 53.80\end{array}$

Block Group 4,

Census Tract 6

Block Group 6,

Census Tract 6

Block Group 1,

Census Tract

14.02

$\begin{array}{llllll}33.3 & 36.40 & 55.60 & 50.00 & 43.00 & 43.60\end{array}$

$\begin{array}{llllll}33.3 & 36.40 & 55.60 & 50.00 & 43.00 & 43.60\end{array}$

Block Group 2,

Census Tract

14.02

Block Group 4,

Census Tract

10.02

$\begin{array}{llllll}72.2 & 63.60 & 77.80 & 80.00 & 71.40 & 73.00\end{array}$

Block Group 1,

Census Tract

10.01

Block Group 5,

Census Tract 6

Block Group 1,

Census Tract

11.02

$42.9 \quad 43.90$

33.30

42.00

42.90

42.20

$\begin{array}{llllll}50 & 36.40 & 77.80 & 60.00 & 85.70 & 62.00\end{array}$

Block Group 4, Census Tract 3

Block Group 3, Census Tract

12.01

$\begin{array}{rrrrrr}42.8 & 54.70 & 54.40 & 63.00 & 48.50 & 52.80 \\ 21.1 & 28.20 & 27.20 & 30.00 & 43.00 & 22.90 \\ & & & & & \\ 33 & 32.00 & 22.00 & 40.00 & 43.00 & 34.00 \\ 43.8 & 55.00 & 58.00 & 55.00 & 56.70 & 53.80 \\ & & & & & \\ 47.5 & 57.50 & 63.20 & 58.00 & 57.00 & 56.70\end{array}$


Block Group 1, Census Tract

12.02

$\begin{array}{llllll}45 & 57.60 & 62.00 & 56.00 & 58.30 & 55.80\end{array}$

Block Group 1, Census Tract

11.01

Block Group 3,

Census Tract

11.02

Block Group 3,

Census Tract

14.02

Block Group 3,

Census Tract

14.01

Block Group 2,

Census Tract

14.01

Block Group 1,

Census Tract

14.01

Block Group 3,

Census Tract

2.02

$\begin{array}{llllll}39 & 48.30 & 56.80 & 52.00 & 36.00 & 46.40\end{array}$

$\begin{array}{llllll}50 & 86.00 & 67.00 & 80.00 & 86.00 & 74.00\end{array}$

Block Group 1,

Census Tract

5.02

Block Group 2,

Census Tract

12.02

$\begin{array}{llllll}72.2 & 63.60 & 77.80 & 80.00 & 71.40 & 73.00\end{array}$

Block Group 3,

Census Tract

11.02

Block Group 3,

Census Tract

7.02

$\begin{array}{llllll}38.9 & 68.20 & 55.60 & 60.00 & 57.10 & 56.00\end{array}$

$\begin{array}{llllll}44.4 & 41.00 & 55.60 & 60.00 & 71.40 & 54.50\end{array}$

Block Group 2,

Census Tract

4.02

Block Group 1,

$\begin{array}{llllll}38.9 & 68.20 & 55.60 & 60.00 & 57.10 & 56.00\end{array}$

$\begin{array}{llllll}57.8 & 61.00 & 86.70 & 59.00 & 79.20 & 68.70\end{array}$

$\begin{array}{llllll}51 & 63.00 & 74.80 & 68.00 & 76.00 & 70.20\end{array}$

Census Tract

12.01

Block Group 2,

Census Tract

2.01

$\begin{array}{llllll}49.5 & 60.20 & 63.80 & 65.00 & 62.80 & 60.10\end{array}$

$\begin{array}{llllll}48.9 & 70.10 & 48.90 & 60.00 & 55.70 & 54.70\end{array}$

$\begin{array}{llllll}43.8 & 55.00 & 58.00 & 55.00 & 56.70 & 53.80\end{array}$

$\begin{array}{llllll}56 & 82.00 & 67.00 & 100.00 & 86.00 & 78.00\end{array}$

$\begin{array}{llllll}37.7 & 61.80 & 57.80 & 66.00 & 62.80 & 57.20\end{array}$

$\begin{array}{llllll}52.8 & 73.20 & 65.60 & 68.00 & 65.80 & 65.10\end{array}$ 
Block Group 2,

Census Tract

$\begin{array}{lllllll}10.01 & 27.8 & 36.40 & 22.20 & 50.00 & 71.40 & 41.60\end{array}$

Block Group 1,

$\begin{array}{lllllll}\text { Census Tract } 15 & 45.6 & 49.10 & 71.10 & 58.00 & 57.10 & 57.20\end{array}$

Block Group 2,

Census Tract 15

Block Group 1,

Census Tract

$\begin{array}{llllll}58.3 & 68.60 & 65.60 & 41.00 & 45.70 & 55.80\end{array}$

Block Group 2,

Census Tract

1.02

$50 \quad 63.60$

$55.60 \quad 60.00$

57.10

57.30

Block Group 1,

Census Tract

1.02

$43.8 \quad 55.00$

58.00

55.00

$56.70 \quad 53.80$

Block Group 1,

Census Tract

7.01

$50 \quad 70.00$

71.30

72.00

68.70

66.40

Block Group 2,

Census Tract

7.01

Census Tract

10.02

$47.8 \quad 56.30$

69.00

52.00

62.80

57.50

Block Group 2,

Census Tract

$\begin{array}{lllllll}11.01 & 44.4 & 45.50 & 66.70 & 30.00 & 57.10 & 48.70\end{array}$

Block Group 3,

Census Tract 13

$11.1 \quad 36.40$

22.20

$20.00 \quad 28.60$

23.70

Facility: park facility score

Amenity: park amenity score

Aesthetic: park aesthetic feature score

Maintain: park maintenance\&cleanliness score

Incivility: park incivility score

Overall: Park Overall Quality 
Appendix E. Park Proximity, Park Quality, and Park Need among all the Block Groups in Cache County, Utah 


\begin{tabular}{|c|c|c|c|}
\hline GEOdisplaylabel & $\begin{array}{c}\text { Park } \\
\text { Proximity }\end{array}$ & $\begin{array}{l}\text { Park } \\
\text { Quality }\end{array}$ & $\begin{array}{l}\text { Park } \\
\text { Need }\end{array}$ \\
\hline $\begin{array}{l}\text { Block Group 2, } \\
\text { Census Tract }\end{array}$ & & & \\
\hline $\begin{array}{l}11.02 \\
\text { Block Group 2, } \\
\text { Census Tract }\end{array}$ & 48.72 & 54.80 & 63.1494 \\
\hline $\begin{array}{l}12.01 \\
\text { Block Group 3, } \\
\text { Census Tract }\end{array}$ & 17.06 & 62.70 & 39.9351 \\
\hline $\begin{array}{l}5.01 \\
\text { Block Group 2, } \\
\text { Census Tract }\end{array}$ & 52.30 & 62.00 & 68.0195 \\
\hline $\begin{array}{l}5.01 \\
\text { Block Group 3, }\end{array}$ & 100.00 & 62.00 & 80.6818 \\
\hline $\begin{array}{l}\text { Census Tract } 6 \\
\text { Block Group 2, }\end{array}$ & 100.00 & 22.90 & 60.2273 \\
\hline $\begin{array}{l}\text { Census Tract } 6 \\
\text { Block Group 1, }\end{array}$ & 38.75 & 43.60 & 75.487 \\
\hline $\begin{array}{l}\text { Census Tract } 6 \\
\text { Block Group 4, }\end{array}$ & 10.91 & 43.60 & 57.3052 \\
\hline $\begin{array}{l}\text { Census Tract } 8 \\
\text { Block Group 3, } \\
\text { Census Tract }\end{array}$ & 100.00 & 59.50 & 76.1364 \\
\hline $\begin{array}{l}7.01 \\
\text { Block Group 3, }\end{array}$ & 33.49 & 54.30 & 56.3312 \\
\hline $\begin{array}{l}\text { Census Tract } 8 \\
\text { Block Group 2, }\end{array}$ & 100.00 & 49.50 & 76.1364 \\
\hline $\begin{array}{l}\text { Census Tract } 8 \\
\text { Block Group 1, }\end{array}$ & 100.00 & 58.20 & 69.4805 \\
\hline $\begin{array}{l}\text { Census Tract } 8 \\
\text { Block Group 3, }\end{array}$ & 100.00 & 59.00 & 77.5974 \\
\hline $\begin{array}{l}\text { Census Tract } 9 \\
\text { Block Group 1, }\end{array}$ & 80.41 & 64.50 & 68.6688 \\
\hline $\begin{array}{l}\text { Census Tract } 9 \\
\text { Block Group 2, }\end{array}$ & 91.67 & 52.00 & 75.487 \\
\hline $\begin{array}{l}\text { Census Tract } 9 \\
\text { Block Group 2, } \\
\text { Census Tract }\end{array}$ & 66.93 & 69.50 & 62.8247 \\
\hline $\begin{array}{l}10.02 \\
\text { Block Group 1, } \\
\text { Census Tract }\end{array}$ & 100.00 & 25.70 & 70.7792 \\
\hline $\begin{array}{l}10.02 \\
\text { Block Group 1, } \\
\text { Census Tract }\end{array}$ & 100.00 & 57.30 & 66.2338 \\
\hline 2.02 & 17.66 & 56.70 & 60.0649 \\
\hline
\end{tabular}


Block Group 1,

Census Tract 3

Block Group 2,

Census Tract 3

Block Group 1,

Census Tract 13

Block Group 2,

Census Tract 13

$\begin{array}{lll}0.25 & 66.80 & 29.3831\end{array}$

Block Group 2,

Census Tract

1.01

0.00

53.80

31.1688

Block Group 1,

Census Tract

4.01

3.56

55.10

67.2078

Block Group 2,

Census Tract

4.01

4.34

67.70

46.1039

Block Group 1,

Census Tract

4.03

8.01

55.10

46.4286

Block Group 2,

Census Tract

7.02

4.60

59.00

64.2857

Block Group 1,

Census Tract

1.01

2.30

65.60

21.9156

Block Group 1,

Census Tract

9801

0.02

68.60

22.2403

Block Group 3,

Census Tract

1.01

0.59

65.60

32.4675

Block Group 4,

Census Tract

2.02

1.96

70.40

19.4805

Block Group 2,

Census Tract

2.02

7.07

54.20

41.0714

Block Group 2,

Census Tract

4.03

2.54

55.10

31.4935

Block Group 3,

Census Tract 3

0.29

54.00

36.039

Block Group 2,

Census Tract

5.02

27.60

72.50

60.7143 
Block Group 3,

Census Tract

33.67

$69.90 \quad 34.7402$

Block Group 1,

Census Tract

4.02

0.45

60.80

28.5714

Block Group 4,

Census Tract

4.03

29.70

64.70

45.2922

Block Group 4,

Census Tract

5.01

80.20

54.50

79.0584

Block Group 1,

Census Tract

5.01

100.00

53.40

87.6623

Block Group 1, Census Tract

7.02

0.00

53.80

48.7013

Block Group 4, Census Tract 6

62.85

43.60

67.3701

Block Group 6,

41.83

43.60

87.8247

Block Group 1,

Census Tract

14.02

0.28

73.00

28.2467

Block Group 2,

Census Tract

14.02

6.12

42.20

44.8052

Block Group 4, Census Tract

10.02

50.83

$62.00 \quad 57.4675$

Block Group 1, Census Tract

10.01

67.88

52.80

68.5065

Block Group 5, Census Tract 6

$\begin{array}{lll}81.88 & 22.90 & 84.9026\end{array}$

Block Group 1,

Census Tract

11.02

28.69

34.00

40.5844

Block Group 4, Census Tract 3 Block Group 3, Census Tract

12.01

3.99

56.70

36.039 
Block Group 1, Census Tract

12.02

3.75

55.80

36.2013

Block Group 1, Census Tract

11.01

52.19

46.40

61.039

Block Group 3,

Census Tract

11.02

6.43

74.00

40.7467

Block Group 3,

Census Tract

14.02

54.86

73.00

47.4026

Block Group 3,

Census Tract

14.01

11.95

56.00

42.3701

Block Group 2,

Census Tract

14.01

22.21

$54.50 \quad 55.1948$

Block Group 1,

Census Tract

14.01

Block Group 3,

Census Tract

2.02

4.80

68.70

40.0974

Block Group 1,

Census Tract

5.02

12.32

70.20

60.2273

Block Group 2,

Census Tract

12.02

22.46

60.10

40.7467

Block Group 3,

Census Tract

11.02

65.49

54.70

59.5779

Block Group 3,

Census Tract

7.02

0.00

53.80

78.4091

Block Group 2,

Census Tract

4.02

0.94

Block Group 1,

Census Tract

12.01

28.58

57.20

37.8247

Block Group 2,

Census Tract

2.01

5.16

65.10

34.0909 
Block Group 2,

Census Tract

$\begin{array}{lll}46.95 & 41.60 & 72.2403\end{array}$

Block Group 1,

Census Tract 15

0.02

$57.20 \quad 18.6688$

Block Group 2,

Census Tract 15

10.52

57.20

36.039

Block Group 1,

Census Tract

2.01

4.05

55.80

35.0649

Block Group 2,

Census Tract

1.02

0.89

57.30

19.4805

Block Group 1,

Census Tract

1.02

0.00

53.80

36.2013

Block Group 1,

Census Tract

7.01

27.80

66.40

37.987

Block Group 2,

Census Tract

7.01

57.70

39.00

58.4416

Block Group 3,

Census Tract

10.02

40.22

57.50

78.2468

Block Group 2,

Census Tract

11.01

23.65

48.70

33.6039

Block Group 3,

Census Tract 13

2.63

23.70

23.2143 
Appendix F. Proposed Park Proximity and Park Quality among all the Block Groups in Cache County, Utah 


\begin{tabular}{|c|c|c|c|c|c|c|c|}
\hline GEOdisplaylabel & Proximity & Facility & Amenity & Aesthetic & $M \& C$ & Incivility & Overall \\
\hline $\begin{array}{l}\text { Block Group 2, } \\
\text { Census Tract }\end{array}$ & & & & & & & \\
\hline $\begin{array}{l}11.02 \\
\text { Block Group 2, } \\
\text { Census Tract }\end{array}$ & 21.8 & 46.5 & 57.1 & 57.7 & 55.6 & 56.8 & 54.8 \\
\hline $\begin{array}{l}12.01 \\
\text { Block Group 3, } \\
\text { Census Tract }\end{array}$ & 9.8 & 55.6 & 50 & 66.7 & 70 & 71.4 & 62.7 \\
\hline $\begin{array}{l}5.01 \\
\text { Block Group 2, } \\
\text { Census Tract }\end{array}$ & 17.1 & 0 & 0 & 0 & 0 & 0 & 0 \\
\hline 5.01 & 44 & 43.8 & 55 & 58 & 55 & 56.7 & 53.8 \\
\hline $\begin{array}{l}\text { Block Group 3, } \\
\text { Census Tract } 6\end{array}$ & 48.6 & 11.1 & 18.2 & 22.2 & 20 & 43 & 22.9 \\
\hline $\begin{array}{l}\text { Block Group 2, } \\
\text { Census Tract } 6\end{array}$ & 44 & 33.3 & 36.4 & 55.6 & 50 & 43 & 43.6 \\
\hline $\begin{array}{l}\text { Block Group 1, } \\
\text { Census Tract } 6\end{array}$ & 33 & 43.8 & 55 & 58 & 55 & 56.7 & 53.8 \\
\hline $\begin{array}{l}\text { Block Group 4, } \\
\text { Census Tract } 8 \\
\text { Block Group 3, } \\
\text { Census Tract }\end{array}$ & 44 & 52.6 & 65.1 & 62 & 58 & 50.9 & 59.5 \\
\hline 7.01 & 16 & 43.9 & 55.5 & 59.2 & 54.7 & 57.6 & 54.3 \\
\hline $\begin{array}{l}\text { Block Group 3, } \\
\text { Census Tract } 8\end{array}$ & 20 & 50.6 & 66.1 & 70 & 56.7 & 56.9 & 49.5 \\
\hline $\begin{array}{l}\text { Block Group 2, } \\
\text { Census Tract } 8\end{array}$ & 74.4 & 65.9 & 66.8 & 55.3 & 59 & 42.7 & 58.2 \\
\hline $\begin{array}{l}\text { Block Group 1, } \\
\text { Census Tract } 8\end{array}$ & 41.5 & 67 & 68 & 56 & 60 & 43 & 59 \\
\hline $\begin{array}{l}\text { Block Group 3, } \\
\text { Census Tract } 9\end{array}$ & 44.7 & 58.6 & 70.1 & 73 & 63.7 & 56.9 & 64.5 \\
\hline $\begin{array}{l}\text { Block Group 1, } \\
\text { Census Tract } 9\end{array}$ & 20.3 & 33.3 & 55 & 22 & 80 & 71 & 52 \\
\hline $\begin{array}{l}\text { Block Group 2, } \\
\text { Census Tract } 9 \\
\text { Block Group 2, } \\
\text { Census Tract }\end{array}$ & 14.8 & 72.3 & 73 & 80 & 67 & 51 & 69.5 \\
\hline $\begin{array}{l}10.02 \\
\text { Block Group 1, } \\
\text { Census Tract }\end{array}$ & 44.3 & 11.1 & 36.4 & 22.2 & 30 & 28.6 & 25.7 \\
\hline $\begin{array}{l}10.02 \\
\text { Block Group 1, } \\
\text { Census Tract }\end{array}$ & 8.7 & 33.3 & 56 & 56 & 70 & 71.4 & 57.3 \\
\hline 2.02 & 44 & 61.1 & 72.7 & 66.7 & 40 & 42.9 & 56.7 \\
\hline $\begin{array}{l}\text { Block Group 1, } \\
\text { Census Tract } 3\end{array}$ & 0.3 & 72.2 & 81.8 & 55.6 & 60 & 64.3 & 66.8 \\
\hline $\begin{array}{l}\text { Block Group 2, } \\
\text { Census Tract } 3\end{array}$ & 0.3 & 55.6 & 59.1 & 66.7 & 60 & 57.1 & 59.7 \\
\hline
\end{tabular}


Block Group 1,

Census Tract 13

53.1

55.8

$71.3 \quad 57.1$

58

59

Block Group 2,

Census Tract 13

Block Group 2,

Census Tract

1.01

Block Group 1,

Census Tract

4.01

$1.2 \quad 55.6$

75

$80 \quad 64$

67.9

68.5

Block Group 2,

Census Tract

4.01

Block Group 1,

Census Tract

4.03

Block Group 2,

Census Tract

7.02

0

0

0

$0 \quad 0$

0

0

33

43.8

55

$58 \quad 55$

$56.7 \quad 53.8$

3.

66.

68.2

$66.7 \quad 80$

57.1

67.7

22

43.8

55

$58 \quad 55$

$56.7 \quad 53.8$

22

0

$0 \quad 0$

0

Block Group 1,

Census Tract

1.01

0.7

Block Group 1,

Census Tract

9801

Block Group 3,

Census Tract

1.01

Block Group 4,

Census Tract

2.02

Block Group 2,

Census Tract

2.02

Block Group 2,

Census Tract

4.03

$$
0 .
$$

$\begin{array}{lllllll}0.1 & 55.6 & 77.3 & 88.9 & 50 & 71.4 & 68.6\end{array}$

0

0

$0 \quad 0$

$0 \quad 0$

$\begin{array}{lllllll}0.5 & 61.1 & 63.6 & 88.9 & 60 & 78.6 & 70.4\end{array}$

Block Group 3, Census Tract 3 Block Group 2, Census Tract

5.02

Block Group 3,

Census Tract

4.03

Block Group 1,

Census Tract

4.02

Block Group 4,

Census Tract

4.03

Block Group 4,

Census Tract

5.01

$$
1.6
$$

1.65

27.8

31.8

$55.6 \quad 70$

85.7

54.2

0.8

38.

68.2

$55.6 \quad 70$

42.9

55.1

0.1

0

$0 \quad 0$

0

0

$12.7 \quad 52$

65

$\begin{array}{ll}77.8 & 70\end{array}$

80

72.5

12.7

73.1

68.2

$68.6 \quad 68.3$

71.4

69.9

1

44.4

63.6

88.9

$50 \quad 57.1$

60.8

9.2

50

72.7

$66.7 \quad 70$

64.3

64.7

22.1

50

50

55.6

60

57.1

54.5 
Block Group 1,

Census Tract

5.01

Block Group 1,

Census Tract

7.02

$\begin{array}{rrrrrrr}47 & 61 & 77 & 55.6 & 30 & 43 & 53.4 \\ 0 & 0 & 0 & 0 & 0 & 0 & 0 \\ 26.3 & 33.3 & 36.4 & 55.6 & 50 & 43 & 43.6 \\ 0 & 0 & 0 & 0 & 0 & 0 & 0 \\ 0 & 0 & 0 & 0 & 0 & 0 & 0 \\ 1.4 & 42.9 & 43.9 & 33.3 & 42 & 42.9 & 42.2 \\ 13 & 50 & 36.4 & 77.8 & 60 & 85.7 & 62\end{array}$

Block Group 4, Census Tract 6

Block Group 6, Census Tract 6 Block Group 1,

Census Tract

14.02

Block Group 2, Census Tract

14.02

Block Group 4,

Census Tract

10.02

Block Group 1,

Census Tract

10.01

55.

42.8

54.7

$54.4 \quad 63$

48.5

52.8

Block Group 5, Census Tract 6 Block Group 1, Census Tract

11.02

21.

21.4

0

$0 \quad 0$

0

24.

Block Group 4, Census Tract 3 Block Group 3, Census Tract

12.01

Block Group 1, Census Tract

12.02

Block Group 1,

Census Tract

11.01

Block Group 3,

Census Tract

11.02

Block Group 3,

Census Tract

14.02

Block Group 3,

Census Tract

14.01

Block Group 2,

Census Tract

14.01

Block Group 1,

Census Tract

14.01

\begin{tabular}{|c|c|c|c|c|c|c|}
\hline 24.2 & 33 & 32 & 22 & 40 & 43 & 34 \\
\hline 3.3 & 34.2 & 46.6 & 43.2 & 40 & 40 & 41 \\
\hline 33.4 & 47.5 & 57.5 & 63.2 & 58 & 57 & 56.7 \\
\hline 1.8 & 45 & 57.6 & 62 & 56 & 58.3 & 55.8 \\
\hline 22.1 & 39 & 48.3 & 56.8 & 52 & 36 & 46.4 \\
\hline 3.8 & 50 & 86 & 67 & 80 & 86 & 74 \\
\hline 15.7 & 72.2 & 63.6 & 77.8 & 80 & 71.4 & 73 \\
\hline 4.3 & 38.9 & 68.2 & 55.6 & 60 & 57.1 & 56 \\
\hline 4.6 & 44.4 & 41 & 55.6 & 60 & 71.4 & 54.5 \\
\hline 0 & 0 & 0 & 0 & 0 & 0 & 0 \\
\hline
\end{tabular}


Block Group 3,

Census Tract

2.02

57.8

61

$86.7 \quad 59$

79.2

68.7

Block Group 1,

Census Tract

5.02

33

51

63

$74.8 \quad 68$

76

70.2

Block Group 2

Census Tract

12.02

14.

Block Group 3,

Census Tract

11.02

35.

Block Group 3,

Census Tract

7.02

Block Group 2,

Census Tract

4.02

Block Group 1,

Census Tract

12.01

Block Group 2,

Census Tract

2.01

Block Group 2,

Census Tract

10.01

Block Group 1,

Census Tract 15

Block Group 2,

Census Tract 15

Block Group 1,

Census Tract

2.01

Block Group 2,

Census Tract

1.02

Block Group 1,

Census Tract

1.02

Block Group 1,

Census Tract

7.01

Block Group 2,

Census Tract

7.01

Block Group 3,

Census Tract

10.02

Block Group 2,

Census Tract

11.01

13.7

44

43.8

55

$58 \quad 55$

56.7

53.8

33

43.8

55

$58 \quad 55$

56.7

53.8

37.7

61.8

$57.8 \quad 66$

62.8

57.2

52.8

73.2

$65.6 \quad 68$

65.8

65.1

25

27.

36.4

$22.2 \quad 50$

71.4

41.6

0

0

$0 \quad 0$

0

0

$3.8 \quad 45$.

49.1

$71.1 \quad 58$

57.1

57.2

$1.7 \quad 58$

68.6

65.6

41

45.7

55.8

0.2

50

63.6

$55.6 \quad 60$

57.1

57.3

0

0

0

$0 \quad 0$

0

0

17.3

50

70

$71.3 \quad 72$

68.7

66.4

10.7

50

32

$22 \quad 50$

43

39

32

47.8

56.3

$69 \quad 52$

62.8

57.5

Block Group 3,

Census Tract 13

8.9

44

0.7

11.1

36.4

45.5

$66.7 \quad 30$

57.1

48.7

$0.7 \quad 11$

36.4

$22.2 \quad 20 \quad 28.6$

23.7 
Proximity: Proposed park proximity

Facility: Proposed park facility

Amenity: Proposed park amenity

Aesthetic: Proposed park aesthetic feature

M\&C: Proposed park maintenance and cleanliness feature

Incivility: Proposed park incivility feature

Overall: Proposed park overall quality 


\begin{tabular}{|c|c|c|c|c|c|c|c|c|}
\hline NAME & CITY & ACRES & Facility & Amenity & $\begin{array}{l}\text { Aesthetic } \\
\text { Feature }\end{array}$ & $\begin{array}{l}\text { Cleanliness } \\
\text { \&maintenance }\end{array}$ & Incivilities & Overall \\
\hline $\begin{array}{l}\text { Lundstrom } \\
\text { Park }\end{array}$ & Logan & 19.24 & 56 & 82 & 67 & 100 & 86 & 78 \\
\hline $\begin{array}{l}\text { Ray Hugie } \\
\text { Park }\end{array}$ & $\begin{array}{l}\text { Cache } \\
\text { County }\end{array}$ & 11.11 & 38.9 & 36.3 & 22.2 & 20 & 29 & 29.3 \\
\hline Adams Park & Logan & 4.21 & 67 & 68 & 56 & 60 & 43 & 59 \\
\hline $\begin{array}{l}\text { River Hollow } \\
\text { Park } \\
\text { Jens } \\
\text { Johansen } \\
\text { Park }\end{array}$ & Logan & 3.64 & 61.1 & 50 & 88.8 & 50 & 57 & 61.4 \\
\hline $\begin{array}{l}\text { West Willow } \\
\text { Park }\end{array}$ & Logan & 7.75 & 50 & 50 & 77.8 & 60 & 71.4 & 61.8 \\
\hline Dahle Park & Logan & 4.27 & 44.4 & 45.5 & 66.7 & 60 & 57 & 54.7 \\
\hline $\begin{array}{l}\text { Rendezvous } \\
\text { Park } \\
\text { Logan } \\
\text { Meadows } \\
\text { Park }\end{array}$ & Logan & 8.76 & 50 & 54.5 & 77.8 & 40 & 57 & 55.9 \\
\hline 1700 S Park & Logan & 2.13 & 27.8 & 68.2 & 55.6 & 60 & 85.7 & 59.5 \\
\hline $\begin{array}{l}\text { Willow Park } \\
\text { Garff } \\
\text { Wayside } \\
\text { Gardens }\end{array}$ & Logan & 6.78 & 44.4 & 59 & 55.6 & 70 & 71.4 & 57.3 \\
\hline Pioneer Park & Logan & 2.96 & 28 & 50 & 44.4 & 40 & 43 & 41 \\
\hline $\begin{array}{l}\text { Bridgerland } \\
\text { Park }\end{array}$ & Logan & 7.08 & 61 & 77 & 55.6 & 30 & 43 & 53.4 \\
\hline Jones Park & Logan & 1.07 & 50 & 50 & 55.6 & 60 & 57.1 & 54.5 \\
\hline $\begin{array}{l}\text { Mt. Logan } \\
\text { Park }\end{array}$ & Logan & 21.97 & 50 & 86 & 67 & 80 & 86 & 74 \\
\hline $\begin{array}{l}\text { Brookside } \\
\text { Park } \\
\text { Willow Park } \\
\text { Sports }\end{array}$ & Logan & 0.04 & 11.1 & 18.2 & 22.2 & 10 & 28.6 & 18 \\
\hline Complex & Logan & 17.88 & 33.3 & 54.5 & 33.3 & 60 & 28.6 & 41.9 \\
\hline Hillcrest Park & Logan & 1.41 & 50 & 32 & 22 & 50 & 43 & 39 \\
\hline $\begin{array}{l}\text { Kilowatt Park } \\
\text { Majestic } \\
\text { Mountain }\end{array}$ & Logan & 0.96 & 11.1 & 36.4 & 22.2 & 30 & 28.6 & 25.7 \\
\hline Canal Corner & Logan & 0.21 & 11.1 & 18.2 & 22.2 & 20 & 43 & 22.9 \\
\hline $\begin{array}{l}\text { Morningside } \\
\text { Park }\end{array}$ & Logan & 0.94 & 33.3 & 36.4 & 55.6 & 50 & 43 & 43.6 \\
\hline
\end{tabular}




\begin{tabular}{|c|c|c|c|c|c|c|c|c|}
\hline $\begin{array}{l}\text { Fairview } \\
\text { Park }\end{array}$ & Logan & 3.34 & 61.1 & 72.7 & 77.8 & 80 & 71.4 & 72.6 \\
\hline $\begin{array}{l}\text { 10th West } \\
\text { Park } \\
\text { Canyon }\end{array}$ & Logan & 30.20 & 27.8 & 41 & 33.3 & 30 & 28.6 & 32.1 \\
\hline $\begin{array}{l}\text { Entrance } \\
\text { Park }\end{array}$ & $\begin{array}{l}\text { Cache } \\
\text { County }\end{array}$ & 3.27 & 44.4 & 63.6 & 77.8 & 50 & 71.4 & 61.4 \\
\hline Eliason Park & Logan & 0.34 & 50 & 36.4 & 77.8 & 60 & 85.7 & 62 \\
\hline $\begin{array}{l}\text { 6th South } \\
\text { Park }\end{array}$ & Logan & 19.22 & 43.8 & 55 & 58 & 55 & 56.7 & 54 \\
\hline $\begin{array}{l}\text { Northwest } \\
\text { Park Phase } 2\end{array}$ & Logan & 13.61 & 61.1 & 56.4 & 77.8 & 70 & 85.7 & 76.2 \\
\hline $\begin{array}{l}\text { Northwest } \\
\text { Park }\end{array}$ & Logan & 9.51 & 38.9 & 77.3 & 77.8 & 70 & 71.4 & 67 \\
\hline $\begin{array}{l}\text { Merlin Olsen } \\
\text { Central Park }\end{array}$ & Logan & 8.48 & 78 & 82 & 89 & 70 & 57 & 75.2 \\
\hline $\begin{array}{l}\text { Soccer Park } \\
\text { Complex } \\
\text { Southwest } \\
\text { Gateway }\end{array}$ & Logan & 22.93 & 55.6 & 81.8 & 55.6 & 60 & 50 & 60.6 \\
\hline Park & Logan & 8.26 & 22.2 & 36.4 & 22.2 & 60 & 28.6 & 33.9 \\
\hline $\begin{array}{l}\text { Horseshoe } \\
\text { Park }\end{array}$ & Logan & 4.62 & 38.9 & 50 & 66.7 & 50 & 42.9 & 49.7 \\
\hline $\begin{array}{l}\text { Quail West } \\
\text { Park }\end{array}$ & Logan & 0.53 & 33 & 32 & 22 & 40 & 43 & 34 \\
\hline $\begin{array}{l}\text { Zollinger } \\
\text { Park }\end{array}$ & Providence & 10.66 & 55.6 & 72.7 & 55.6 & 60 & 50 & 58.8 \\
\hline $\begin{array}{l}\text { Central Park } \\
\text { Forrester } \\
\text { Acres/ } \\
\text { Richard } \\
\text { Hansen } \\
\text { Baseball } \\
\text { Field }\end{array}$ & Smithfield & 25.98 & 61.1 & 72.7 & 66.7 & 40 & 42.9 & 56.7 \\
\hline Richmond & Richmond & 6.34 & 55.6 & 77.3 & 77.8 & 60 & 57.1 & 65.6 \\
\hline Amalga & Amalga & 5.55 & 72.2 & 81.8 & 55.6 & 60 & 64.3 & 66.8 \\
\hline Newton & Newton & 3.00 & 55.6 & 59.1 & 66.7 & 60 & 57.1 & 59.7 \\
\hline $\begin{array}{l}\text { Clarkston } \\
\text { Alma } \\
\text { Leonhardt } \\
\text { Park }\end{array}$ & Clarkston & 1.51 & 50 & 63.6 & 55.6 & 60 & 40.6 & 55.3 \\
\hline $\begin{array}{l}\text { Braegger } \\
\text { Park }\end{array}$ & Providence & 2.91 & 55.6 & 50 & 66.7 & 70 & 71.4 & 62.7 \\
\hline $\begin{array}{l}\text { Brookside } \\
\text { Park }\end{array}$ & Providence & 0.95 & 27.8 & 41 & 55.6 & 40 & 14.3 & 35.7 \\
\hline $\begin{array}{l}\text { Cattle Corral } \\
\text { Park }\end{array}$ & Providence & 0.71 & 27.8 & 22.7 & 22.2 & 40 & 28.6 & 28.3 \\
\hline
\end{tabular}




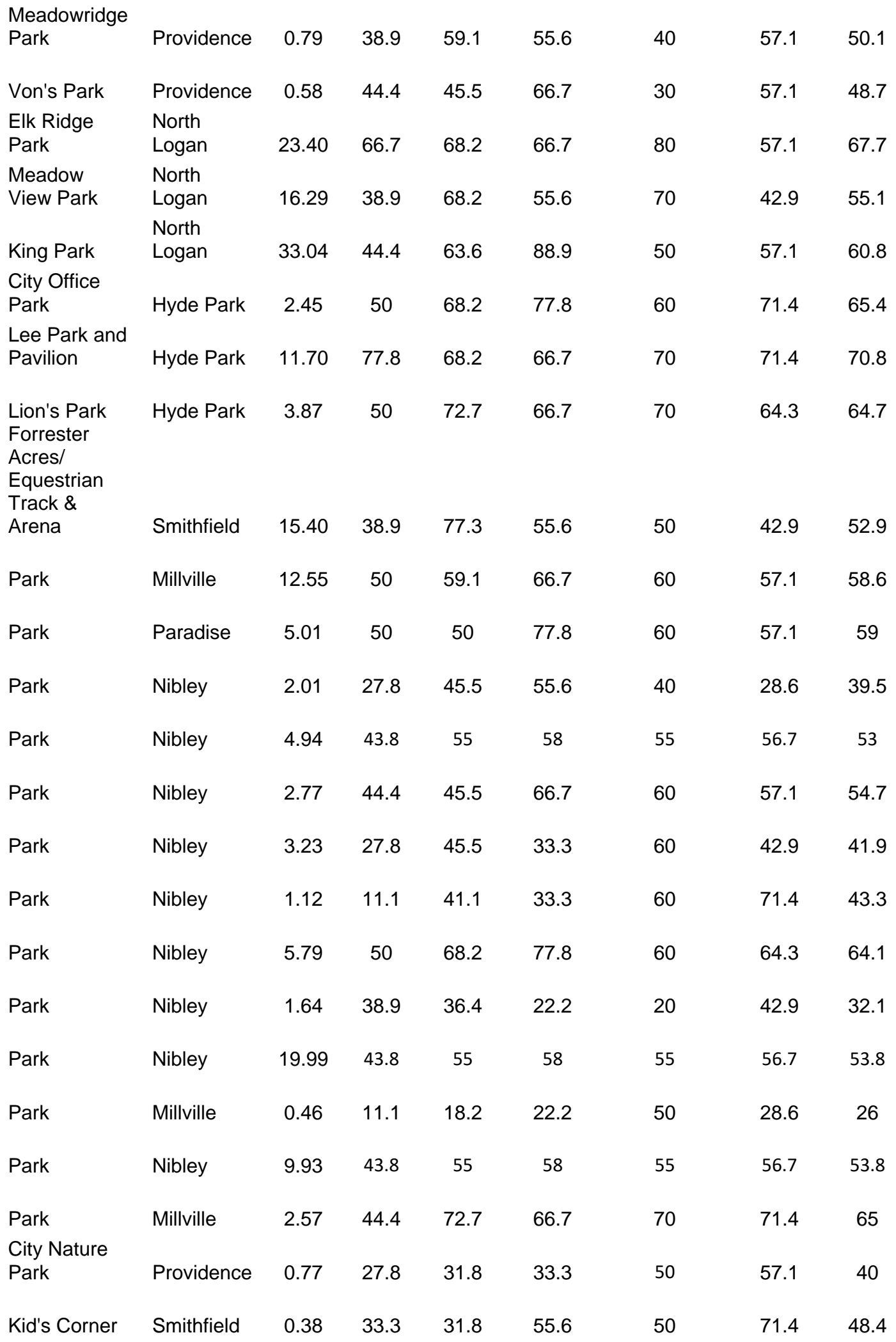




\begin{tabular}{|c|c|c|c|c|c|c|c|c|}
\hline Gutke Park & Smithfield & 2.38 & 27.8 & 36.4 & 66.7 & 50 & 85.7 & 53.3 \\
\hline $\begin{array}{l}\text { Heritage } \\
\text { Park }\end{array}$ & Smithfield & 2.77 & 44.4 & 63.6 & 88.9 & 50 & 57.1 & 60.8 \\
\hline Mack Park & Smithfield & 14.24 & 61.1 & 63.6 & 88.9 & 60 & 78.6 & 70.4 \\
\hline $\begin{array}{l}420 \text { South } \\
\text { Park }\end{array}$ & Smithfield & 0.50 & 27.8 & 31.8 & 55.6 & 70 & 85.7 & 54.2 \\
\hline Park & Nibley & 12.97 & 61.1 & 72.7 & 77.8 & 80 & 78.6 & 74 \\
\hline Park & Mendon & 2.76 & 33.3 & 36.4 & 55.6 & 50 & 42.9 & 43.6 \\
\hline Park & Mendon & 6.66 & 61.1 & 63.6 & 77.8 & 60 & 64.3 & 65.4 \\
\hline $\begin{array}{l}\text { Black Willow } \\
\text { Park }\end{array}$ & Wellsville & 0.58 & 27.8 & 31.8 & 77.8 & 50 & 57.1 & 48.9 \\
\hline School Park & Wellsville & 2.46 & 50 & 41 & 66.7 & 60 & 42.9 & 52.1 \\
\hline Darley Park & Wellsville & 3.53 & 33.3 & 68 & 55 & 40 & 42.9 & 48 \\
\hline $\begin{array}{l}\text { City Square } \\
\text { Park }\end{array}$ & Wellsville & 5.11 & 55.6 & 77.3 & 77.8 & 80 & 78.6 & 73.9 \\
\hline $\begin{array}{l}\text { Equestrian } \\
\text { Park }\end{array}$ & Wellsville & 4.15 & 11.1 & 36.4 & 22.2 & 20 & 28.6 & 23.7 \\
\hline $\begin{array}{l}\text { Wellsville } \\
\text { Park }\end{array}$ & Wellsville & 11.64 & 61.1 & 81.8 & 88.9 & 60 & 71.4 & 72.6 \\
\hline City Square & Hyrum & 4.88 & 72.2 & 63.6 & 77.8 & 80 & 71.4 & 73 \\
\hline East Park & Hyrum & 21.84 & 38.9 & 68.2 & 55.6 & 60 & 57.1 & 56 \\
\hline Pride Park & Hyrum & 0.47 & 44.4 & 41 & 55.6 & 60 & 71.4 & 54.5 \\
\hline $\begin{array}{l}\text { A.J. Park/ } \\
\text { Campground }\end{array}$ & Hyrum & 30.46 & 55.6 & 77.3 & 88.9 & 50 & 71.4 & 68.6 \\
\hline Park & Paradise & 1.63 & 27.8 & 45.5 & 44.4 & 50 & 57.1 & 44.9 \\
\hline Park & $\begin{array}{l}\text { River } \\
\text { Heights }\end{array}$ & 4.53 & 43.8 & 55 & 58 & 55 & 56.7 & 53.8 \\
\hline Ryan's Place & $\begin{array}{l}\text { River } \\
\text { Heights }\end{array}$ & 0.64 & 66.7 & 72.7 & 55.6 & 60 & 57.1 & 62.4 \\
\hline Park & Logan & 52.49 & 43.8 & 55 & 58 & 55 & 56.7 & 53.8 \\
\hline $\begin{array}{l}\text { park } \\
\text { Hyrum City } \\
\text { Soccer } \\
\text { Fields }\end{array}$ & Hyrum & 14.30 & 27.8 & 40.9 & 55.6 & 30 & 42.9 & 37.2 \\
\hline $\begin{array}{l}\text { Hyrum state } \\
\text { park }\end{array}$ & Hyrum & 13.20 & 44.4 & 54.5 & 55.6 & 50 & 50 & 50.9 \\
\hline
\end{tabular}


Appendix H. Parks, Activity, and Recreation among Kids Tool (PARK Tool) 


\begin{tabular}{|l|l|}
\hline $\begin{array}{l}\text { The Parks, Activity and Recreation among Kids (PARK) } \\
\text { Tool }\end{array}$ \\
\hline Family PIN & \\
\hline Observer ID. & \\
\hline ID of co-observer & \\
\hline Observer code. (A or B) & \\
\hline Date & \\
\hline Park ID & \\
\hline Park address & \\
\hline Start time & \\
\hline 1. Type of Usage & \\
\hline Physical activity structured & \\
\hline PA non-structured & \\
\hline PA structured. and non-structured & \\
\hline Passive activities - gardens & \\
\hline Passive only & 2 \\
\hline 2A1. Tennis: & \\
\hline Check if present & \\
\hline 2A2. Check if accessible & \\
\hline 2A3. Check if in good condition & \\
\hline 2A4. Check if restricted & \\
\hline 2B1. Basketball: & \\
\hline Check if present & \\
\hline 2B2. Check if accessible & \\
\hline 2B3. Check if in good condition & \\
\hline 2B4. Check if restricted & \\
\hline 2C1. Badminton/Volleyball: & \\
\hline Check if present & \\
\hline
\end{tabular}




\begin{tabular}{|c|c|}
\hline 2C2. Check if accessible & \\
\hline 2C3. Check if in good condition & \\
\hline 2C4. Check if restricted & \\
\hline 2D1. Soccer/Football/Rugby: & \\
\hline Check if present & \\
\hline 2D2. Check if accessible & \\
\hline 2D3. Check if in good condition & \\
\hline 2D4. Check if restricted & \\
\hline 2E1. Baseball/Softball: & \\
\hline Check if present & \\
\hline 2E2. Check if accessible & \\
\hline 2E3. Check if in good condition & \\
\hline 2E4. Check if restricted & \\
\hline 2F1. Hockey/Cosom/Ringette: & \\
\hline Check if present & \\
\hline 2K2. Check if accessible & \\
\hline 2F3. Check if in good condition & \\
\hline 2F4. Check if restricted & \\
\hline 2G1. Race Track: & \\
\hline Check if present & \\
\hline 2G2. Check if accessible & \\
\hline 2G3. Check if in good condition & \\
\hline 2H1. Foot Path: & \\
\hline Check if present & \\
\hline 2H2. Check if accessible & \\
\hline 2H3. Check if in good condition & \\
\hline 2I1. Bicycle/Rollerblade Path: & \\
\hline Check if present & \\
\hline 2I2. Check if accessible & \\
\hline 2I3. Check if in good condition & \\
\hline
\end{tabular}




\begin{tabular}{|l|c|}
\hline 2J1. Skate Park: & \multirow{2}{}{} \\
\hline Check if present & \\
\hline 2J2. Check if accessible & \\
\hline 2J3. Check if in good condition & \\
\hline 2J4. Check if restricted & \\
\hline 2K1. 6+ Play Area: & \\
\hline Check if present & \\
\hline 2K2. Check if accessible & \\
\hline 2K3. Check if in good condition & \\
\hline 2L1. Multi-Use Space: & \\
\hline Check if present & \\
\hline 2L2. Check if accessible & \\
\hline 2L3. Check if in good condition & \\
\hline 2M1. School Yard: & \\
\hline Check if present & \\
\hline 2M2. Check if accessible & \\
\hline 2M3. Check if in good condition & \\
\hline 3.a) Equipment Rental: & \\
\hline Check if present & \\
\hline b) Specify: & \\
\hline 4. Pool & \\
\hline Check if present & \\
\hline 5. Pool Length: & \\
\hline Under 25m & \\
\hline Longer or equal to 25m & \\
\hline Impossible to evaluate & \\
\hline 6. Condition Around the Pool: & \\
\hline No deterioration & \\
\hline Presence of deterioration without need for repairs & \\
\hline
\end{tabular}




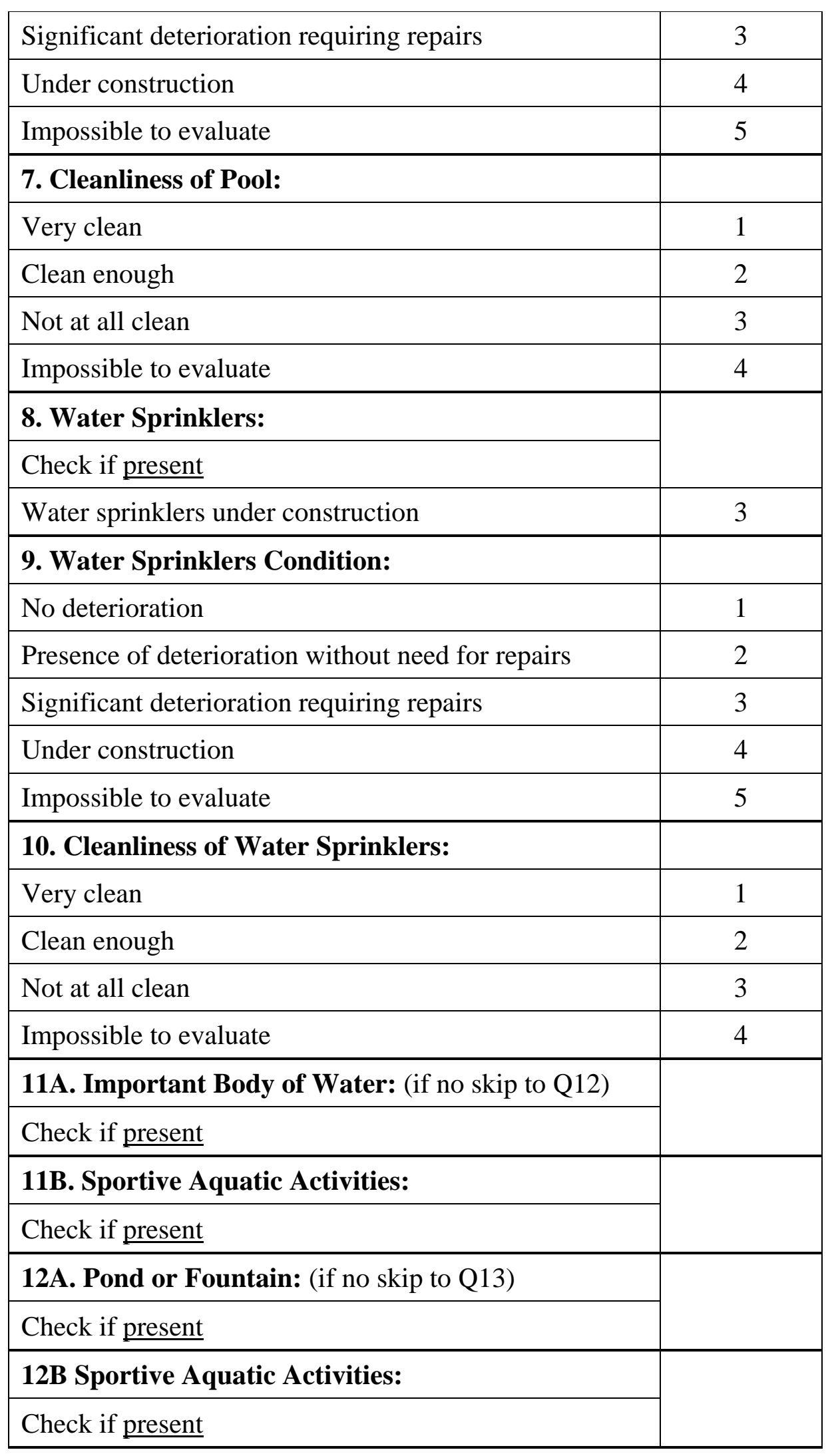




\begin{tabular}{|l|c|}
\hline 13A. Decorative or Cultural Physical Elements: & \multirow{2}{|}{} \\
\hline Check if present (if no skip to Q14) & \multirow{2}{*}{ TEXT } \\
\hline 13B. If present, specify: & \\
\hline 14. Gardens: & \\
\hline Check if present & 1 \\
\hline 15. Shade: & 2 \\
\hline Many places & 3 \\
\hline Some places & \\
\hline None & \\
\hline 16. No Dogs Allowed Sign: & \\
\hline Check if present & 1 \\
\hline 17. Graffiti: & 2 \\
\hline None & 3 \\
\hline Some & \\
\hline A lot & 1 \\
\hline 18. Broken Items/ Vandalism: & 2 \\
\hline None & 2 \\
\hline Possibly & 3 \\
\hline Definitely & \\
\hline 19. Litter/Garbage: & \\
\hline None & \\
\hline Some & \\
\hline A lot & \\
\hline 20. Garbage Bins: & \\
\hline Yes, in usable condition & \\
\hline Yes, but unusable & \\
\hline No & \\
\hline 21. Drinking Fountains: & \\
\hline Yes, in usable condition & \\
\hline Yes, but unusable & \\
\hline
\end{tabular}




\begin{tabular}{|c|c|}
\hline No & 3 \\
\hline \multicolumn{2}{|l|}{ 22. Picnic Tables: } \\
\hline Yes, in usable condition & 1 \\
\hline Yes, but unusable & 2 \\
\hline No & 3 \\
\hline \multicolumn{2}{|l|}{ 23. Sitting Benches: } \\
\hline Yes, in usable condition & 1 \\
\hline Yes, but unusable & 2 \\
\hline No & 3 \\
\hline \multicolumn{2}{|l|}{ 24. Bleachers: } \\
\hline Yes, in usable condition & 1 \\
\hline Yes, but unusable & 2 \\
\hline No & 3 \\
\hline \multicolumn{2}{|l|}{ 25A. Public Toilets: } \\
\hline Yes & 1 \\
\hline No & $\begin{array}{c}2 \text { (Skip to } \\
\text { Q26) }\end{array}$ \\
\hline Impossible to determine & $\begin{array}{c}3 \text { (Skip to } \\
\text { Q26) }\end{array}$ \\
\hline \multicolumn{2}{|l|}{ 25B. Condition of Toilets: } \\
\hline Good & 1 \\
\hline $\mathrm{Bad}$ & 2 \\
\hline Impossible to determine & 3 \\
\hline \multicolumn{2}{|c|}{ 26A. Chalet/Change rooms: } \\
\hline Yes & 1 \\
\hline No & $\begin{array}{c}2 \text { (Skip to } \\
\text { Q27) }\end{array}$ \\
\hline \multicolumn{2}{|c|}{ 26B. Condition of Chalet/Change rooms: } \\
\hline Good & 1 \\
\hline Bad & 2 \\
\hline Impossible to determine & 3 \\
\hline 27. Parking: & \\
\hline
\end{tabular}




\begin{tabular}{|c|c|}
\hline Yes, reserved for the park & 1 \\
\hline Yes, on the street only & 2 \\
\hline No & 3 \\
\hline \multicolumn{2}{|l|}{ 28. Bicycle Locks: } \\
\hline \multicolumn{2}{|l|}{ Check if present } \\
\hline \multicolumn{2}{|l|}{ 29. Public Transportation: } \\
\hline Check if present & \\
\hline \multirow{2}{*}{\multicolumn{2}{|c|}{$\begin{array}{l}\text { 30. Sufficient Lighting to Light the Majority of the } \\
\text { Park: } \\
\text { Check if present }\end{array}$}} \\
\hline & \\
\hline \multirow{2}{*}{\multicolumn{2}{|c|}{$\begin{array}{l}\text { 31. At least } 1 \text { Street Visible from the Centre of the } \\
\text { Park: } \\
\text { Check if yes }\end{array}$}} \\
\hline & \\
\hline \multirow{2}{*}{\multicolumn{2}{|c|}{$\begin{array}{l}\text { 32. At least } 1 \text { House Visible from the Centre of the } \\
\text { Park: } \\
\text { Check if yes }\end{array}$}} \\
\hline & \\
\hline \multicolumn{2}{|l|}{ 33. Adjacent Streets are Local: } \\
\hline All & 1 \\
\hline Some & 2 \\
\hline None & 3 \\
\hline \multicolumn{2}{|l|}{$\begin{array}{l}\text { 34. Adjacent Streets have Traffic Calming } \\
\text { Measures: }\end{array}$} \\
\hline All & 1 \\
\hline Some & 2 \\
\hline None & 3 \\
\hline \multicolumn{2}{|l|}{$\begin{array}{l}\text { 35. Adjacent Streets have Pedestrian Facilitation } \\
\text { Measures: }\end{array}$} \\
\hline All & 1 \\
\hline Some & 2 \\
\hline None & 3 \\
\hline \multicolumn{2}{|l|}{ 36. Is the Park Attractive for Youth? } \\
\hline Very attractive & 1 \\
\hline Attractive enough & 2 \\
\hline
\end{tabular}




\begin{tabular}{|l|l|}
\hline Not attractive & 3 \\
\hline 37. Is the Park Safe? & 1 \\
\hline Very safe & 2 \\
\hline Safe enough & 3 \\
\hline Not safe & \\
\hline 38. Is the Park Pretty/ Attractive? & 1 \\
\hline Very pretty/ attractive & 2 \\
\hline Pretty/ attractive enough & 3 \\
\hline Not pretty/ attractive & 1 \\
\hline 39. Is the Park Appealing for Walking? & 2 \\
\hline Very appealing & 3 \\
\hline Appealing enough & \\
\hline Not appealing & \\
\hline 40. Is the Park Appealing for Cycling? & 1 \\
\hline Very appealing & 2 \\
\hline Appealing enough & 3 \\
\hline Not appealing & \\
\hline 41. Is the Park Appealing for Active Play? & \\
\hline Very appealing & \\
\hline Appealing enough & \\
\hline Not appealing & \\
\hline 42. Time of Completion: & \\
\hline & \\
\hline
\end{tabular}


Appendix I. Simplified PARK Tool, 


\begin{tabular}{|r|l|l|}
\hline & Park Name: & \\
\hline & City: & \\
\hline & Address: & \\
\hline & Acreage: & \\
\hline & Fate: & \\
\hline 1 & Tennis Court & \\
\hline 2 & Basketball Court & \\
\hline 3 & Badminton / Volleyball court & \\
\hline 4 & Soccer / Football / Rugby field & \\
\hline 5 & Baseball / Softball field & \\
\hline 6 & Playground / Play Area & \\
\hline 7 & Skate Park & \\
\hline 8 & Pool / Important body of water & \\
\hline 9 & Pond / Fountain & \\
\hline 10 & Garden & \\
\hline 11 & Multi-use Space & \\
\hline 12 & School Yard & \\
\hline \multicolumn{2}{|l|}{} & Is this park appealing for active play? \\
\hline & Is this park appealing for walking? & \\
\hline \multicolumn{2}{|l|}{} \\
\hline & Amenity (22) & \\
\hline 1 & Race Track & \\
\hline 2 & Foot Path & \\
\hline 3 & Bicycle / Rollerblade Path & \\
\hline 4 & Equipment Rental & \\
\hline 5 & Shade & \\
\hline 6 & No Dog Sign & \\
\hline 7 & Drinking Fountain & \\
\hline 8 & Garbage Bin & \\
\hline 9 & Water Sprinkler & \\
\hline 10 & Picnic Table & \\
\hline 11 & Sitting Benches & \\
\hline 12 & Chalet / Change Room & \\
\hline 13 & Parking Area & \\
\hline & & \\
\hline
\end{tabular}




\begin{tabular}{|l|l|l|}
\hline 14 & Bicycle lockers & \\
\hline 15 & Public Transportation & \\
\hline 16 & Lighting & \\
\hline 17 & Adjacent Street & \\
\hline 18 & Public Toilet & \\
\hline 19 & Bleachers & \\
\hline \multicolumn{2}{|l|}{ Is this park appealing for cycling? } & \\
\hline \multicolumn{2}{|l|}{} & \\
\hline & Aesthetic Features (9) & \\
\hline 1 & Sportive Aquatic Activities & \\
\hline 2 & Cultural Elements & \\
\hline 3 & At least one house visible from the center of the park? & \\
\hline 4 & At least one street visible from the center of the park? & \\
\hline 5 & Decorative Elements (Landscaping) & \\
\hline 6 & Water Features & \\
\hline \multicolumn{2}{|l|}{ Is this park attractive for youth? } & \\
\hline \multicolumn{2}{|l|}{} \\
\hline & Cleanliness \& Maintenance (10) & \\
\hline 1 & Adjacent streets have traffic calming measures & \\
\hline 2 & Adjacent streets have pedestrian facilitation measures & \\
\hline 3 & Safe Measures & \\
\hline 4 & Pool condition & \\
\hline 5 & Toilet condition & \\
\hline 6 & Chalet condition & \\
\hline 7 & Water sprinkler condition & \\
\hline \multicolumn{2}{|l|}{ Is this park safe? } \\
\hline \multicolumn{2}{|l|}{} \\
\hline & Incivilities (7) & \\
\hline 1 & Graffiti & \\
\hline 2 & Broken items & \\
\hline 3 & Litter / Garbage & \\
\hline 4 & Vandalism & \\
\hline \multicolumn{2}{|l|}{ Is this park pretty / attractive? } \\
\hline
\end{tabular}

